\title{
$\leadsto$ PHOENIX
}

PHOEN IX C ON VEYOR BELT SYSTEM S

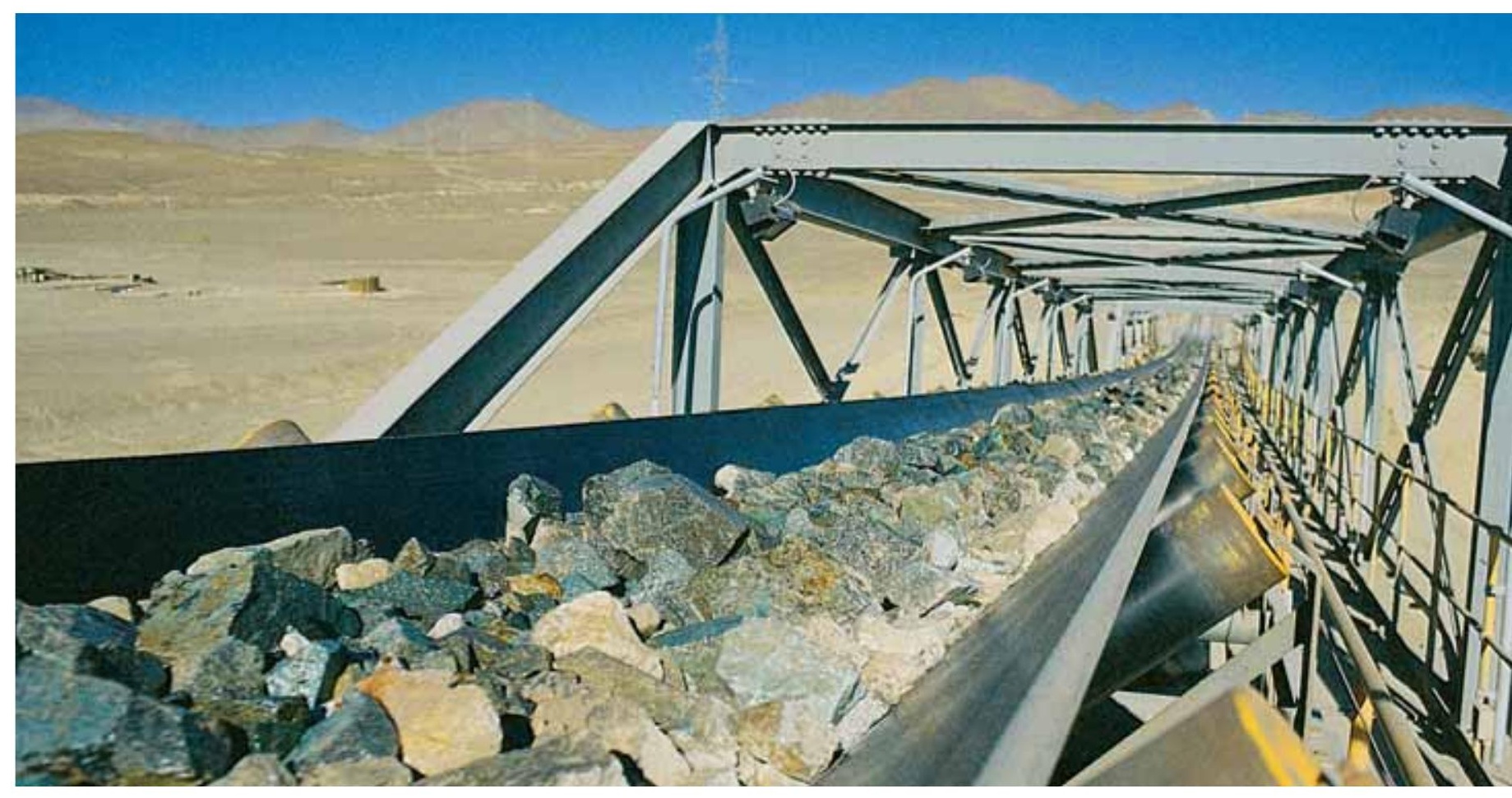

\section{Phoenix Conveyor Belts Design Fundamentals}




\section{Phoenix Conveyor Belts Design Fundamentals}

Hannoversche Strasse 88 D-21079 Hamburg, Germany Internet: www.phoenix-ag.com Phone +49-40-7667-1526, 1540

Fax +49-40-7667-2987

Emailinfopcbs@phoenix-ag.com 


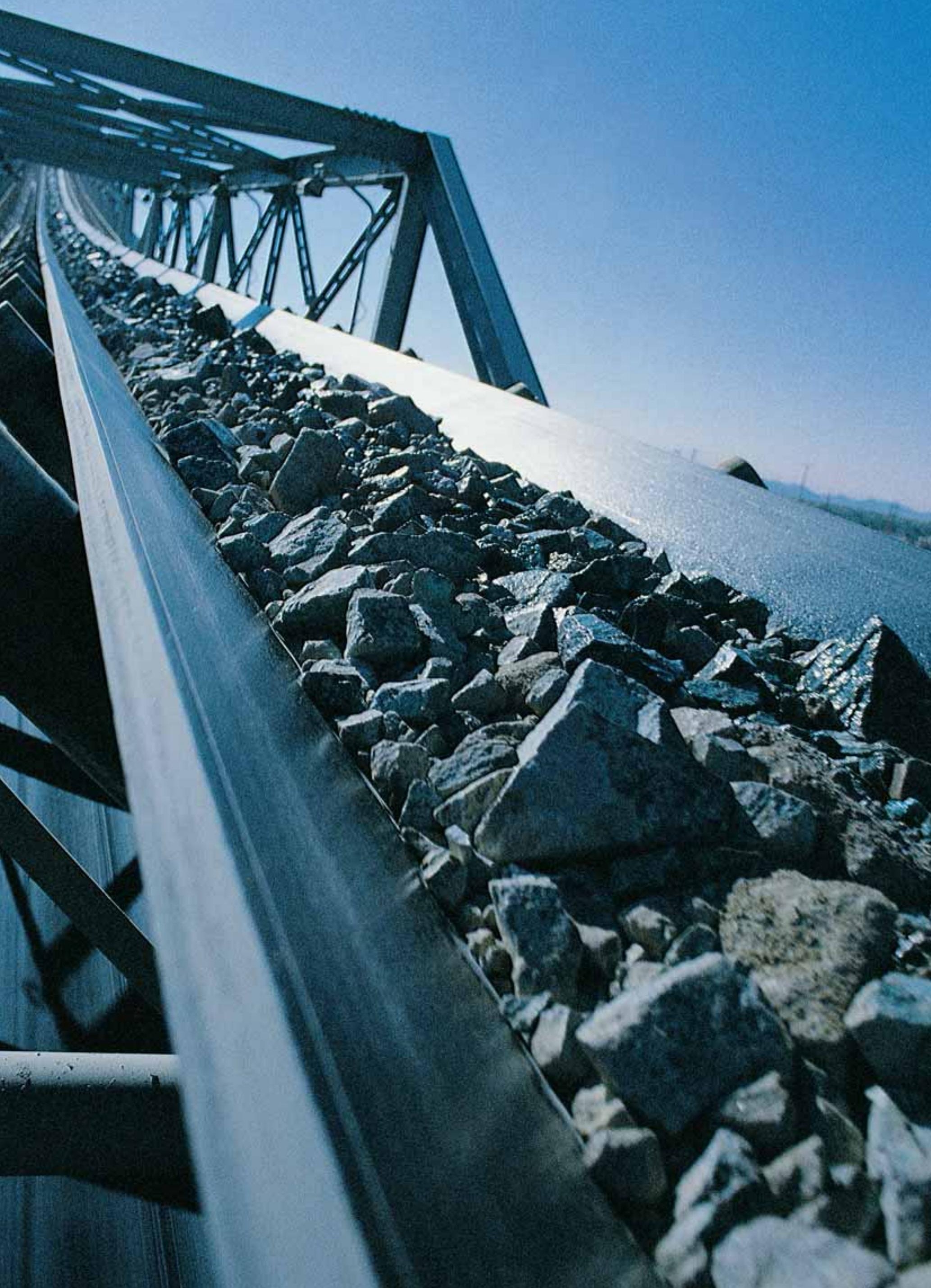




\section{Contents}

\begin{tabular}{|c|c|c|}
\hline \multirow[b]{2}{*}{1} & \multicolumn{2}{|c|}{ Page } \\
\hline & Preface & 5 \\
\hline 2 & Symbols and Units & 6 \\
\hline 3 & $\begin{array}{l}\text { General design fundamentals for belt } \\
\text { conveyor systems }\end{array}$ & 8 \\
\hline 3.1 & $\begin{array}{l}\text { Motional resistances and power required } \\
\text { in the steady operating state }\end{array}$ & 8 \\
\hline 3.1.1 & Power required & 8 \\
\hline 3.1 .2 & Motional resistances & 9 \\
\hline 3.2 & $\begin{array}{l}\text { Motional resistances and driving forces in } \\
\text { non-steady operating states }\end{array}$ & 12 \\
\hline 3.2 .1 & Start Up & 12 \\
\hline 3.2 .2 & Stopping & 13 \\
\hline 3.3 & Belt tensions & 14 \\
\hline 3.3.1 & Sequential calculation & 15 \\
\hline 3.3.2 & $\begin{array}{l}\text { Minimum belt tensions for transmitting the pulley } \\
\text { peripheral forces }\end{array}$ & 16 \\
\hline
\end{tabular}

3.3.3 Minimum belt tensions for belt sag limitation $\begin{array}{ll}\text { and correct tracking } & 17\end{array}$

3.3.4 Takeup forces 17

$\begin{array}{ll}3.4 & \text { Lateral distribution of tensions } \\ 3.4 .18\end{array}$

$\begin{array}{ll}3.4 .1 & \text { Transition zones } \\ 3.4 .2 & 18\end{array}$

\begin{tabular}{ll}
3.4 .2 & Vertical curves \\
\hline
\end{tabular}

$4 \quad$ Phoenix computer program capacity 20

4.1 Major computer program features 20

4.2 Process and target of calculations 22

4.3 Hints for designing complex belt conveyor systems 22

$5 \quad$ Sizing of belt conveyor systems based on Phoenix computer program results 25

5.1 Conveyor belt $\quad 25$

5.1.1 Tensile members $\quad 25$

5.1.2 Covers 26

5.2 Other constructional components 27

5.2.1 Minimum pulley diameters $\quad 27$

5.2.2 Takeup device 28

$\begin{array}{lll}5.3 & \text { Belt tracking } & 29\end{array}$

$\begin{array}{lll}\text { 5.3.1 Transition lengths } & 29\end{array}$

5.3.2 Transition curves 30

$\begin{array}{lll}\text { 5.3.3 Belt turnover } & 31\end{array}$

6 Phoenix questionnaire: "Technical data for the layout of belt conveyor systems"

$7 \quad$ Tables for belt conveyor systems design and calculation 

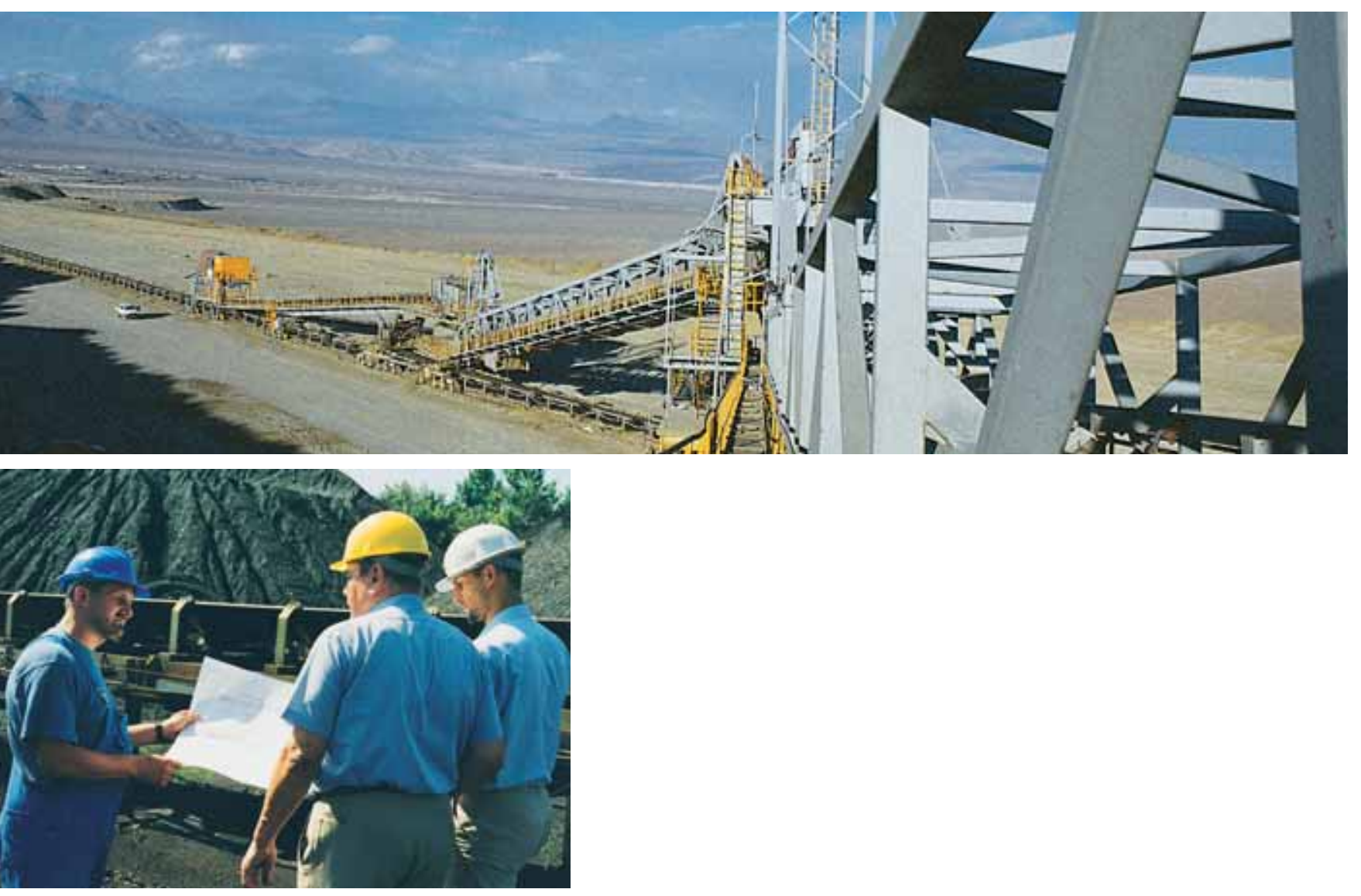


\section{Preface}

Worldwide, Phoenix is the major specialist for the design and manufacture of conveyor belts.

Most modern production facilities combined with an exemplary quality assurance system including ISO 9001 certification, as well as trail-blazing test equipment for practice-oriented product engineering, in connection with an experience in conveyor belt technology going back to an origin of 100 years ago, are the foundation of the highest level of economy of Phoenix conveyor belts.

In this brochure Phoenix offers the interested specialist a document for calculating and designing conveyor belt systems. The principles which deal with power requirements and belt tensions, belt strength and tractive power distribution over the belt width, additionally deal with transition zones and vertical curves. The subsequent chapters describe special design interpretations for the conveyor belt and its essential components, as well as for the required belt tracking. An extensive tabulated section at the back of the brochure comprises all of the details which are essential for the calculation and design of belt conveyor systems.

The principles of calculation are mainly based on DIN 22101 which appeared in the August 2002 edition.

Where complex calculations are involved, modern Phoenix computer programs can be availed of. We thus recommend to complete and to return the questionnaire (see chapter 6) enclosed in this brochure. The Phoenix specialists' know-how and experience will ensure the optimum conveyor belt design to be selected. Do not hesitate to utilize the expertise available from Phoenix. 


\begin{tabular}{|c|c|c|c|c|c|}
\hline Symbols & Description & Unit & Symbols & Description & Unit \\
\hline $\mathrm{B}$ & Conveyor belt width & $\mathrm{mm}$ & a & Acceleration or deceleration & $\mathrm{m} / \mathrm{s}^{2}$ \\
\hline C & $\begin{array}{l}\text { Coefficient for all-inclusive consideration } \\
\text { of secondary resistance }\end{array}$ & - & $b_{S}$ & $\begin{array}{l}\text { Part of belt width lying on the side } \\
\text { idler (only in idler stations with } 2 \text { or } \\
3 \text { idlers) }\end{array}$ & $\mathrm{mm}$ \\
\hline & Pulley diameter & $\mathrm{mm}$ & & & \\
\hline$E_{\text {LGk }}$ & $\begin{array}{l}\text { Elasticity module of the tensile member } \\
(=\text { belt core) related to the width of the belt }\end{array}$ & $\mathrm{N} / \mathrm{mm}$ & $\mathrm{c}_{\mathrm{K}}$ & $\begin{array}{l}\text { Coefficient for the dynamic splice- } \\
\text { efficiency corresponding to the } \\
\text { width related belt tension in the } \\
\text { belt edges }\end{array}$ & - \\
\hline \multirow[t]{2}{*}{$\begin{array}{l}\mathrm{F}_{\mathrm{ai}} \\
\mathrm{F}_{\mathrm{a}}\end{array}$} & \multirow{2}{*}{$\begin{array}{l}\text { Acceleration-/Deceleration } \\
\text { dependent belt tension force component } \\
\text { of system section }\left(\mathrm{F}_{\mathrm{a}}\right) \text {, respectively } \\
\text { the entire acceleration/deceleration } \\
\text { forces from top run and bottom run }\left(\mathrm{F}_{\mathrm{a}}\right)\end{array}$} & \multirow[t]{2}{*}{$\mathrm{N}$} & $c_{I U ̈}$ & $\begin{array}{l}\text { Coefficient for determination of } \\
\text { guide values for the minimum length } \\
\text { of the troughing transition }\end{array}$ & - \\
\hline & & & $c_{R}$ & $\begin{array}{l}\text { Coefficient for calculating the masses } \\
\text { of the idlers reduced to their periphery }\end{array}$ & - \\
\hline $\mathrm{F}_{\mathrm{E}}$ & $\begin{array}{l}\text { Rolling indentation resistance of the } \\
\text { conveyor belt }\end{array}$ & $\mathrm{N}$ & $\mathrm{C}_{\mathrm{Re}}$ & Coefficient for determination of & - \\
\hline $\mathrm{F}_{\mathrm{H}}$ & Total primary resistances & $\mathrm{N}$ & & guide values for the minimum radius & \\
\hline $\mathrm{F}_{\mathrm{N}}$ & Total secondary resistances & $\mathrm{N}$ & & OT convex vertical curves & \\
\hline$F_{R}$ & Running resistance of the idlers & $\mathrm{N}$ & $d_{D p}$ & Cover thickness & $\mathrm{mm}$ \\
\hline $\mathrm{F}_{\mathrm{S}}$ & Total special resistances & $\mathrm{N}$ & $d_{G}$ & Belt thickness & $\mathrm{mm}$ \\
\hline $\mathrm{F}_{\mathrm{Sp}}$ & $\begin{array}{l}\text { Takeup force (= force at the axis } \\
\text { of the takeup pulley) }\end{array}$ & $\mathrm{N}$ & $\mathrm{d}_{\mathrm{Gk}}$ & $\begin{array}{l}\text { Thickness of the tensile member } \\
\text { (longitudinal tensile member: belt core) }\end{array}$ & $\mathrm{mm}$ \\
\hline $\mathrm{F}_{\mathrm{St}}$ & Total gradient resistances & $\mathrm{N}$ & $d_{R}$ & Idler diameter & $\mathrm{mm}$ \\
\hline $\mathrm{F}_{\mathrm{T}}$ & Local belt tension force & $\mathrm{N}$ & e & Base of natural logarithms & - \\
\hline $\mathrm{F}_{\mathrm{Tri}}$ & $\begin{array}{l}\text { Peripheral force of the pulley with } \\
\text { index } i\end{array}$ & $\mathrm{~N}$ & $f_{i}, f$ & $\begin{array}{l}\text { Fictitious friction coefficient of a con- } \\
\text { veyor section }\left(f_{i}\right) \text {, respectively of the }\end{array}$ & - \\
\hline \multirow[t]{3}{*}{$\mathrm{F}_{\mathrm{W}}$} & \multirow{3}{*}{$\begin{array}{l}\text { Total motional resistances of } \\
\text { top and return runs in steady } \\
\text { state operation }\end{array}$} & \multirow[t]{3}{*}{$\mathrm{N}$} & & total conveyor in top and bottom run (f) & \\
\hline & & & g & Acceleration due to gravity $\left(\mathrm{g}=9.81 \mathrm{~m} / \mathrm{s}^{2}\right)$ & $\mathrm{m} / \mathrm{s}^{2}$ \\
\hline & & & $\mathrm{h}_{\mathrm{K} 0}$ & Distance from the belt edge to the & $\mathrm{mm}$ \\
\hline $\mathrm{H}$ & $\begin{array}{l}\text { Conveying height } \\
\text { ( } \mathrm{H}>0 \text { : uphill conveying; } \\
\mathrm{H}<0 \text { : downhill conveying) }\end{array}$ & $\mathrm{m}$ & $\mathrm{h}_{\mathrm{K} 1}$ & $\begin{array}{l}\text { Distance from the belt edge to the } \\
\text { level at the pulley surface }\end{array}$ & $\mathrm{mm}$ \\
\hline \multirow{5}{*}{$\begin{array}{l}I_{m} \\
I_{V} \\
L \\
P_{M}\end{array}$} & \multirow{5}{*}{$\begin{array}{l}\text { Mass flow } \\
\text { Volume flow } \\
\text { Conveying length ( } \approx \text { center distance) } \\
\text { Total power of the drive motors } \\
\text { required due to the motional resis- } \\
\text { tances in steady state operation }\end{array}$} & \multirow{2}{*}{$\begin{array}{l}\mathrm{kg} / \mathrm{s} \\
\mathrm{m}^{3} / \mathrm{s}\end{array}$} & \multirow[t]{2}{*}{$\mathrm{h}_{\mathrm{Tr}}$} & \multirow{2}{*}{$\begin{array}{l}\text { Pulley lift in the transition zone com- } \\
\text { pared to the level at the deepest point } \\
\text { of the trough }\end{array}$} & \multirow[t]{2}{*}{$\mathrm{mm}$} \\
\hline & & & & & \\
\hline & & $\mathrm{m}$ & \multirow[t]{2}{*}{$\mathrm{h}_{\text {rel }}$} & \multirow{2}{*}{$\begin{array}{l}\text { Maximum belt sag related to spacing } \\
\text { between carrying idlers }\end{array}$} & \multirow[t]{2}{*}{$\%$} \\
\hline & & W & & & \\
\hline & & & k & Belt tension related to belt width & $\mathrm{N} / \mathrm{mm}$ \\
\hline \multirow[t]{2}{*}{$P_{W}$} & \multirow{2}{*}{$\begin{array}{l}\text { Total power at the periphery of the } \\
\text { driving pulley(s) required due to the } \\
\text { motional resistances in steady state } \\
\text { operation }\end{array}$} & \multirow[t]{2}{*}{ W } & & $\begin{array}{l}\text { Belt tension related to belt width at } \\
\text { the belt edge }\end{array}$ & $\mathrm{N} / \mathrm{mm}$ \\
\hline & & & $\left(k_{\mathrm{K}}\right)_{\operatorname{amax}}$ & $\begin{array}{l}\text { Maximum temporarily occurring } \\
\text { (in steady state and non-stationary } \\
\text { operation) width related belt tension }\end{array}$ & $\mathrm{N} / \mathrm{mm}$ \\
\hline \multirow{2}{*}{$\mathrm{R}_{\mathrm{a}}$} & \multirow{2}{*}{$\begin{array}{l}\text { Radius of concave vertical transition } \\
\text { curve }\end{array}$} & \multirow[t]{2}{*}{$\mathrm{m}$} & & at the belt edges & \\
\hline & & & $\mathrm{k}_{\mathrm{M}}$ & Belt tension related to belt width in & $\mathrm{N} / \mathrm{mm}$ \\
\hline $\mathrm{R}_{\mathrm{e}}$ & $\begin{array}{l}\text { Radius of convex vertical transition } \\
\text { curve }\end{array}$ & $\mathrm{m}$ & $\mathrm{k}_{\mathrm{N}}$ & $\begin{array}{l}\text { the midale of the conveyor belt } \\
\text { Rated breaking strength of the belt }\end{array}$ & $\mathrm{N} / \mathrm{mm}$ \\
\hline $\mathrm{S}_{0}$ & $\begin{array}{l}\text { Safety factor related to the condi- } \\
\text { tions of the conveyor belt splice }\end{array}$ & - & & $\begin{array}{l}\text { related to belt width ( } \approx \text { minimum } \\
\text { breaking strength) }\end{array}$ & \\
\hline & manufacturing & & $\mathrm{k}_{\mathrm{t}}$ & Reference dynamic splice efficiency & $\mathrm{N} / \mathrm{mm}$ \\
\hline $\mathrm{S}_{1}$ & Safety factor related to the expected & - & & & \\
\hline & $\begin{array}{l}\text { life time and the operational stresses } \\
\text { and strains on the conveyor belt }\end{array}$ & & $\mathrm{k}_{\text {trel }}$ & $\begin{array}{l}\text { Relative dynamic splice efficiency } \\
\text { of the belt }\end{array}$ & - \\
\hline
\end{tabular}




\begin{tabular}{|c|c|c|c|c|c|}
\hline Symbols & Description & Unit & Symbols & Description & Unit \\
\hline $\begin{array}{l}I_{i} \\
I_{K}\end{array}$ & $\begin{array}{l}\text { Conveying length of a conveyor section } \\
\text { Length of the belt edge in the }\end{array}$ & $\begin{array}{l}\mathrm{m} \\
\mathrm{m}\end{array}$ & $\lambda$ & $\begin{array}{l}\text { Troughing angle of the conveyor } \\
\text { belt in top or bottom run }\end{array}$ & 。 \\
\hline $\mathrm{I}_{\mathrm{M}}$ & $\begin{array}{l}\text { troughing transition } \\
\text { Roll face length of the middle idler }\end{array}$ & $\mathrm{mm}$ & $\mu$ & $\begin{array}{l}\text { Friction coefficient between con- } \\
\text { veyor belt and pulley surface }\end{array}$ & - \\
\hline & in a 3-idler station & & $\rho$ & Bulk density of the material handled & $\mathrm{kg} / \mathrm{m}^{3}$ \\
\hline $\mathrm{I}_{\mathrm{R}}$ & Idler spacing in top or bottom run & $\mathrm{m}$ & $\Delta \mathrm{k}$ & Difference between the width & $\mathrm{N} / \mathrm{mm}$ \\
\hline 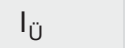 & Length of transition zone & $\mathrm{m}$ & & related belt tension at the & \\
\hline IÜeff & Effective length of transition zone & $\mathrm{m}$ & & $\begin{array}{l}\text { edges and in the middle of } \\
\text { the conveyor belt }\end{array}$ & \\
\hline $\mathrm{I}_{\mathrm{W}}$ & Belt turnover length & $\mathrm{m}$ & $\Delta \mathrm{k}_{\mathrm{IÜ}}$ & $\begin{array}{l}\text { Difference between the width } \\
\text { related belt tension at the edges }\end{array}$ & $\mathrm{N} / \mathrm{mm}$ \\
\hline$m_{G}^{\prime}$ & Length related mass of the conveyor belt & $\mathrm{kg} / \mathrm{m}$ & & and in the middle of the con- & \\
\hline$m "_{G}$ & Area related mass of the conveyor belt & $\mathrm{kg} / \mathrm{m}^{2}$ & & $\begin{array}{l}\text { veyor belt in the troughing } \\
\text { transition zone }\end{array}$ & \\
\hline $\begin{array}{l}m_{, L i}^{\prime} \\
m_{L}^{\prime}\end{array}$ & $\begin{array}{l}\text { Length related mass of the } \\
\text { conveyed material uniformly distri- } \\
\text { buted across a section of the con- } \\
\text { veying flight }\left(m^{\prime}{ }^{\prime}\right) \text {, respectively the } \\
\text { total length }\left(m_{L}\right)\end{array}$ & $\mathrm{kg} / \mathrm{m}$ & $\Delta \mathrm{k}_{\mathrm{Ra}}$ & $\begin{array}{l}\text { Difference between the width } \\
\text { related belt tension at the edges } \\
\text { and in the middle of the conveyor } \\
\text { belt in concave vertical curves }\end{array}$ & $\mathrm{N} / \mathrm{mm}$ \\
\hline $\begin{array}{l}\mathrm{m}_{\mathrm{Ri}}^{\prime} \\
\mathrm{m}_{\mathrm{R}}^{\prime}\end{array}$ & $\begin{array}{l}\text { Length related mass of the rotating } \\
\text { parts of the idlers in a conveyor } \\
\text { section }\left(m^{\prime}{ }_{R i}\right) \text {, respectively the total } \\
\text { length }\left(m_{R}^{\prime}=m_{R o}^{\prime}+m_{R u}^{\prime}\right)\end{array}$ & $\mathrm{kg} / \mathrm{m}$ & $\Delta \mathrm{k}_{\mathrm{Re}}$ & $\begin{array}{l}\text { Difference between the width } \\
\text { related belt tension at the edges } \\
\text { and in the middle of the conveyor } \\
\text { belt in convex vertical curves }\end{array}$ & $\mathrm{N} / \mathrm{mm}$ \\
\hline $\mathrm{p}_{\mathrm{A}}$ & Start-up factor related to peripheral & - & $\Delta \mathrm{l}_{\mathrm{U}}$ & 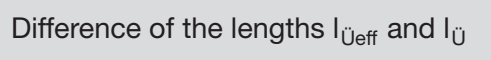 & $\mathrm{m}$ \\
\hline & $\begin{array}{l}\text { forces of all drive pulleys in steady } \\
\text { state operation }\end{array}$ & & $\Sigma m$ & Sum of translatorially moving & $\mathrm{kg}$ \\
\hline $\mathrm{p}_{\mathrm{AO}}$ & $\begin{array}{l}\text { Start-up factor related to the rated } \\
\text { torque of all drive motors }\end{array}$ & - & & $\begin{array}{l}\text { and non-braked rotating masses } \\
\text { reduced to their periphery }\end{array}$ & \\
\hline$p_{B}$ & $\begin{array}{l}\text { Breaking factor related to peripheral } \\
\text { forces of all drive pulleys in steady } \\
\text { state operation }\end{array}$ & - & & & \\
\hline $\mathrm{p}_{\mathrm{B} 0}$ & $\begin{array}{l}\text { Breaking factor related to the rated } \\
\text { torque of all drive motors }\end{array}$ & - & Indices & & \\
\hline q & $\begin{array}{l}\text { Coefficient for determination } \\
\text { of primary resistances }\end{array}$ & - & Index & Meaning & \\
\hline $\mathrm{s}_{\mathrm{B}}$ & Braking distance & $\mathrm{m}$ & $A$ & At start-up & \\
\hline $\mathrm{s}_{\mathrm{Sp}}$ & Takeup (pulley) travel & $\mathrm{m}$ & $\mathrm{B}$ & At stopping (braking) & \\
\hline$t_{A}$ & Start-up time & s & a & $\begin{array}{l}\text { Non-steady state operation } \\
\text { (start-up and braking) }\end{array}$ & \\
\hline$t_{B}$ & Stopping time & s & erf & Required & \\
\hline $\mathrm{v}$ & Conveying speed & $\mathrm{m} / \mathrm{s}$ & ges & Total & \\
\hline$\alpha$ & Angle of pulley wrap & ${ }^{\circ}, \mathrm{rad}$ & $\mathrm{i}$ & Index for driven/braked pulleys & \\
\hline$\beta$ & $\begin{array}{l}\text { Equivalent angle of repose of conveyed } \\
\text { material }\end{array}$ & $\circ$ & & 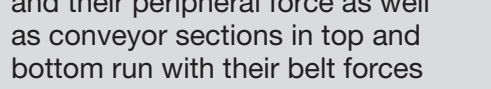 & \\
\hline$\varepsilon_{\mathrm{bl}}$ & $\begin{array}{l}\text { Permanent elongation of the } \\
\text { conveyor belt }\end{array}$ & $\%$ & inst & Installed & \\
\hline$\varepsilon_{\mathrm{el}}$ & Elastic elongation of the conveyor belt & $\%$ & $\max$ & $\begin{array}{l}\text { Maximum } \\
\text { Minimum }\end{array}$ & \\
\hline$\delta$ & Gradient angle of belt conveyor system & 。 & & Top run & \\
\hline$\eta_{\text {ges }}$ & $\begin{array}{l}\text { Overall efficiency of all transmission } \\
\text { elements between motor and pulley shaft }\end{array}$ & - & & Theoretical & \\
\hline$\varphi_{\mathrm{St}}$ & $\begin{array}{l}\text { Coefficient for determining the volume } \\
\text { flow of gradient conveyor belt system }\end{array}$ & - & $\begin{array}{l}\text { u } \\
\text { zul }\end{array}$ & $\begin{array}{l}\text { Bottom run } \\
\text { Allowable }\end{array}$ & \\
\hline
\end{tabular}




\section{General Design Fundamentals for Belt Conveyor Systems}

The general fundamentals of design according to DIN 22101 are elucidated below for determining motional resistances and power requirement of driving and braking processes as well as the belt tensions of a conveyor belt system.

The belt tension curve in different operating conditions is determined by means of a sequential calculation, by sectional addition of the pertinent motional resistances along the belt conveyor system.

At the end of sequential calculations, there shall be checked specific conditions as regards the minimum amount of belt tensions, which ensure driving and braking forces to be induced into the belt, in a slip-free way, over pulleys driven or braked respectively to ensure proper belt ride. To provide these minimum belt tensions, there are required equivalent take-up forces.

Upon completion of belt tensions calculations to determine the rated breaking strength of the belt as required, there shall be selected such safety factors to ensure safe and trouble-free operation of the belt and of its splices for the whole service life as planned.

\subsection{Motional Resistances and Power Required in the Steady Operating State}

\subsubsection{Power Required}

To overcome the motional resistances in a conveyor belt system the required (mechanical) power is determined by:

$$
\mathrm{P}_{\mathrm{W}}=\mathrm{F}_{\mathrm{W}} \cdot \mathrm{v}
$$

$\mathrm{P}_{\mathrm{W}} \quad$ total as a result of loading conditions in a steady operating state of necessary power at the periphery of the driving pulley

$F_{W}$ total of the motional resistances in top run/return run in a steady state operation

v belt speed

For unfavorable loading conditions on a conveyor belt system with uphill and downhill sections and an unevenly distributed rated load on the entire conveying flight, the determined motional resistance $F_{W}$ may be exceeded noticeably:

$$
\begin{aligned}
& \left|F_{\text {Wmax }}\right| \geq\left|F_{W}\right| \\
& \left|P_{W \max }\right| \geq\left|P_{W}\right|
\end{aligned}
$$

With the determination of the motional resistances allocated to the installed required motor as well as the distribution of the drive on several of the driving pulleys at the head and tail, the various conveying systems are differentiated from one another:

\section{norizontal and Upward Conveying Systems}

$$
\begin{array}{ll}
P_{\text {Merf }} & =\frac{P_{\text {Wmax }}}{\eta_{\text {ges }}} \\
P_{\text {Merf }} & \text { total power required of the drive motors } \\
P_{\text {Wmax }} \quad \begin{array}{l}
\text { maximum power required at the periphery of } \\
\text { the drive pulley(s) }
\end{array} & \\
\eta_{\text {ges }} \quad \begin{array}{l}
\text { the overall efficiency of all transmission elements } \\
\text { between motor and pulley shaft }
\end{array}
\end{array}
$$

In horizontal and weakly tilted conveyor belt systems with motors at only the head and tail stations, minimum belt tensions arise if the drive power $\mathrm{P}_{\text {Merf }}$ is distributed with relation to the motional resistances of the top run and return run.

In steep climbing conveyor systems without intermediate drives, minimum belt forces result when all of the drive motors are arranged at the head of the system.

\section{Downward Conveying Systems}

$$
\begin{array}{ll}
P_{\text {Merf }}=\frac{P_{\text {Wmax }}}{\eta_{\text {ges }}} & \begin{array}{l}
\text { with } P_{\text {Wmax }}>0 \\
\text { (motor operated drive) }
\end{array} \\
P_{\text {Merf }}=P_{\text {Wmax }} \cdot \eta_{\text {ges }} & \begin{array}{l}
\text { with } P_{\text {Wmax }}<0 \\
\text { (generator operated drive) }
\end{array}
\end{array}
$$

With this belt conveying system, minimum belt tensions result when the drive motors are arranged at the tail of the system in operating states, where the drive works generatorically.

Independent of the existing system variant, the actual installed total capacity of the drive motors is usually higher than the capacity required.

$$
\left|P_{\text {Minst }}\right| \geq\left|P_{\text {Merf }}\right|
$$

Accordingly, the required total capacity $\mathrm{P}_{\text {Merf }}$ is determined by exposure. That is valid only for systems with an evenly distributed load over the entire conveying flight. In contrast, an unevenly loaded belt conveyor system having uphill and downhill sections, must be considered for an optimal design, one in which the maximum power $\mathrm{P}_{\text {Wmax }}$ is usually only required for short time periods. 


\subsubsection{Motional Resistances}

With the belt movement in a steady operating state, motional resistances arise from friction, weight and mass forces:

$$
F_{W}=F_{H}+F_{N}+F_{S t}+F_{S}
$$

\begin{tabular}{llc}
$\mathrm{F}_{\mathrm{H}}$ & $\begin{array}{l}\text { total primary } \\
\text { resistances }\end{array}$ & $\begin{array}{c}\text { - acting in top run/return run } \\
\text { along conveying flight }\end{array}$ \\
\hline $\mathrm{F}_{\mathrm{N}}$ & $\begin{array}{l}\text { total secondary } \\
\text { resistances }\end{array}$ & $\begin{array}{c}\text { - locally limited to the head } \\
\text { and tail of the system }\end{array}$ \\
\hline $\mathrm{F}_{\mathrm{St}}$ & $\begin{array}{l}\text { total gradient } \\
\text { resistances }\end{array}$ & $\begin{array}{l}\text { - caused by the height } \\
\text { differences between bulk } \\
\text { material feed and discharge }\end{array}$ \\
\hline $\mathrm{F}_{\mathrm{S}}$ & $\begin{array}{l}\text { total special } \\
\text { resistances }\end{array}$ & $\begin{array}{l}\text { - occurs in particular instances, } \\
\text { in top run/return run } \\
\text { (considered separately) }\end{array}$ \\
\hline
\end{tabular}

\section{- Primary Resistances $\mathrm{F}_{\mathrm{H}}$ of the Conveying Flight}

The primary resistances of the conveying flight are composed of the parts occurring in the sections. These consist of flexing resistances of the conveyor belt as well as the bulk material and the rolling resistances of the idlers. The flexing resistance of the belt arises mainly from its indentation rolling resistance; its bending resistance is of secondary minor importance.

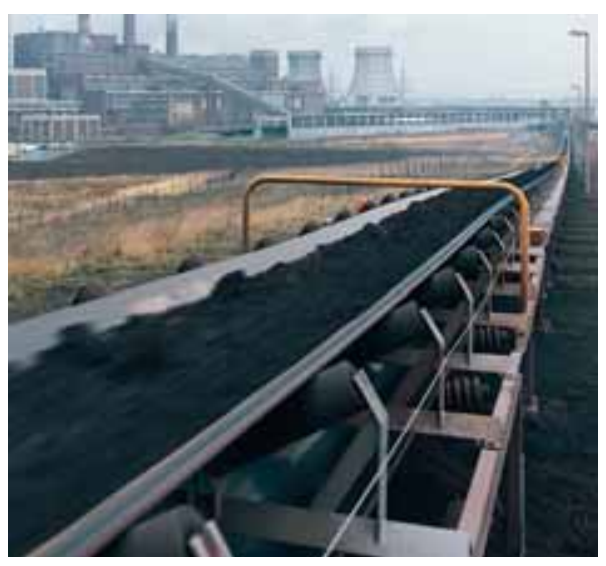

The main resistances of the system sections are simplified by using a linear dependency of the moveable mass - split up for top run and return run - and are determined as follows:

$$
F_{H i}=f_{i} \cdot l_{i} \cdot g \cdot\left[m_{R i}^{\prime}+\left(m_{G}^{\prime}+m_{L i}^{\prime}\right) \cdot \cos \delta_{i}\right]
$$

The sum of the primary resistances which occur in the system sections can be determined for an evenly tilted belt conveyor system as follows:

$$
F_{H}=f \cdot L \cdot g \cdot\left[m_{R}^{\prime}+\left(m_{G}^{\prime}+m_{L}^{\prime}\right) \cdot \cos \delta\right]
$$

$f_{i}, f$ fictitious friction factor of a system section $\left(f_{i}\right)$, respectively in top/return run together (f)

$\mathrm{I}_{\mathrm{i}}, \mathrm{L}$ belt length of a system section $\left(\mathrm{I}_{\mathrm{i}}\right)$, respectively of the entire conveying length $(\mathrm{L} \approx$ center distance $)$

g acceleration due to gravity $\left(\mathrm{g}=9.81 \mathrm{~m} / \mathrm{s}^{2}\right)$

$\mathrm{m}_{\mathrm{Ri}}$, Length related mass of the rotating

$m_{R}^{\prime}$ parts of the idlers in a conveyor section $\left(m_{R i}^{\prime}\right)$, respectively the total length $\left(m_{R}^{\prime}=m_{R o}^{\prime}+m_{R u}^{\prime}\right)$

$m_{G}^{\prime}$ length related mass of conveyor belt

$m_{L i}^{\prime}$, length related mass of the conveyor belt

$m_{L}^{\prime}$ of a section of the system $\left(m_{L i}^{\prime}\right)$, respectively the loaded run with an evenly distributed load on the conveying track $\left(\mathrm{m}_{\mathrm{L}}\right.$ )

$\delta_{i}, \delta$ conveying/inclination angle of a section $\left(\delta_{i}\right)$, respectively the entire stretch of an evenly inclined conveying track $(\delta)$

i running index for the designation of a system section 
In Tables 1, 2, 3, 4 and $\mathbf{5}$ (see Chapter 7) hints to determine the parameters $m_{L}^{\prime}, m_{R}^{\prime}$ and $m_{G}^{\prime}$ are given.

The primary resistances determined for the top run $\left(\mathrm{F}_{\mathrm{Ho}_{\mathrm{O}}}\right)$ as well as the return run $\left(\mathrm{F}_{\mathrm{Hu}}\right)$, are deciding factors in the local belt tension distribution of top run/return run and are relevant as the sum of the motional resistances and required power of the belt conveyor.

The parameter $f_{i}$ sectionally to be chosen and the applied common friction coefficient $f$ for the top and return run have an overweighing significance for the sizing of the system in the case of long, weakly tilted conveyor belt systems, at which only relatively minor secondary and gradient resistances are to be considered.

If the value of the friction factor $f_{i}$ shows no corresponding measurement or known values, the operating and constructive conditioning factors for the rated load guide values for the parameter $f$ can be taken from Table 6.1. The use of these values to calculate the primary resistances $\mathrm{F}_{\mathrm{Hi}}$ in the individual sections of the top run and return run, i.e., the taking of $f_{i}=f$, is only justifiable in a case where there are no exacting requirements.

On the other hand, if measurements for the running resistance of the idlers $F_{R}$ and the identation rolling resistance of the conveyor belt $F_{E}$ are available, this allows for systems in the rated load area, primary resistances of the (loaded) top run and (unloaded) return run to be determined more exactly as follows, rather than with the use of the value $f$ :

Top run $\quad F_{H_{O}}=\frac{1}{q_{o}} \cdot\left(F_{\mathrm{Ro}}+F_{E_{0}}\right)$

Return run $\mathrm{F}_{\mathrm{Hu}}=\frac{1}{\mathrm{qu}_{\mathrm{u}}} \cdot\left(\mathrm{F}_{\mathrm{Ru}}+\mathrm{F}_{\mathrm{Eu}}\right)$

q coefficient to determine the primary resistances: Top run: $0.5 \leq \mathrm{q}_{\mathrm{o}} \leq 0.85$; medium value: 0.7 . Return run: $\mathrm{q}_{\mathrm{u}}=0.9$

In Table 6.2 hints as to the size of the coefficient $\mathrm{q}_{\mathrm{o}}$ are given.

\section{Secondary Resistances $F_{N}$ of Individual Conveyor Sections}

The total secondary resistances $F_{N}$ result from the sum of locally limited motional resistances in the top run and return run, particularly at the head and tail of a belt conveyor system:

Bulk material feed

- acceleration resistance and frictional resistance between material handled and belt

- chute frictional resistance

Belt cleaner

- scraper resistance

Pulleys (not driven)

- deflection resistance due to belt bending

- resistance of the pulley bearings

The total of the above resistance is characterized by the coefficient $\mathrm{C}$ :

$$
\mathrm{C}=1+\frac{\mathrm{F}_{\mathrm{N}}}{\mathrm{F}_{\mathrm{H}}}
$$

It is evident that the relative influence of secondary resistances on the power requirement of a conveyor belt system depends greatly on its conveying length. The longer it is, the larger the primary resistance $F_{H}$ is and the closer the coefficient $C$ comes to a value of 1.0 , according to the above equation; even in very long systems $(L \geq 2000 \mathrm{~m})$ the value of 1.05 is assumed to be the lower limit (DIN 22101).

Table 7 shows guide values for the coefficient $C$ for loaded belt conveyor systems depending on their conveying length $\mathrm{L}$.

For loaded systems with $L>80 \mathrm{~m}$, the secondary resistances $F_{N}$ can be approximately determined by means of the following ratio:

$$
F_{N}=(C-1) \cdot F_{H}
$$

For loaded as well as unloaded systems with $L<80 \mathrm{~m}$, the secondary resistances should be determined individually. Appropriate information and equations are given in DIN 22101. 


\section{- Gradient Resistance $\mathbf{F}_{\mathbf{S t}}$ of the Material Handled}

The gradient resistance of conveyed material and conveyor belt in top run and return run have a particularly large influence in the distribution of belt forces in conveyors with a large gradient. In these cases the sum of these resistances determine a large part of the required drive force and drive power.

The gradient resistance of a section under consideration of the share of the belt is to be determined as follows:

$$
F_{S t i}=h_{i} \cdot g \cdot\left(m_{G}^{\prime}+m_{L i}^{\prime}\right)
$$

$\mathrm{h}_{\mathrm{i}} \quad$ height difference of the system section $h_{i}>0$ : uphill running direction of conveyor belt $h_{i}<0$ : downhill running direction of conveyor belt

For top run and return run, the gradient resistance $\mathrm{F}_{\mathrm{St}}$ in the case of an evenly loaded top run over the entire length (length related mass of the conveyor belt $\mathrm{m}_{\mathrm{L}} \mathrm{L}$ ) is calculated together as follows:

$$
F_{S t}=H \cdot g \cdot m_{L}^{\prime}
$$

H Conveying Height

$\mathrm{H}>0$ : uphill conveying

$\mathrm{H}<0$ : downhill conveying

Note:

The gradient resistances of the belt in top run and return run cancel each other out in the total motional resistance of a system and are thus disregarded in this connection. They shall, however, be given consideration when local belt tension is calculated (compare 3.3.1).

\section{- Special Resistances $\mathbf{F}_{\mathbf{S}}$}

Special resistances $F_{S}$ generally occur only with special purpose designs of belt conveyor systems. They are caused by:

tilted idler position

- tilting resistance

chutes outside the feeding points

- chute friction resistance

devices for lateral bulk material discharge along the conveying length

- scraper resistances

Tilting and chute friction resistances can be determined by means of the ratios listed in DIN 22101.

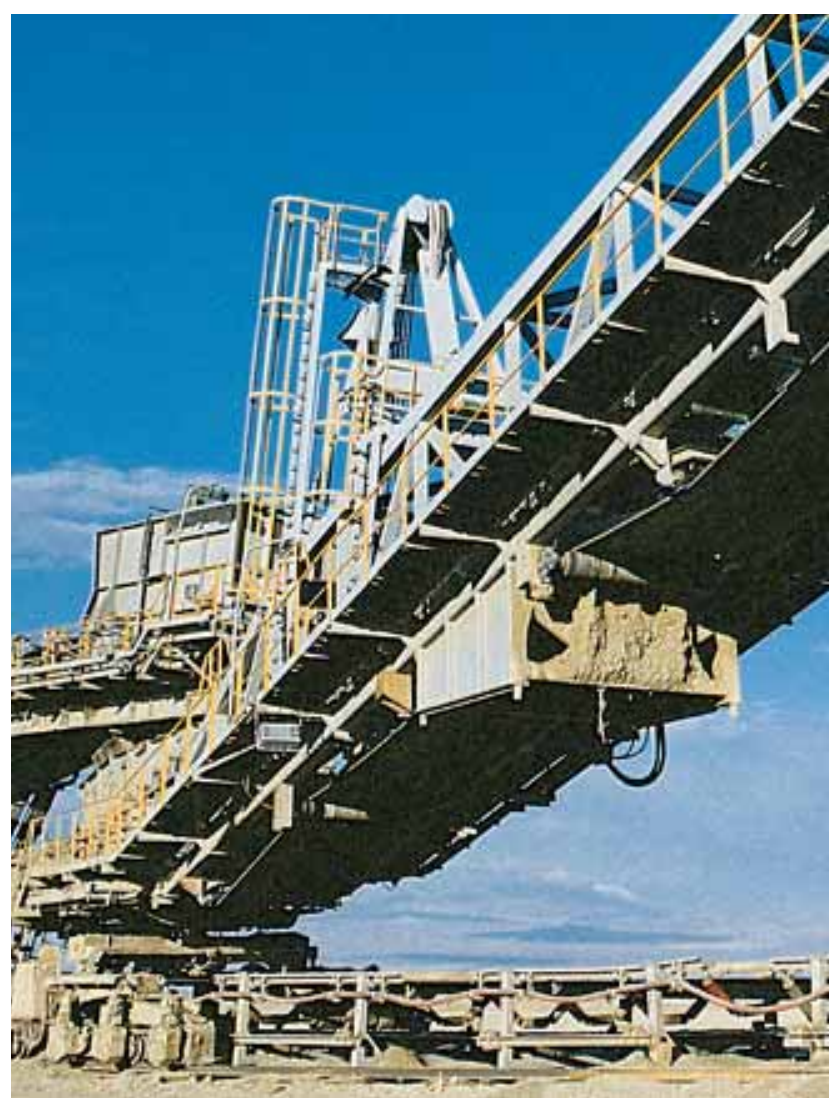




\subsection{Motional Resistances and Driving Forces in Non-Steady Operating States}

To calculate the non steady operating states

\section{starting-up and braking (stopping)}

of a belt conveyor system, its motional resistances are simply taken to be the same as in the steady operating state. Those in this operating state in top run/return run with acceleration and deceleration occurring resistances $\mathrm{F}_{\mathrm{a}}$ are, in view of their influence on the local sectional distribution of belt tensions and in their relation to the accompanying motional resistances, determined as follows:

$$
F_{a i}=a \cdot I_{i} \cdot\left(c_{R i} \cdot m_{R i}^{\prime}+m_{G}^{\prime}+m_{L i}^{\prime}\right)
$$

$$
\mathrm{F}_{\mathrm{a}}=\mathrm{a} \cdot \Sigma \mathrm{m}
$$

with $\Sigma m=\Sigma\left[I_{i} \cdot\left(c_{R i} \cdot m_{R i}^{\prime}+m_{G}^{\prime}+m_{L i}^{\prime}\right)\right]$

Apart from the already defined parameters $\mathrm{I}_{\mathrm{i}}, \mathrm{m}_{\mathrm{Ri}}$, $m_{G}^{\prime}, m_{L i}^{\prime}$, the following are:

a acceleration $(\mathrm{a}>0)$, respectively deceleration $(\mathrm{a}<0)$

$\mathrm{C}_{\mathrm{Ri}}$ coefficient for calculating the masses of the idlers reduced to their periphery $\left(\mathrm{C}_{\mathrm{Ri}} \approx 0.9\right)$

Note:

Possibly existing pulleys on the conveying flight as well as the rotating part of the drive and brake setup, which are accelerated or decelerated through the conveyor belt, are to be taken into special consideration.

In connection with the motional resistances $F_{w}$ of a belt conveyor system, the force $F_{a}$ is related to the sum of the transmitting pulley peripheral forces $\mathrm{F}_{\mathrm{TrA}}$ and $\mathrm{F}_{\mathrm{TrB}}$ at start-up and stopping in the following way:

$\begin{array}{ll} & F_{T r A}=F_{w}+F_{a A} \\ & F_{T r B}=F_{w}+F_{a B} \\ F_{a A} & \text { total acceleration force at start-up }\left(F_{a A}>0\right) \\ F_{a B} & \text { total deceleration force at stopping }\left(F_{a B}<0\right) \\ F_{w} & \begin{array}{l}\text { total motional resistances of top run and } \\ \text { return run }\end{array}\end{array}$

\subsubsection{Start Up}

A significant characteristic value for acceleration at the startup of a conveyor belt system with its high belt and drive tensions, is the startup factor $p_{A}$ which connects the peripheral forces of all driving pulleys at startup $\mathrm{F}_{\text {TrA }}$ with those in a steady operating state, i.e. with the total motional resistances $\mathrm{F}_{\mathrm{w}}$ as follows:

$$
\mathrm{p}_{\mathrm{A}}=\frac{\mathrm{F}_{\mathrm{TrA}}}{\mathrm{F}_{\mathrm{w}}}
$$

In DIN 22101 recommendations for the size of the pulley peripheral forces $\mathrm{F}_{\mathrm{TrA}}$, especially for a larger belt conveyor, are given. Accordingly these forces should

- not exceed 1.7 times the determined motional resistances of the belt conveyor system $F_{\text {Wmax }}$ (see Point 3.1.1 for this); i.e. starting factor $\mathrm{p}_{\mathrm{A}} \leq 1.7$ in order to avoid undesirably high belt tensions.

- be so measured, that the total of the acceleration forces $F_{a}$ in an unfavourable startup ( $F_{\text {Wmax }}$ !) is at least 0.2 times the motional resistances formed by friction and that the startup time of the drive does not exceed a thermally acceptable time limit.

- be so limited, that the friction grip between conveyor goods and conveyor belt is not endangered.

- be transmitted into the conveyor belt as slowly as possible so as to limit the intensity of the longitudinal vibrations.

Assuming a start-up factor $\mathrm{p}_{\mathrm{A}}$ with known values $F_{w}$ and $\Sigma m$, the following can be calculated quite simple:

- sum of the transmitting pulley peripheral forces at start-up:

$$
\mathrm{F}_{\mathrm{TrA}}=\mathrm{p}_{\mathrm{A}} \cdot \mathrm{F}_{\mathrm{W}}
$$

- start-up acceleration:

$$
a_{A}=\frac{\left(p_{a}-1\right) \cdot F_{W}}{\Sigma m}
$$

- total acceleration resistance in top and return run:

$$
F_{a A}=\left(p_{A}-1\right) \cdot F_{W}
$$

- start-up time (with constant values of $\mathrm{p}_{\mathrm{A}}$ respectively $\left.a_{A}\right)$ :

$$
t_{A}=\frac{v}{a_{A}}
$$


Changing the equations, e.g. by specifying the start-up time, also enables the start-up acceleration, the total acceleration resistance, the start-up pulley peripheral forces as well as the start-up factor to be determined.

The start-up factor $p_{A}$ has a major influence on the occurring accelerations and belt forces. It is related to the startup factor $\mathrm{p}_{\mathrm{A} 0}$ which characterises the load of the drives.

Where the mass moments of inertia of the rotating drive components are low and the motor operation of the drives are in steady operating state, i.e. in the event of horizontal and uphill belt conveyor systems, the start-up factor $p_{A 0}$ related to the rated torque of all drive motors can approximately be determined as follows:

$$
\mathrm{p}_{\mathrm{A} 0}=\mathrm{p}_{\mathrm{A}} \cdot \frac{\mathrm{P}_{\text {Merf }}}{\mathrm{P}_{\text {Minst }}}
$$

$\mathrm{p}_{\mathrm{AO}} \quad$ start-up factor related to the rated torque of all drive motors

$\mathrm{p}_{\mathrm{A}} \quad$ start-up factor related to the peripheral force of all driving pulleys in a steady operating state

$\mathrm{P}_{\text {Merf }}$ total capacity of the drive motors required in a steady operating state

$\mathrm{P}_{\text {Minst }}$ installed capacity of the drive motors

\subsubsection{Stopping}

Analogous to the calculation of the start-up process, the stopping factor $p_{B}$ is an important factor of the drive, braking and belt tension forces occurring in the conveyor system during deceleration.

The stopping factor $p_{B}$ is defined as the quotient between the peripheral force of all the driving pulleys when stopping $\mathrm{F}_{\mathrm{TrB}}$ and in steady state operation, i.e. as the total of the motional resistances $F_{w}$.

$$
\mathrm{p}_{\mathrm{B}}=\frac{\mathrm{F}_{\mathrm{TrB}}}{\mathrm{F}_{\mathrm{W}}}
$$

The required force $\mathrm{F}_{\mathrm{TrB}}$ must be determined for the most unfavorable braking conditions. The following must be given:

$$
\begin{aligned}
& \text { Braking distance } s_{B} \text { or } \\
& \text { braking time } t_{B}
\end{aligned}
$$

In view of the deceleration $a_{B}$ it must be seen to that the frictional grip between the belt and the material handled be maintained.
With braking distance $\mathrm{s}_{\mathrm{B}}$ being specified with a constant deceleration $\mathrm{a}_{\mathrm{B}}$ it is easy to determine:

- stopping time:

$$
t_{B}=\frac{s_{B} \cdot 2}{v}
$$

- stopping deceleration:

$$
a_{B}=-\frac{v}{t_{B}}
$$

- total deceleration resistance in top run and return run:

$$
\mathrm{F}_{\mathrm{aB}}=\mathrm{a}_{\mathrm{B}} \cdot \Sigma \mathrm{m}
$$

- sum of pulley peripheral forces in the stopping process:

$$
\mathrm{F}_{\mathrm{TrB}}=\mathrm{F}_{\mathrm{W}}+\mathrm{a}_{\mathrm{B}} \cdot \Sigma \mathrm{m}
$$

The braking factor $p_{B}$ has a major influence on the occurring decelerations and belt forces. It is related to the braking factor $\mathrm{p}_{\mathrm{B} 0}$ which characterizes the load of the drives respectively the brakes.

Where the mass moments of inertia of the rotating drive components are low and the motor operation of the drives is in a steady operating state, i.e. in the event of horizontal and uphill belt conveyor systems, the braking factor $\mathrm{p}_{\mathrm{B} 0}$ related to the rated torque of all drive motors can approximately be determined as follows:

$$
p_{B 0}=\eta_{\text {ges }}^{2} \cdot p_{B} \cdot \frac{P_{\text {Merf }}}{P_{\text {Minst }}}
$$

$\mathrm{p}_{\mathrm{B} 0} \quad$ braking factor related to the rated torque of all drive motors

$\mathrm{P}_{\text {Merf }}$ total capacity of the drive motors required in a steady operating state

$\mathrm{P}_{\text {Minst }}$ total installed capacity of the drive motors

$\eta_{\text {ges }} \quad$ overall efficiency of all transmission elements between motor and pulley shaft 


\subsection{Belt Tensions}

The belt tension of a conveyor belt system is of a varying value along the system flight and is governed by the following influencing factors:

- Length and local track of the system,

- Number and arrangement of the pulleys as driven/braked,

- Characteristics of the driving and braking equipments,

- Type and location of the belt takeup device,

- Operating and loading state of the system.

In addition there are required minimum belt tensions which

- ensure the friction grip on the pulleys as driven and braked,

- limit the belt sag between the idlers with a view to the belt being tracked correctly and satisfactorily.
The determination of the belt tensions, on principle, begins with a sequential calculation starting from a specific point of the system. Then, the belt tensions as calculated will be reviewed or modified respectively with regard to the friction grip on the pulleys driven/ braked and to the belt sag. Besides, the belt tensions are modified as regards the belt takeup device and the takeup location as selected.

In the event of belt conveyor systems providing drives at the system head and tail, an exact systematization of the location and designation of the pulleys driven or braked and of the local belt tensions is of prime importance. These parameters shall, therefore, be clearly defined.

For the theoretically possible case of a belt conveyor system providing two pulleys driven/braked at the system head and tail, the designations to Fig. 1 shall be entered accordingly.

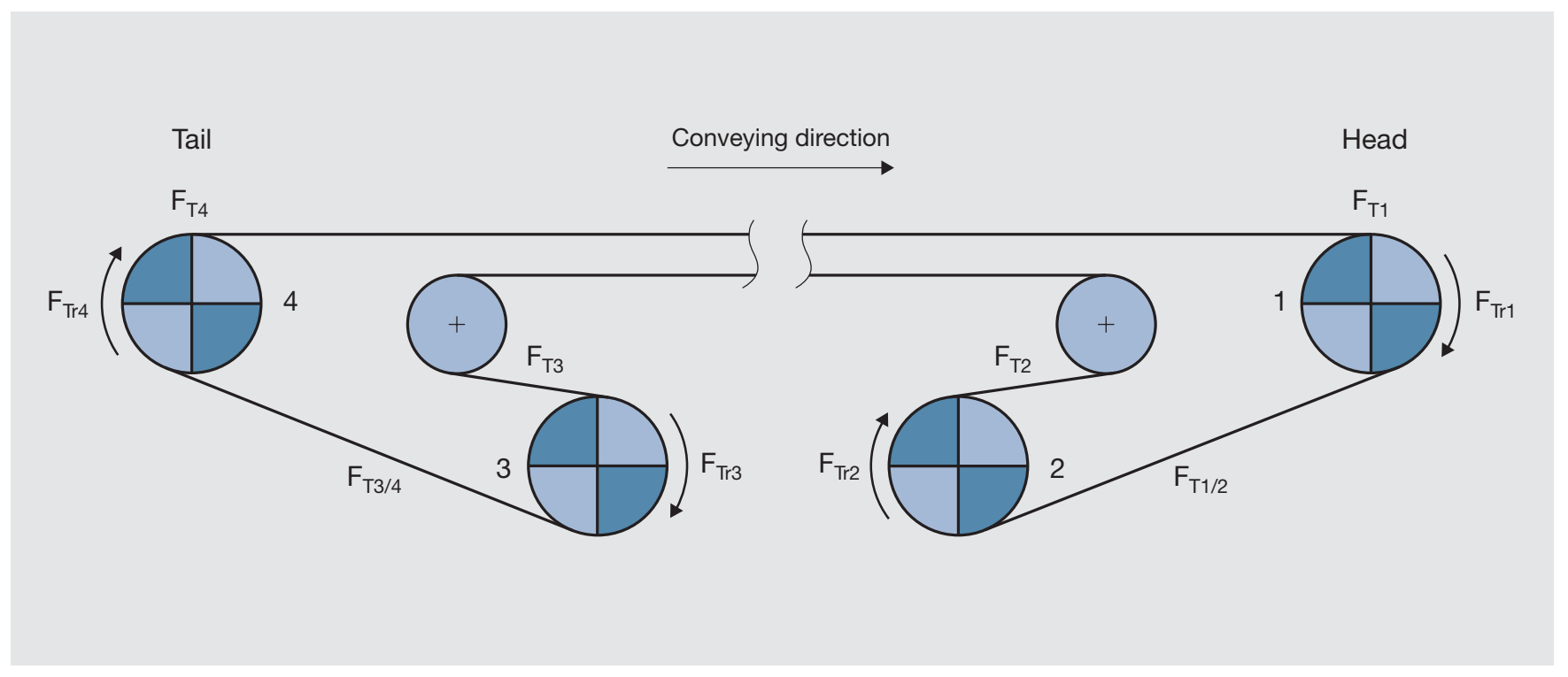

Fig. 1: The location and designation of the pulley as driven/braked as well as the belt tensions $\mathrm{F}_{\mathrm{T} 1}$ to $\mathrm{F}_{\mathrm{T} 4}$ of a belt conveyor system with driving and braking facilities at system head and tail. 


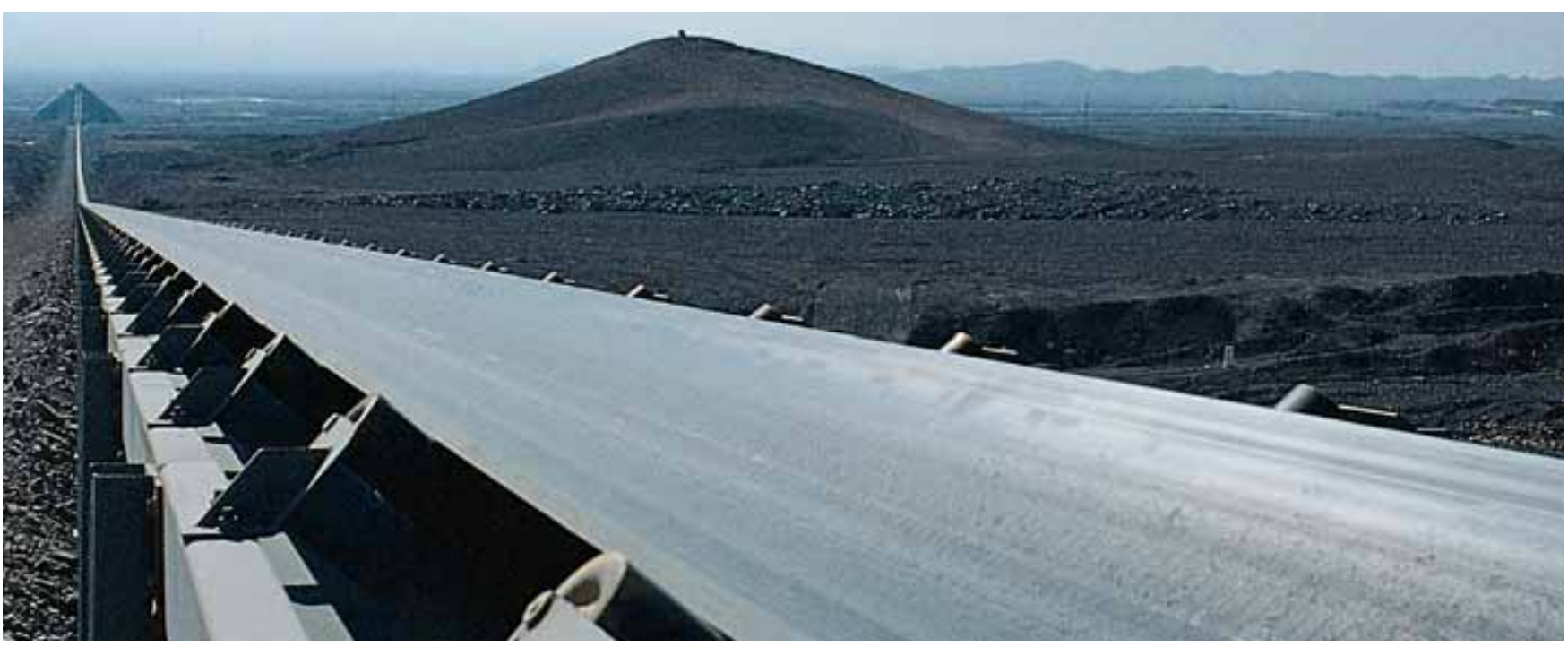

\subsubsection{Sequential Calculation}

Sequential calculations should appropriately be begun in both the stationary and nonstationary operating states at the tail of the system in the top run, with the belt tension $\mathrm{F}_{\mathrm{T} 4}$ in use by the resistance forces ascertained earlier (compare to Figure 1).

\section{- Steady State Operation}

$\mathrm{F}_{\mathrm{T} 4}=0$ (initial value)

$\mathrm{F}_{\mathrm{T} 1}=\mathrm{F}_{\mathrm{T} 4}+\mathrm{F}_{\mathrm{Ho}}+\mathrm{F}_{\mathrm{No}}+\mathrm{F}_{\mathrm{Sto}}+\mathrm{F}_{\mathrm{So}}$

$\mathrm{F}_{\mathrm{T} 1 / 2}=\mathrm{F}_{\mathrm{T} 1}-\mathrm{F}_{\mathrm{Tr} 1}$

$\mathrm{F}_{\mathrm{T} 2}=\mathrm{F}_{\mathrm{T} 1 / 2}-\mathrm{F}_{\mathrm{Tr} 2}$

$\mathrm{F}_{\mathrm{T} 3}=\mathrm{F}_{\mathrm{T} 2}+\mathrm{F}_{\mathrm{Hu}}+\mathrm{F}_{\mathrm{Nu}}+\mathrm{F}_{\mathrm{Stu}}+\mathrm{F}_{\mathrm{Su}}$

$\mathrm{F}_{\mathrm{T} 3 / 4}=\mathrm{F}_{\mathrm{T} 3}-\mathrm{F}_{\mathrm{Tr} 3}$

$\mathrm{F}_{\mathrm{T} 4}=\mathrm{F}_{\mathrm{T} 3 / 4}-\mathrm{F}_{\mathrm{Tr} 4}=0$ !! Verification!!

$\mathrm{F}_{\mathrm{Ho}, \mathrm{u}}$ total primary resistances in the top and return run

$\mathrm{F}_{\mathrm{No}, \mathrm{u}}$ total secondary resistances in the top and return run

$\mathrm{F}_{\text {Sto, u }}$ total gradient resistances of the belt and when applicable the transported material in the top and return run

$\mathrm{F}_{\mathrm{So}, \mathrm{u}}$ total special resistances in the top and return run

$\mathrm{F}_{\mathrm{Tr} 1} \quad$ Pulley 1 peripheral force

$F_{\text {Tr2 }} \quad$ Pulley 2 peripheral force

$\mathrm{F}_{\mathrm{Tr} 3} \quad$ Pulley 3 peripheral force

$\mathrm{F}_{\mathrm{Tr} 4} \quad$ Pulley 4 peripheral force

\section{Non-steady Operation State}

(A: start-up, B: stopping (braking))

$\mathrm{F}_{\mathrm{T} 4 \mathrm{~A}, \mathrm{~B}}=0$ (initial value)

$\mathrm{F}_{\mathrm{T} 1 \mathrm{~A}, \mathrm{~B}}=\mathrm{F}_{\mathrm{T} 4 \mathrm{~A}, \mathrm{~B}}+\mathrm{F}_{\mathrm{Ho}}+\mathrm{F}_{\mathrm{No}}+\mathrm{F}_{\mathrm{Sto}}+\mathrm{F}_{\mathrm{So}}+\mathrm{F}_{\mathrm{aoA}, \mathrm{B}}$

$F_{T 1 / 2 A, B}=F_{T 1 A, B}-F_{T r 1 A, B}$

$\mathrm{F}_{\mathrm{T} 2 \mathrm{~A}, \mathrm{~B}}=\mathrm{F}_{\mathrm{T} 1 / 2 \mathrm{~A}, \mathrm{~B}}-\mathrm{F}_{\mathrm{T} 2 \mathrm{~A}, \mathrm{~B}}$

$\mathrm{F}_{\mathrm{T} 3 \mathrm{~A}, \mathrm{~B}}=\mathrm{F}_{\mathrm{T} 2 \mathrm{~A}, \mathrm{~B}}+\mathrm{F}_{\mathrm{Hu}}+\mathrm{F}_{\mathrm{Nu}}+\mathrm{F}_{\mathrm{Stu}}+\mathrm{F}_{\mathrm{Su}}+\mathrm{F}_{\mathrm{auA}, \mathrm{B}}$

$\mathrm{F}_{\mathrm{T} 3 / 4 \mathrm{~A}, \mathrm{~B}}=\mathrm{F}_{\mathrm{T} 3 \mathrm{~A}, \mathrm{~B}}-\mathrm{F}_{\mathrm{Tr} 3 \mathrm{~A}, \mathrm{~B}}$

$\mathrm{F}_{\mathrm{T} 4 \mathrm{~A}, \mathrm{~B}}=\mathrm{F}_{\mathrm{T} 3 / 4 \mathrm{~A}, \mathrm{~B}}-\mathrm{F}_{\mathrm{Tr} 4 \mathrm{~A}, \mathrm{~B}}=0$ !! Verification !! 


\subsubsection{Minimum Belt Tensions for Transmitting the Pulley Peripheral Forces}

Pulley peripheral force transmission both in stationary and non-stationary operating states requires specific minimum belt tension.

The ratios quoted below as an example for the forces at pulley 1 in Fig. 1 normally apply for pulleys when driven or braked.

For motor or generator-induced operation of the drives, the following applies in general

$$
F_{\text {Tmin }} \geq\left|F_{T r 1}\right| \cdot\left(\frac{1}{e^{\mu \alpha_{1}}-1}\right)
$$

- Motor operation of the drives:

$$
\begin{aligned}
& \mathrm{F}_{\mathrm{T} \min }=\mathrm{F}_{\mathrm{T} 1 / 2} \\
& \mathrm{~F}_{\mathrm{T} \min }=\mathrm{F}_{\mathrm{T} 1}
\end{aligned}
$$

- Generator-induced of the drives:

$\mu \quad$ friction coefficient between conveyor belt and pulley surface

$\alpha_{1} \quad$ Pulley 1 angle of wrap (unit: Radiant!)

The values for the parameter $\mu$ are listed in Table 8 and for the term $\frac{1}{\mathrm{e}^{\mu \alpha_{1}-1}} \quad$ in Table 9.

\section{Steady Operating State}

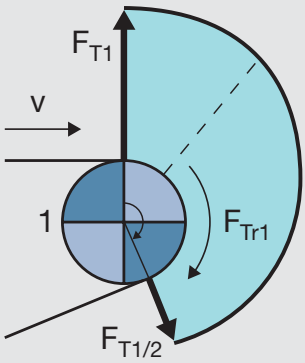

Motor operation

of the drives $\left(\mathrm{F}_{\mathrm{Tr} 1}>0\right)$

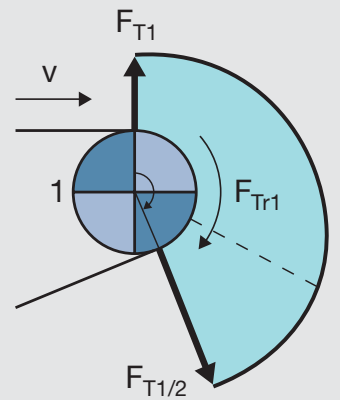

Generator-induced operation of the drives $\left(F_{T r 1}<0\right)$

Fig. 2: Belt tension curves on drive pulley 1 in Fig. 1 with motor und generator-induced operation of the drives in a steady operating state with incomplete utilization of the angle of pulley belt wrap $\alpha_{1}$
The following generally applies for pulley 1 as driven or braked:

$$
F_{T \min A, B} \geq\left|F_{T r 1 A, B}\right| \cdot\left(\frac{1}{e^{\mu^{\alpha}{ }_{1}}-1}\right)
$$

- Start-up: $\quad \mathrm{F}_{\mathrm{Tmin} A}=\mathrm{F}_{\mathrm{T} 1 / 2 \mathrm{~A}}$

- Braking: $\mathrm{F}_{\mathrm{Tmin} B}=\mathrm{F}_{\mathrm{T} 1 \mathrm{~B}}$

For every operating and loading state, the friction grip is to be checked on all pulleys, driven or braked. To be taken into consideration is that the entire transmitting pulley peripheral forces $\mathrm{F}_{\mathrm{Tr}}, \mathrm{F}_{\mathrm{TrA}}, \mathrm{F}_{\mathrm{TrB}}$ are distributed among the pulleys according to the torque of the drives and brakes.

\section{Non-steady Operating State}
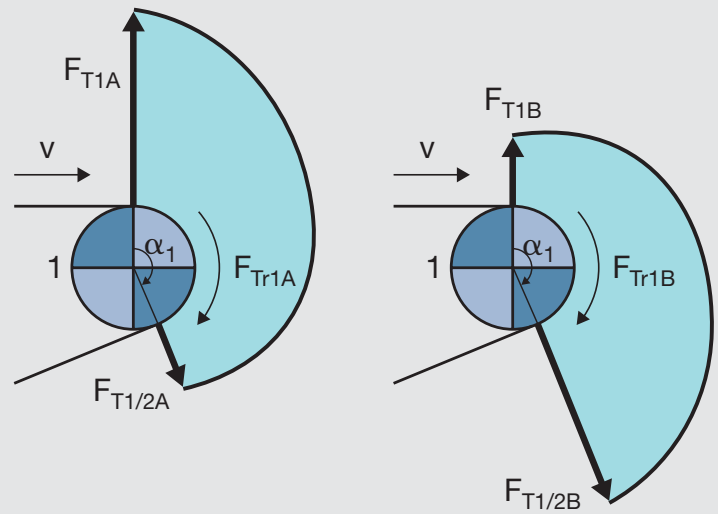

Start-up

$\left(F_{T r 1 A}>0\right)$

Stopping (braking) $\left(\mathrm{F}_{\mathrm{Tr} 1 \mathrm{~B}}<0\right)$

Fig. 3: Belt tension curves of pulley 1 as driven or braked in Fig. 1 when the belt conveyor system is started or stopped at complete utilization of the angle of wrap $\alpha_{1}$ 


\subsubsection{Minimum Belt Tensions for Belt Sag Limitation and Correct Tracking}

To optimize a belt conveyor system with regard to correct and satisfactory belt tracking, the maximum belt sag $h_{\text {rel }}$, in relation to the particular carrying idler spacing, should have values limited to $1 \%$ in a stationary operating state; in the non stationary operating state, a larger value is allowable. The sag should then be less, the greater the conveying speed and the lumpier the load. From this, the resulting minimum belt tensions required are as follows: (Designation of forces in $\mathrm{N}$, given $\mathrm{h}_{\text {rel }}$ in \%):

- Top run (loaded)

$$
F_{T o}=\frac{12.5 \cdot g \cdot\left(m_{L i}^{\prime}+m_{G}^{\prime}\right) \cdot I_{R o}}{h_{\text {rel }}}
$$

- Return run (unloaded)

$$
\mathrm{F}_{\mathrm{Tu}}=\frac{12.5 \cdot \mathrm{g} \cdot \mathrm{m}_{\mathrm{G}}^{\prime} \cdot \mathrm{I}_{\mathrm{Ru}}}{\mathrm{h}_{\mathrm{rel}}}
$$

(For the significance of the parameters $\mathrm{m}_{\mathrm{Li}}$ and $\mathrm{m}_{\mathrm{G}}$ see chapter 3.1.2)

In view of the flawless operation of the conveyor belt, the retention of larger minimum belt tensions may also be required in the following cases (DIN 22101):

- conveyor belt with a small amount of transverse rigidity

- conveyor belt with a belt turnover

- conveyor belt with an uneven distribution of local forces over the belt width

- strongly tilted conveyor belt on the return run.

\subsubsection{Takeup Forces}

To ensure the belt tensions as calculated above, the conveyor belt should be suitably tensioned. This can be attained by means of a takeup device providing a

- flying takeup pulley or a

- fixed takeup pulley.

\section{- Takeup Device Providing a Flying Takeup Pulley}

In the event of a takeup device providing a flying takeup pulley, its takeup force $F_{S p}$ (= force at the axis of the takeup pulley) remains unchanged in all operating states.

Example (compare Fig. 1):

Tensioning of the belt where the belt tension is $\mathrm{F}_{\mathrm{T} 2}$,

then: $F_{\mathrm{T} 2}=\mathrm{F}_{\mathrm{T} 2 \mathrm{~A}}=\mathrm{F}_{\mathrm{T} 2 \mathrm{~B}}=$ constant

and $\mathrm{F}_{\mathrm{Sp}}=2 \cdot \mathrm{F}_{\mathrm{T} 2}=$ constant

\section{- Takeup Device Providing a Fixed Takeup Pulley}

With a takeup device providing a fixed takeup pulley, the total length of the belt in the top run and return run is a constant value independent of the belt conveyor system operating and load states.

In the event of conveyor belts providing a quasi-linear tension-elongation characteristic curve in the operating range of the belt, a constant belt length also implies a constant mean belt tension $\mathrm{F}_{\mathrm{Tm}}$. This, however, implies that the belt tension at the location of the takeup device depends on the local belt tension curve in the respective load and operating state of the conveyor belt system.

Takeup force $F_{S p}$ (= force at the axis of the takeup pulley) is, thus, a value depending on the operating state of the system.

Example (compare Fig. 1):

Tensioning of the belt at the location of belt tension $\mathrm{F}_{\mathrm{T} 2}$,

then: $\mathrm{F}_{\mathrm{T} 2} \neq \mathrm{F}_{\mathrm{T} 2 \mathrm{~A}} \neq \mathrm{F}_{\mathrm{T} 2 \mathrm{~B}} \neq$ constant

and $\quad \mathrm{F}_{\mathrm{Sp}} \neq$ constant

For systems uniformly inclined and loaded, the following applies for the operating states of steady state condition, start-up and braking:

$$
\begin{aligned}
\mathrm{F}_{\mathrm{Tm}}= & \frac{\left(\mathrm{F}_{\mathrm{T} 1}+\mathrm{F}_{\mathrm{T} 2}+\mathrm{F}_{\mathrm{T} 3}+\mathrm{F}_{\mathrm{T} 4}\right)}{4}=\frac{\left(\mathrm{F}_{\mathrm{T} 1 \mathrm{~A}}+\mathrm{F}_{\mathrm{T} 2 \mathrm{~A}}+\mathrm{F}_{\mathrm{T} 3 \mathrm{~A}}+\mathrm{F}_{\mathrm{T} 4 \mathrm{~A}}\right)}{4} \\
= & \frac{\left(\mathrm{F}_{\mathrm{T} 1 \mathrm{~B}}+\mathrm{F}_{\mathrm{T} 2 \mathrm{~B}}+\mathrm{F}_{\mathrm{T} 3 \mathrm{~B}}+\mathrm{F}_{\mathrm{T} 4 \mathrm{~B}}\right)}{4}=\mathrm{constant}
\end{aligned}
$$

Notes on dimensioning of the takeup device are given in chapter 5.2.2.

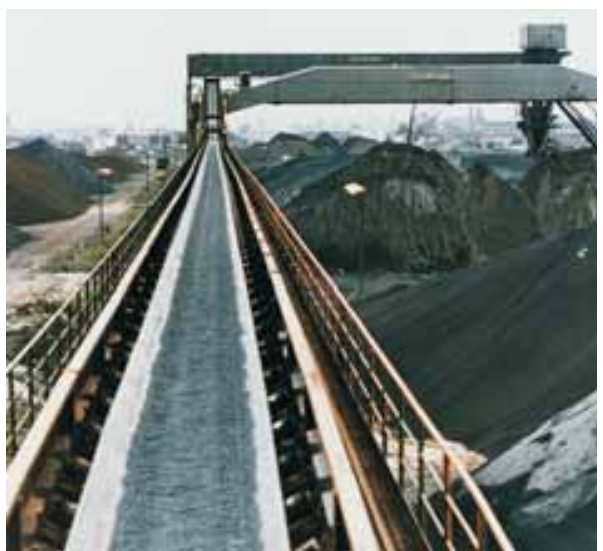




\subsection{Lateral Distribution of Tensions}

With flat-to-trough and trough-to-flat transitions, as well as by the tracking of a conveyor belt through convex or concave vertical curves, the belt edges run a different way than the belt midsection. This results in the distribution of belt forces not being constant over the entire width of the belt. That is also valid for the running operation of the horizontal curve in which one belt side is more burdened than the other.

a.

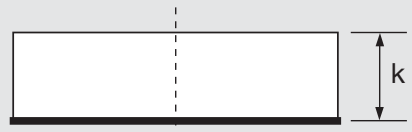

b.

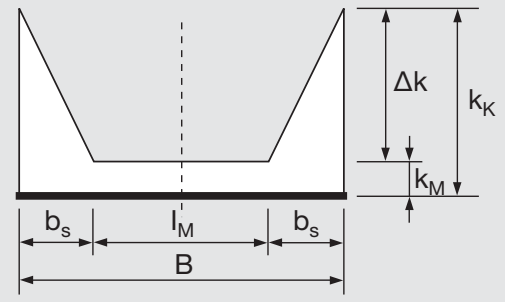

Fig. 4: Distribution of the belt tensions on the belt width of a conveyor belt in relationship to its running in a convex vertical curve (according to DIN 22101)

a. even distribution of forces ouside of the transition area

b. idealized distribution of forces inside of a transition area
The geometry of the transition must be sized in a way that the dominant belt forces on any specific point of the conveying path do not allow for an inadmissably high burden or a resulting compression of the belt.

Figure 4 depicts the transition zone tracking of a conveyor belt in a convex vertical curve with an idealized distribution across the belt width. Accordingly, between the width related forces on the belt edge $k_{K}$ and those in the midsection $\mathrm{k}_{\mathrm{M}}$, the difference $\Delta \mathrm{k}$, as well as the midsectionally related belt tension $\mathrm{k}$, show the following connection:

$$
\begin{aligned}
& \mathrm{k}_{\mathrm{M}}=\mathrm{k}-\Delta \mathrm{k} \cdot \frac{\mathrm{b}_{\mathrm{s}}}{\mathrm{B}} \\
& \mathrm{k}_{\mathrm{K}}=\mathrm{k}_{\mathrm{M}}+\Delta \mathrm{k}
\end{aligned}
$$

The example of a transition zone tracking into a convex curve also illustrates, accordingly, the valid relationships among concave vertical curves.

\subsubsection{Transition Zones}

Assuming that a medial running of the conveyor belt in the transition zone can be determined for a 2 and 3 part carrying idlers arrangement, the difference of the width related belt forces $\Delta \mathrm{k}$ between edge and midsection of the conveyor belt is as follows:

$$
\Delta \mathrm{k}_{\mathrm{IU}}=\frac{\mathrm{I}_{\mathrm{K}}-\mathrm{I}_{\ddot{U}}}{\mathrm{I}_{\ddot{\mathrm{efff}}}} \cdot \mathrm{E}_{\mathrm{LGK}}
$$
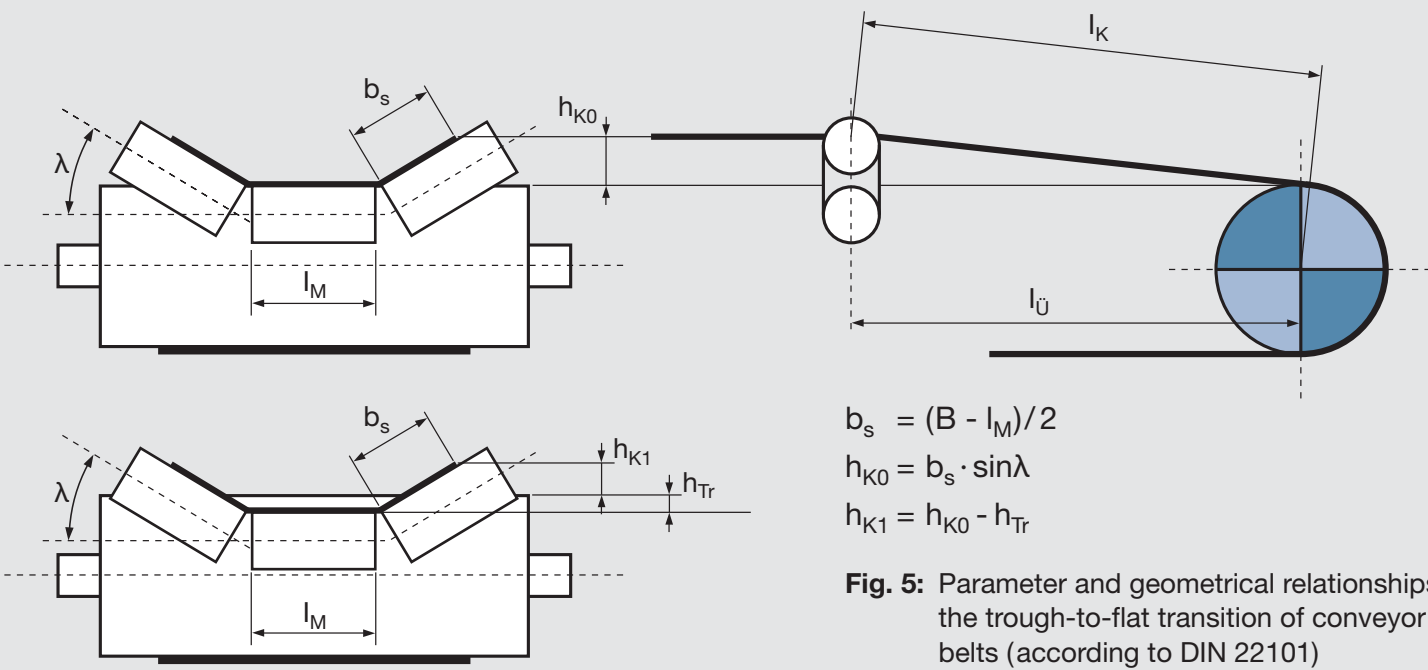

$b_{s}=\left(B-I_{M}\right) / 2$

$h_{\mathrm{K} 0}=b_{\mathrm{s}} \cdot \sin \lambda$

$\mathrm{h}_{\mathrm{K} 1}=\mathrm{h}_{\mathrm{KO}}-\mathrm{h}_{\mathrm{Tr}}$

Fig. 5: Parameter and geometrical relationships in the trough-to-flat transition of conveyor belts (according to DIN 22101) 
$I_{K} \quad$ length of the belt edge in the transition zone (for calculations of $I_{K}$ see Fig. 5)

I. length of the transition zone

IÜeff effective length of transition zone

Textile belt: $\quad \mathrm{I}_{\text {Üeff }}=\mathrm{I}_{\mathrm{U}}$

Steel cord belt: $\mathrm{l}_{\text {Üeff }}=\mathrm{l}_{\mathrm{U}}+\Delta \mathrm{l}_{\ddot{U}}$

$\mathrm{E}_{\mathrm{LGk}}$ elasticity module of the tensile member (= belt core) related to the width of the belt

The equation determining the effective length of the tran-

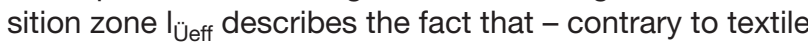
belts - the elongations induced in a steel cord belt are not only effective in the area where they are generated, but also in adjacent areas.

For the 2 and 3 part carrying idlers arrangement, the size $\Delta \mathrm{I}_{\mathrm{u}}$ for the presently used steel cord belts with the prerequisite $\mathrm{l}_{\mathrm{U}} \geq 14 \cdot\left(\mathrm{h}_{\mathrm{KO}}-\mathrm{h}_{\mathrm{Tr}}\right)$, can be approximately determined as follows:

$$
\Delta \mathrm{l}_{\ddot{U}}=90 \cdot\left(\mathrm{h}_{\mathrm{K} 0}-\mathrm{h}_{\mathrm{Tr}}\right) \cdot\left(1-\frac{\mathrm{h}_{\mathrm{Tr}}}{3 \cdot \mathrm{h}_{\mathrm{Tr} \max }}\right)
$$

$h_{K 0}$ distance between the belt edge and the deepest level of the trough (values for $h_{K 0}$ see Table 17)

$\mathrm{h}_{\mathrm{Tr}} \quad$ pulley lifting in the troughing zone compared to the deepest level of the trough

$\left(\mathrm{h}_{\mathrm{Trmax}}=\mathrm{h}_{\mathrm{KO}} / 3\right.$ according to DIN 22101)

With the specification of the elasticity module $E_{L G k}$ and the geometrical parameters of a transition zone, the difference $\Delta \mathrm{k}$ in connection with the medium, width related forces $\mathrm{k}, \mathrm{k}_{\mathrm{M}}$ in the midsection of the belt and those on the belt edges $k_{\mathrm{K}}$ can be determined.

\subsubsection{Vertical Curves}

Belt conveyor systems with ascending and/or descending sections of varying gradient angles are marked by the appearance of convex and concave transitional curves. With convex belt tracking, additional lengthenings of the belt edge and shortenings of the belt midsection appear, in contrast to additional lengthenings of the belt midsection and shortenings of the belt edge with concave belt tracking. These lengthenings and shortenings of the allocated additional elongation in the conveyor belt, with small and medium lengths of the curves, are only detected at a relatively high value. Since the sum is always smaller than those which appear in longer curves, values independent from the construction of the conveyor belt allow for 2 and 3 carrying idlers arrangement of the following approximation for the difference of the width related belt tensions $\Delta \mathrm{k}$ to be calculated between belt edge and belt midsection:

Convex curves: $\quad \Delta \mathrm{k}_{\mathrm{Re}} \leq \frac{\mathrm{h}_{\mathrm{Ko}}}{\mathrm{R}_{\mathrm{e}}} \cdot \mathrm{E}_{\mathrm{LGk}}$

Concave curves: $\Delta \mathrm{k}_{\mathrm{Ra}} \geq-\frac{\mathrm{h}_{\mathrm{Ko}}}{\mathrm{R}_{\mathrm{a}}} \cdot \mathrm{E}_{\mathrm{LGk}}$

Here $R_{e}$ and $R_{a}$ are the radii of convex (index e) and concave transition curves (index a) according to Fig. 6.

With the determined values $\Delta \mathrm{k}$, using the accompanying width related belt tensions, $\mathrm{k}_{\mathrm{M}}$ and $\mathrm{k}_{\mathrm{K}}$ can be calculated.

\section{Note:}

In concave belt tracking with small radii, excessive requirements do not appear as a rule since the belt is lifted from the idlers.

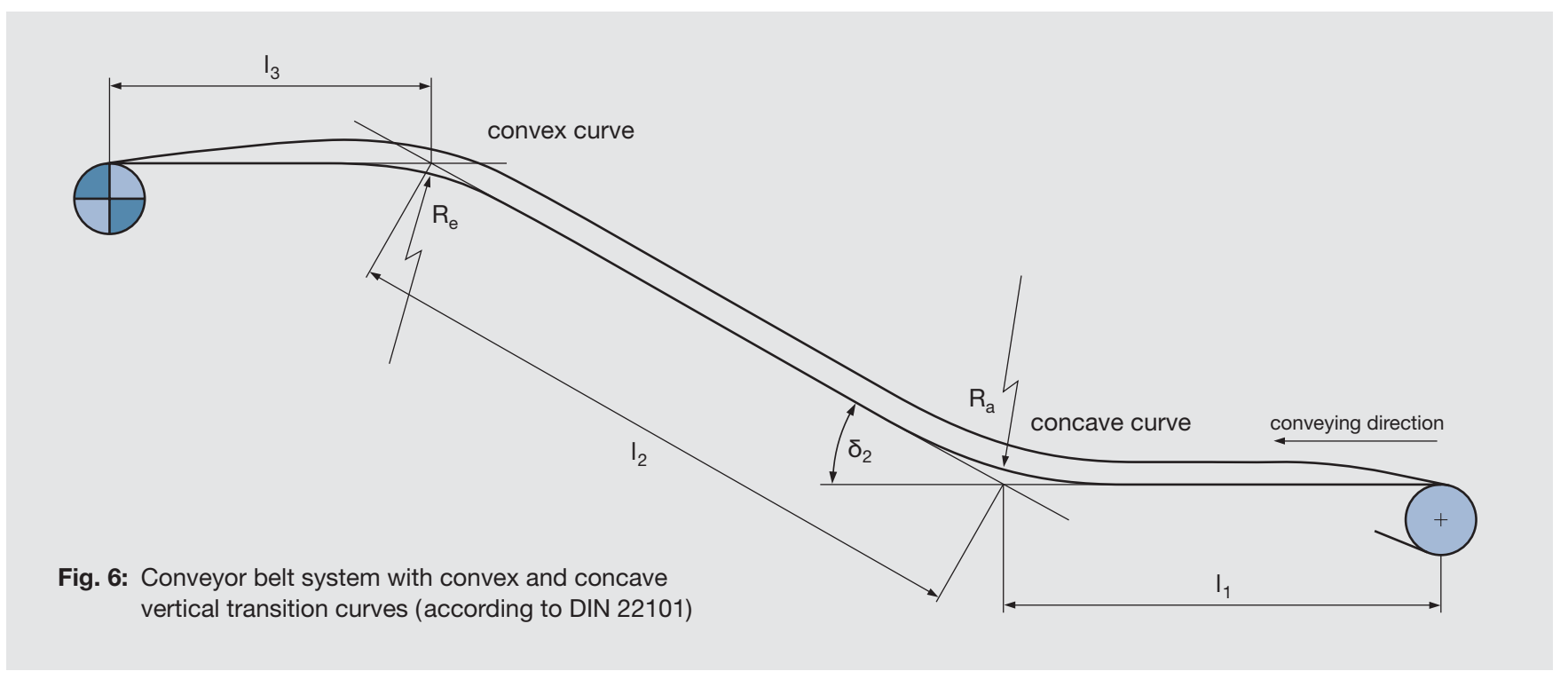




\section{Phoenix Computer Program Capacity}

The Phoenix computer program for the calculation and design of belt conveyor systems for transporting bulk materials is based mainly on the calculating principles as outlined in DIN 22101 in the August 2002 version.

In accordance with the customary calculating procedure for sizing belt conveyor systems, DIN 22101 is divided into the following sections:

- Volume flow and mass flow

- Motional resistances and power requirement

- Drive system layout

- Belt tension and takeup forces

- Belt tensile force distribution over the belt width

- Conveyor belt layout

- Minimum pulley diameters

- Layout of transition curves and transition zones as well as radii of vertical transition curves

With its computer program, Phoenix has the following goals:

- High flexibility in treating the most diverse system configurations

- Treating all tasks as set in the design of belt conveyor systems, where possible with a computational algorithm

- Simulation of all load and operating conditions of a belt conveyor system

- Optimum belt selection with regard to performance and price

- Plain programming

- Short calculation and response times

- Rapid output of the results

- Clear depiction of the results

\subsection{Major Computer Program Features}

1. For calculation and design purposes, the belt conveyor system to be sized is divided into characteristic sections. In these sections, the specific parameters, e.g., length, height, loads, idler spacings, etc., can be varied. In conjunction with the variable types and arrangements of drive, braking and takeup devices, there amounts high flexibility on iterative optimization of the system and a safe and economic design of the associated conveyor belt.

2. In addition to investigating the primary input parameters, e.g. allocation of the conveying speed, mass flow and troughing angle of the conveyor belt, the Phoenix computer program is characterized by the following features:

- Thorough systematization of the drive concept results in any combination of head and tail drive

- Sizing of the drive and braking settings/fittings, as well as the determination of the optimization/optimal distribution of the corresponding pulleys at the head and tail.

3. When the belt tension or tensioning forces are determined, the following influencing variables are taken into account in the Phoenix computer program:

- System length and its local routing,

- Number and arrangement of the pulleys driven and braked,

- Characteristics of the drive and braking devices,

- Type and location of the belt takeup equipment,

- Transition zones and vertical curves, provided they are present.

A system design also requires the above factors to be optimized to obtain the lowest possible local belt tensions. This, however, must not overlook the minimum belt tensions as required with regard to the friction grip on the pulleys as driven and braked as well as to belt sag limitation to ensure perfect belt tracking. These conditions shall be met in any operating and loading state.

4. The Phoenix calculation covers the following operating states:

- Start up,

- Steady operating state,

- Stopping (with or without the effects of braking devices).

For all loading and operating states that occur, an investigation is made to see whether the friction grip on the pulleys as driven and braked is ensured, that the belt sag is limited to the extent as required, and hat with transition zones, in the event of vertical curves, no excessively high or low belt tension is allowed to occur.

Through the possibility given by the Phoenix computer program of preselecting suitable acceleration or deceleration times respectively which can be attained by appropriate sizing of the drive and braking devices, unfavorably high or low belt tensions can be prevented. The goal of suitable optimization is to determine the most economic system or belt design. 
5. As to tensioning of the conveyor belt, on principle, there is made a differentiation between takeup devices with a fixed or flying takeup pulley. The Phoenix computer program determines that location of the takeup device at which the lowest belt tension occurs in a steady operating state, however, any other point of the system can be selected as tensioning location.

6. Dividing the belt conveyor system into sectors ensures that systems with ascending or descending sections as well as with sectionally differing loads can be displayed in the computer with a view to simulating the locally occurring belt tensions.

With regard to the optimum layout of conveyor belts, the knowledge of the belt tension curve along the system is of prime importance in every loading and operating state, particularly as regards the location and the amount of extreme belt tensions.

Accordingly, the Phoenix computer program permits to simulate differing loads on the pertinent sections for any operating requirements, so that sizing the belt and other system components can be optimally coordinated to the conveyance-technical task (for instance, when the belt is running in vertical and horizontal curves).

7. The Phoenix computer program specializes in offering the possibility of allowing additional motional resistances or drive forces to be taken into account at any chosen point in the conveyor belt system.

By this means, intermediate drives (e.g. booster drives) can also be taken into account through the calculation and dimension sizing of a conveyor belt system. Over and above that, the frictional forces on the additional skirting sidewalls outside of the feeding area or 'scraper' resistances can be made accessible for calculation.

8. The outcome of the calculations is that the belt tensions as well as the safety factors for the belt and its splice are shown graphically and in a tabular scheme at any point of the system for any operating and loading instance. This allows rapid verification with regard to compliance with the safety factors as required and the admissible stresses and strains in the belt.

For the drive or braking devices to be installed, the capacities of braking torques as required are allocated and their dividing up on the pertinent pulleys at the head and tail of the system.

To complete the calculation part, the customer, with a Phoenix quotation, is furnished with all systemspecific data, e.g. takeup length, pulley diameters, flat-to-trough and trough-to-flat transition lengths, transition radii of concave and convex curves and belt turnover length, if required, for various appropriate versions of the conveyor belt.

To sum up, it is stated that the amount of possibilities provided by the Phoenix computer program enables a rapid and optimum layout of major constructional components of a belt conveyor system, particularly of the conveyor belt.

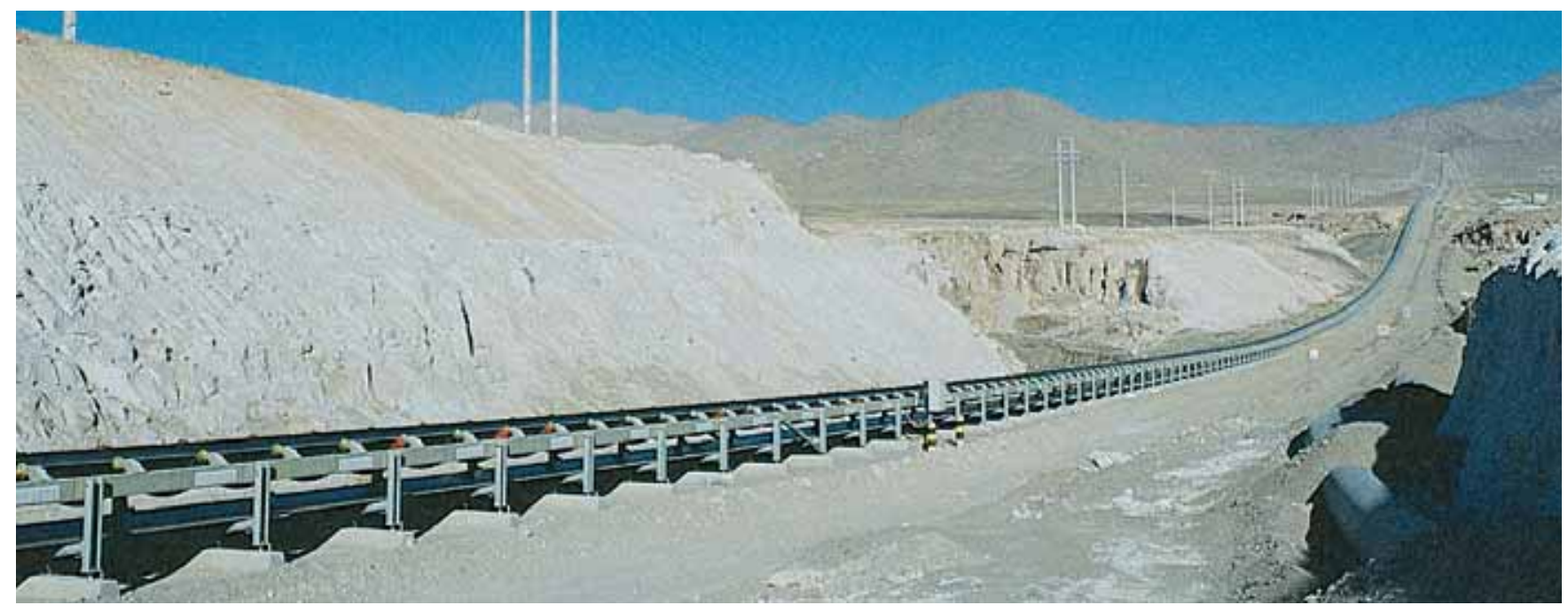




\subsection{Process and Target of Calculations}

The process of calculating and designing belt conveyor systems within the Phoenix computer program is run to the following scheme:

- input dialog using the Phoenix questionnaire according to Chapter 6,

- calculation of the motional resistances and the power requirement in the steady operating state, taking into account any loading states,

- calculation of the motional resistances and the forces of the drive and braking devices in non-steady operating states taking into account the start-up/braking factors, start-up/braking times as given or also the braking distances,

- calculation of the belt tensions in any operating or loading states and checking over with regard to:

- Friction grip of pulleys as driven/braked

- Belt sag

- Takeup type and location

- Pre-tensioning force value

- Belt tracking in transition zones and in the event of vertical curves

- optimum selection of the suitable conveyor belt with regard to its minimum breaking strength and determination of other major components of a belt conveyor system,

- output of the following values determining the design:

- Motional resistances

- Power requirement

- Local belt tensions

- Maximum and minimum belt tensions

- Minimum transition lengths in transition zones and minimum vertical radii in transition curves

- Safety factors for belt and splice

The goal of the aforementioned extensive calculations is to determine the most economic design of the belt conveyor system, particularly of the conveyor belt by means of rapid and optimum design, in particular with regard to minimum belt tensions. This requires to see to the following aspects:

- Optimum motor capacity distribution on the drive pulleys,

- Optimum distribution of the pulley peripheral forces in the stopping process,

- Sensible limitation of start-up and stopping times,

- Selection of the optimum belt takeup device with regard to type and location.

\subsection{Hints for Designing Complex Belt Conveyor Systems}

As previously mentioned, in the event of belt conveyor systems providing drives at the head and at the tail of the system, an accurate systematization as to the position and description of pulleys as driven or braked along with the local belt tensions is of prime importance. To prevent any misunderstanding in the Phoenix computer program, the pulley arrangements along with the pertinent belt tension locations, according to Fig. 1, are clearly defined.

The description of the belt tensions at exposed points of the system layout, for instance in the event of belt conveyor systems providing sectionally differing gradients, loadings and/or idler spacings is stipulated in Fig. 7.

The terminology to Figs. 1 and 7 applies both for uphill and downhill conveying systems and eases replies to possible queries on belt design.

When complex belt conveyor systems are designed, for instance providing several sections of a differing gradient (see Fig. 8), top run and return run shall be divided up into sections. The calculation expenditure to determine layout-determining values such as

- maximum power requirement as well as

- location and amount of the maximum and minimum belt tensions

is considerably higher according to the number of sections than in the event of "simple" systems, since a great variety of loads shall be considered.

The Phoenix computer program routinely reviews all possible loads and specifies the design determining values, particularly the maximum and minimum belt tensions. Taking into account the briefly permissable overloads of the drives, an evaluation of the loads and their calculated result is calculated according to the probability of occurrence.

As to the example of a system according to Fig. 8 the routine requirements for the calculation of all load and operating states are shown in Fig. 9. For this example, a total of 900 belt tension values must be checked and analysed so as to determine the loads acting on the belt as well as those of the drive and braking devices under any load distribution and in any operating state. 


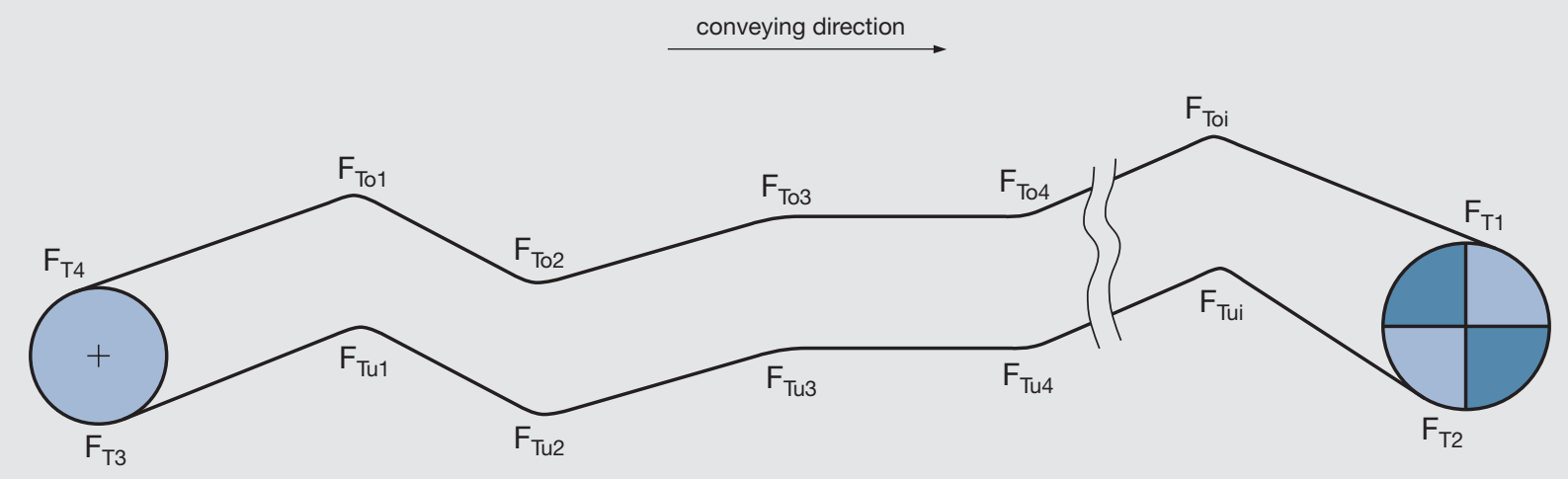

Fig. 7: Description of local belt tensions in a belt conveyor system providing $i+1$ sectional flights of different gradient angles.

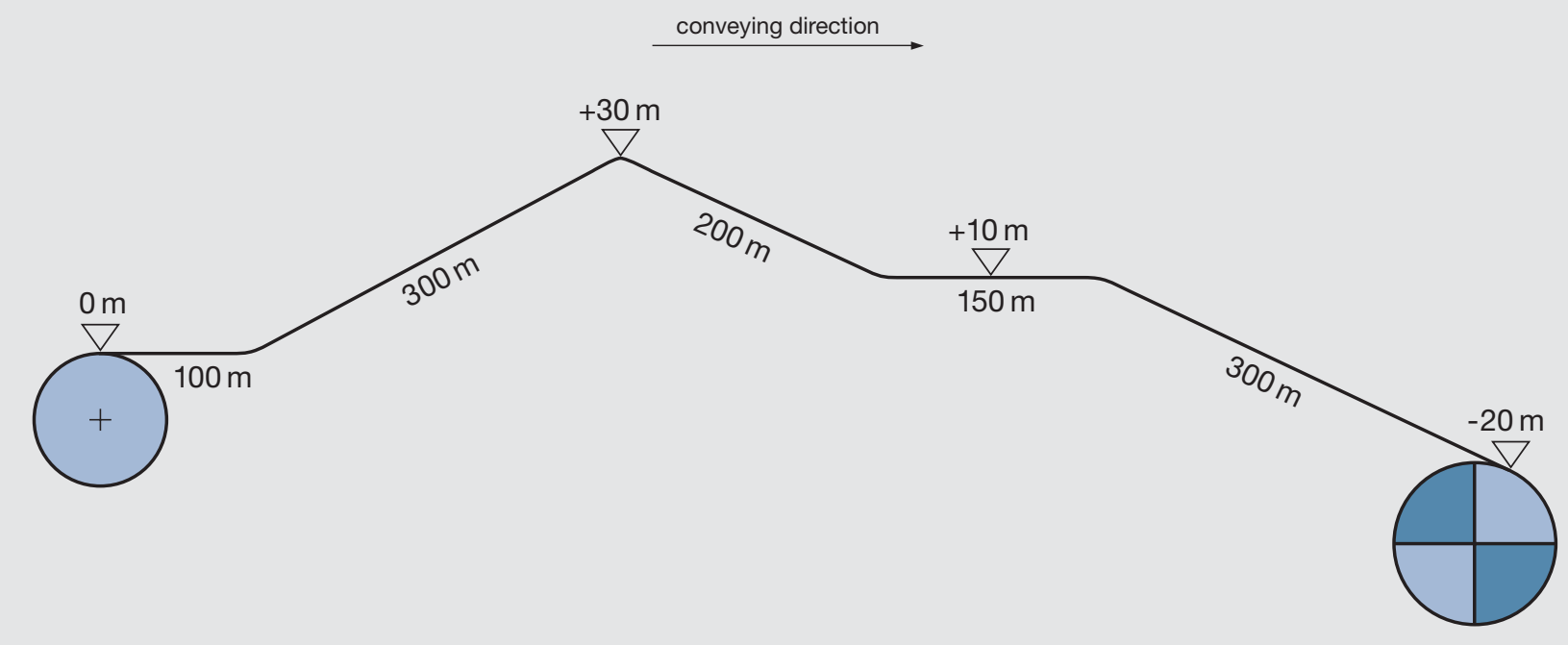

Fig. 8: Example of a belt conveyor system providing uphill and downhill sections along the conveying path. 


\begin{tabular}{|c|c|c|}
\hline Load Cases & $\begin{array}{c}\text { Number of } \\
\text { Calculation Cycles *) }\end{array}$ & Total \\
\hline No-load operation & 1 & 1 \\
\hline Rated load & 1 & 2 \\
\hline Special types of load: & & \\
\hline - Load starting & 4 & 3 to 6 \\
\hline - Load ending & 4 & 7 to 10 \\
\hline - Horizontal sections only under load & 2 & 11 to 12 \\
\hline - Horizontal and uphill sections only under load & 2 & 13 to 14 \\
\hline - Horizontal and downhill sections only under load & 5 & 15 to 19 \\
\hline - Uphill sections only under load & 1 & 20 \\
\hline - Downhill sections only under load & 2 & 21 to 22 \\
\hline - Tilted sections only under load & 3 & 23 to 25 \\
\hline For the steady operating state: Number of calculation runs & \multicolumn{2}{|c|}{25} \\
\hline $\begin{array}{l}\text { Number of operating states } \\
\text { (steady operating state, start-up, stopping) }\end{array}$ & \multicolumn{2}{|c|}{3} \\
\hline Number of local belt tensions in the top run & \multicolumn{2}{|c|}{6} \\
\hline Number of local belt tensions in the return run & \multicolumn{2}{|c|}{6} \\
\hline Total belt tension data to be analysed & \multicolumn{2}{|c|}{900} \\
\hline
\end{tabular}

Fig. 9: Expenditure of calculations to determine the load of the conveyor belt and of the pertinent drive and braking devices in all operating and loading states of the belt conveyor system according to Fig. 8
*) Only the calculation runs of those load distributions that were not included in the loads as previously listed are considered.
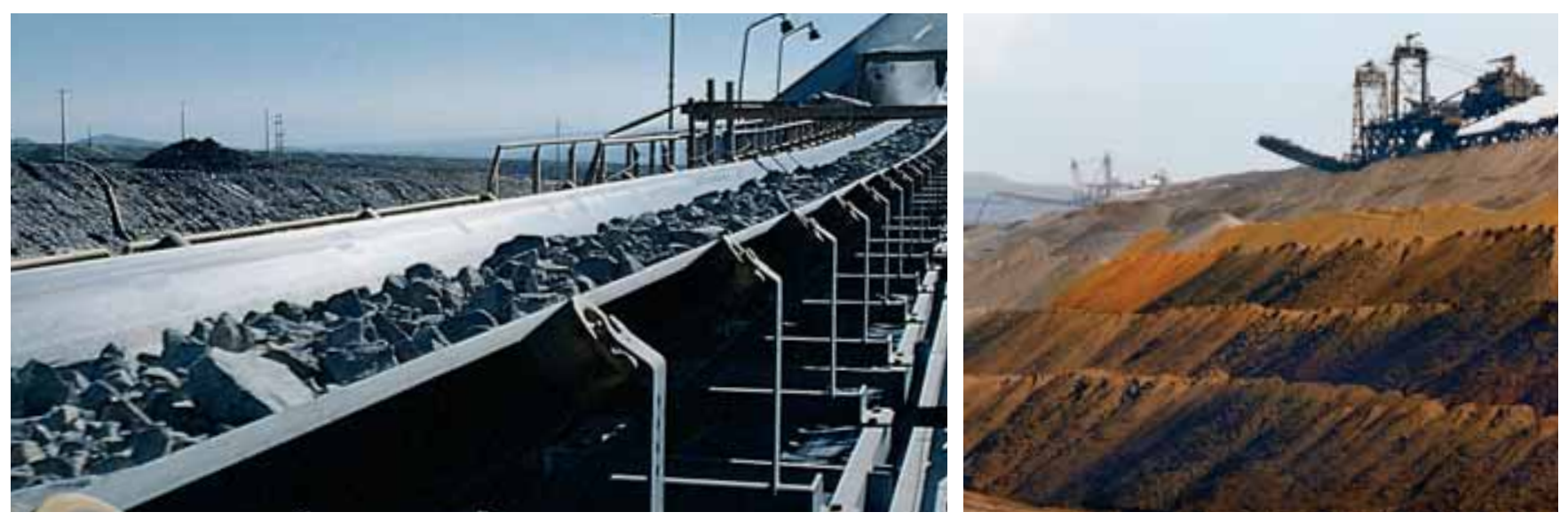


\section{Sizing of Belt Conveyor Systems based on Phoenix Computer Program Results}

When the operating conditions and the stresses and strains of the conveyor belt and of the drive and stopping devices are known in any operating and loading state, the performance specification can be drawn up to completely determine the design of a belt conveyor system.

This is followed by the layout of the conveyor belt and by sizing the other major components of a belt conveyor system to be designed, and by the stipulation of the characteristical parameters of belt tracking (for instance, transition lengths and curves).

However, right from the beginning of designing a conveyor belt, there shall be taken into account the effects of a belt construction as selected on the whole of the belt conveyor system, since particularly belt tracking and the design of certain system components can be decisively affected by the conveyor belt.

\subsection{Conveyor Belt}

\subsubsection{Tensile Members}

A major influence for the belt selection is the strength of the splice under dynamic load. For vulcanised splices this can be measured with the test procedure according to DIN 22110 part 3. The design can be based on the splice strength determined by this procedure or on the width related dynamic splice efficiency $\mathrm{k}_{\text {trel }}$.

$$
\begin{array}{ll} 
& k_{\text {trel }}=\frac{k_{t}}{k_{N}} \\
k_{t} & \text { splice strength } \\
k_{N} & \text { rated breaking force related to belt width }
\end{array}
$$

The parameter $k_{\text {trel }}$ is characteristic for a specific type of belt and its splice. In DIN 22101 there are additional details as to its size for textile as well as for steel cord conveyor belts.

While the values of the relative dynamic splice efficiency for splices are determined, manufactured and checked under ideal conditions, there are situations and restricted operating conditions which divert from these ideal conditions and these are taken into account through the safety factor $S_{0}$ (see Table 10). In contrast, practical influences, such as the frequency of increased mechanical stresses and strains, the effect of natural aging processes, as well as the influence of chemical and physical demands, will be taken into account through the safety factor $S_{1}$ (see Table 11).

If the necessity to deviate exists while selecting safety factors from the values according to Tables $\mathbf{1 0}$ and 11, Phoenix can give you suggestions, based on countless investigations, as to the expected life time of the splices.
The required minimum dynamic splice efficiency of the conveyor belt and its connection $\mathrm{k}_{\mathrm{tmin}}$ as well as the rated breaking strength of the belt $\mathrm{k}_{\mathrm{N}}$ as related to the belt width, result from the maximum, previously determined force $\mathrm{k}_{\mathrm{K} \max }$ on the belt edge.

$$
\begin{aligned}
& \mathrm{k}_{\text {tmin }}=\mathrm{c}_{\mathrm{K}} \cdot \mathrm{k}_{\mathrm{Kmax}} \cdot \mathrm{S}_{0} \cdot \mathrm{S}_{1} \\
& \mathrm{k}_{\mathrm{N}} \geq \frac{\mathrm{k}_{\text {tmin }}}{\mathrm{k}_{\text {trel }}}=\mathrm{c}_{\mathrm{K}} \cdot \mathrm{k}_{\mathrm{Kmax}} \cdot \frac{\mathrm{S}_{0} \cdot \mathrm{S}_{1}}{\mathrm{k}_{\text {trel }}}
\end{aligned}
$$

Textile belt: $\quad \mathrm{c}_{\mathrm{K}}=1$

Steel cord belt: $c_{K}=1.25$ : Troughing transition

$$
=1.00: \text { Other forms of tracking }
$$

Here the value of the coefficient $\mathrm{c}_{\mathrm{K}}$ is given according to DIN 22101.

In order to avoid extreme strain in the non-steady operating condition, as well as in an unfavorable loading distribution with rising and falling sections along the system, the following conditions must be checked and adhered to for the maximum width related tension occurring on the belt edges $\left(\mathrm{k}_{\mathrm{K}}\right)_{\mathrm{amax}}$ :

$$
\mathrm{k}_{\mathrm{tmin}} \geq 1.1 \cdot \mathrm{c}_{\mathrm{K}} \cdot\left(\mathrm{k}_{\mathrm{K}}\right)_{\mathrm{amax}}
$$

If this is not the case, the selection of the belt must be based on the higher value $\mathrm{k}_{\mathrm{tmin}}=1.1 \cdot \mathrm{c}_{\mathrm{K}} \cdot\left(\mathrm{k}_{\mathrm{K}}\right)_{\mathrm{amax}}$.

Further influences on the sizing of the tensile members of a conveyor belt can be requirements for high impact strength and a specific transverse stiffness.

In the planning and setting up of a large conveyor system, with a view to an optimal sizing of the conveyor belt and its further system components, according to the type and rated breaking strength of the conveyor belt, there are factors which should be agreed upon with Phoenix. Table 12 shows the characteristics of Phoenix conveyor belts.

In the range of strength which is covered by several types of belt, the selection of the tensile member in general follows with a view to its purpose and/or location, as well as an achievable splicing system, making allowances for its relative dynamic splice efficiency. Where several possibilities exist, the economically most efficient will, of course, be the preferred one.

Since each conveyor belt is only as durable as its splice, the manufacture of the belt splice must especially be taken into consideration when choosing the tensile member. 


\subsubsection{Covers}

The covers of a conveyor belt are intended to protect its tensile member and shall be appropriate for the particular application and location of use with a view to quality and to minimum thickness.

The quality, e.g. the material of covers, in principle, is stipulated, at first, with a view to the location of use and to the scope of requirements of the conveyor belt.

\section{Use above ground:}

Cover materials are selected here with a view to the particular use and, thus, to the special scope of requirements (see Tables 13 and 14).

\section{Underground mining:}

Here, particularly for use in German coal mining, only cover materials are admitted with suitable tensile member materials that meet safety and fire-engineering requirements and those that comply with hygienic and electrical specifications.

The cover gauges as required on the top and bottom sides of a conveyor belt depend on the cover material used and on the material and design of the tensile member. Due to the effects of the material handled, the cover shall have a thickness of the carrying side of the belt exceeding the minimum thickness.

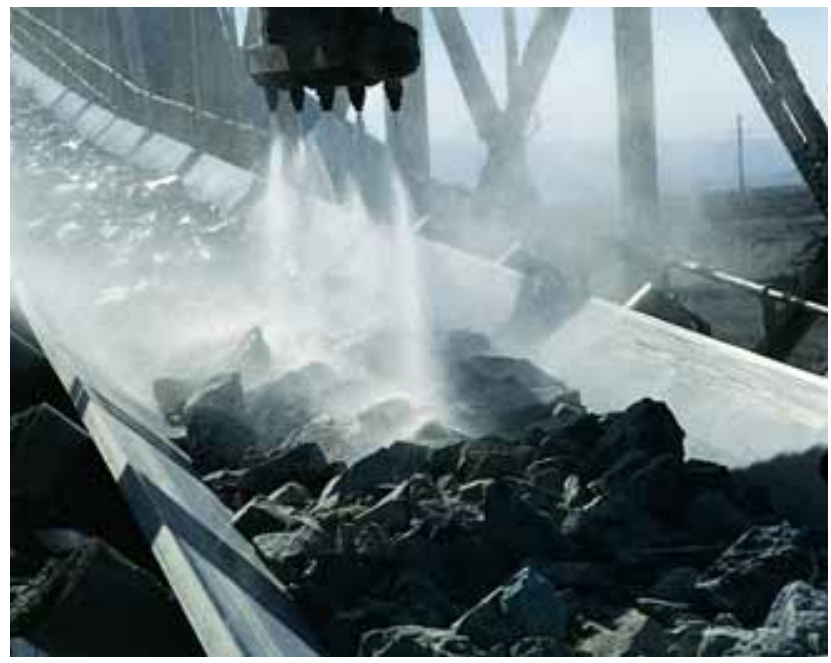

Minimum cover gauges on the top and bottom sides (depending on the tensile member):

\section{Textile carcass belt:}

The minimum cover gauge depends on the thickness and on the material of the tensile member and should be 1 to $2 \mathrm{~mm}$, depending on the fabric.

\section{Steel cord conveyor belt:}

The minimum cover gauge should be $4 \mathrm{~mm}$. On belts with cable diameters exceeding $5.9 \mathrm{~mm}$, the minimum thickness should be 0.7 times the cable diameter.

Additions to the minimum cover gauges on the top side are determined as a function of:

- Physical and chemical properties of the material handled

- Lump size and their shape, density, abrasiveness, chemical composition, temperature

- Loading conditions

- Feeding height, feeding speed, feeding direction

- Loading frequency

- Belt revolving frequency

- Planned belt service life.

By means of rating numbers according to DIN 22101 the necessary addition to the minimum gauge of the top side cover can be determined as an approximation.

Guide values for top and bottom side cover gauges of conveyor belts for various applications can be taken from Table 15.

\section{Attention:}

A particularly effective protection of the tensile member and, thus, a noticeably increased service life of conveyor belts subjected to high strain will be achieved by the use of

PHOENOTEC ${ }^{\circledR}$ transverse reinforcement system.

The impact resistance as well as the indentation and tear resistances of a belt so protected is considerably increased by using the PHOENOTEC ${ }^{\circledR}$ protection system. It is based on high-elongation cords of synthetic fibres which are arranged in a defined spacing across the longitudinal direction of the belt, the cord pitch being stipulated by Phoenix, according to the application (see Fig. 10).

The protective cords are incorporated jointless in the topand/or bottom side of the conveyor belt even up to extreme belt widths. Here, the level of the cords within the belt is specified, taking into account the trough of the belt and the optimum protective effect in compliance with the respective use. 
The protective cords are an integral part of in the conveyor belt bonded by means of a special adhesion process that ensures high dynamical capability, thermal stability and resistance to moisture.

\section{Additional information is given in the}

Phoenix PHOENOTEC ${ }^{\circledR}$ Protection System brochure.

The great variability as to

- Tensile member,

- Splicing system,

- Cover material,

- Cover gauge,

- Transverse reinforcement,

ensures a long service life of Phoenix conveyor belts.

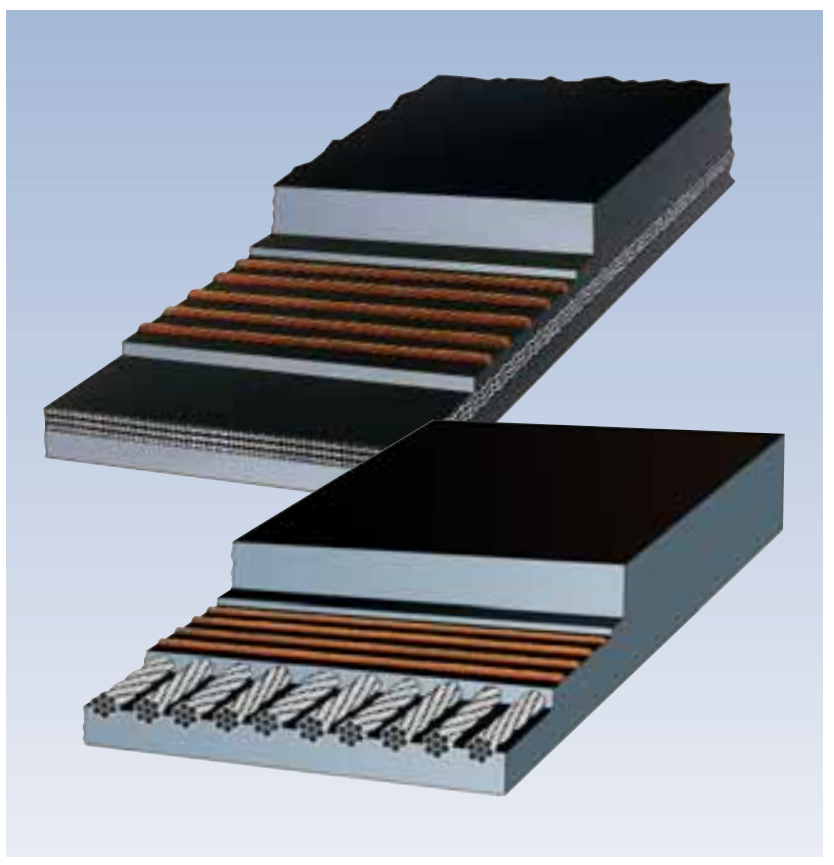

Fig. 10: Conveyor belt with fabric plies (above) and with steel cords (below), reinforced with PHOENOTEC ${ }^{\circledR}$ transverse reinforcement.

\subsection{Other Constructional Components}

The selected tensile member in the conveyor belt also affects the system components

\section{- Pulleys and}

\section{- Takeup devices.}

The effect of the tensile member with regard to the minimum diameter of the pulleys in a belt conveyor system is described below.

\subsubsection{Minimum Pulley Diameters}

The minimum pulley diameters in a belt conveyor system are largely oriented to the structure and load of the tensile member in a conveyor belt and to kind and type of its splices.

For determining the minimum diameters of the pulleys, the following pulley groups should be distinguished:

- Group A

- Drive pulleys and other pulleys in the range of high belt tension

- Group B

- Pulleys in the range of low belt tensions

- Group C

- Snub or deflection pulleys (change in belt moving direction $\leq 30^{\circ}$ )

The minimum pulley diameter can be roughly determined according to DIN 22101 from the tensile member thickness and from a global material parameter (see Table 16). The tensile member thickness shall be determined by means of the data of Table 5.

If the data in Table 5, needed to calculate the tension $\mathrm{k}_{\max }$ during the planning, is not yet present, the selection of allowable tension $\mathrm{k}_{\mathrm{zul}}$ is based upon:

$$
\mathrm{k}_{\mathrm{zul}}=\frac{\mathrm{k}_{\mathrm{N}} \cdot \mathrm{k}_{\text {trel }}}{\mathrm{S}_{0} \cdot \mathrm{S}_{1}}
$$

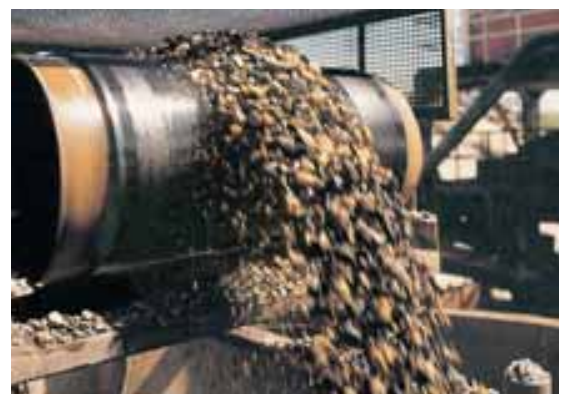




\section{Attention:}

For UNIFLEX ${ }^{\circledR}$ Compact Conveyor Belts for underground use please see our special brochure.

\subsubsection{Take-up Device}

To generate necessary tensions (see Point 3.3.4) and to counterbalance belt elongations, take-up devices are required. There is to be distinguished between take-up devices with

- flying take-up pulley and

- fixed take-up pulley.

With a view to design expenditure, it is pratical to install the take-up device where there are low belt tensions anticipated in the steady operating state. However, in the design of take-up devices providing a fixed takeup pulley, it should be considered that, as a rule, substantially higher belt tensions occur at the point of the takeup device, when a conveyor belt system is stopped than compared to the steady operating state. The takeup device shall be sized for the maximum tension $\mathrm{F}_{\mathrm{Spmax}}$ that can occur.

Generally the take-up device of a belt conveyor system shall be designed so, with regard to the achievable take-up distance, that it will absorb the lengthening of the belt arising from its

$$
\begin{gathered}
\text { - Elastic elongation } \quad \varepsilon_{\mathrm{el}} \text { and } \\
\text { - Permanent elongation } \varepsilon_{\mathrm{bl}} \\
\mathrm{s}_{\mathrm{Sp}}=\frac{\mathrm{L} \cdot\left(\varepsilon_{\mathrm{el}}+\varepsilon_{\mathrm{bl}}\right)}{100}
\end{gathered}
$$

$\mathrm{s}_{\mathrm{Sp}}$ Take-up length

L Distance center to center

$\varepsilon \quad$ Elongation

The elastic belt elongation is determined by the modulus of elasticity acting in longitudinal direction $f$ all supporting belt plies (tensile member) and by the curve of the local belt tensions, in the top run and in the return run.

The permanent belt elongation depends on the material and the constructive design of the tensile member and is affected by the amount and the time of exposure to the belt tensions.
The take-up length depends on the belt tension in the conveyor. Therefore it is dependant on the operational state of the conveyor. The design regarding the length of the take-up must be based on the most unfavorable operational state.

An exact determination of the take-up length as required is feasible only with a view to the tension elongation characteristic of the supporting belt carcass and of the whole of the occurring loading and operating states of the belt conveyor system.

For a rough determination of the take-up length, the following values for the elastic and permanent elongation $\left(\varepsilon_{\mathrm{el}}+\varepsilon_{\mathrm{bl}}\right)$ should be taken into consideration:

EP-Belt: approx. $1.5 \%$

St-Belt: $\quad$ approx. $0.25 \%$

Should this data prove inadequate, Phoenix can determine the tension elongation characteristics of the Phoenix conveyor belt.

\section{Note:}

In the case of a take-up device with a fixed take-up pulley, the take-up pulley of a new conveyor belt must be readjusted during the time of the first operation and also the pretensions of the belt after a lengthy operation, checked over longer time intervals. This applies mootly to conveyor belts with textile tensile members. Suggestions for the sizing of the take-up length are also given in ISO 3870 .

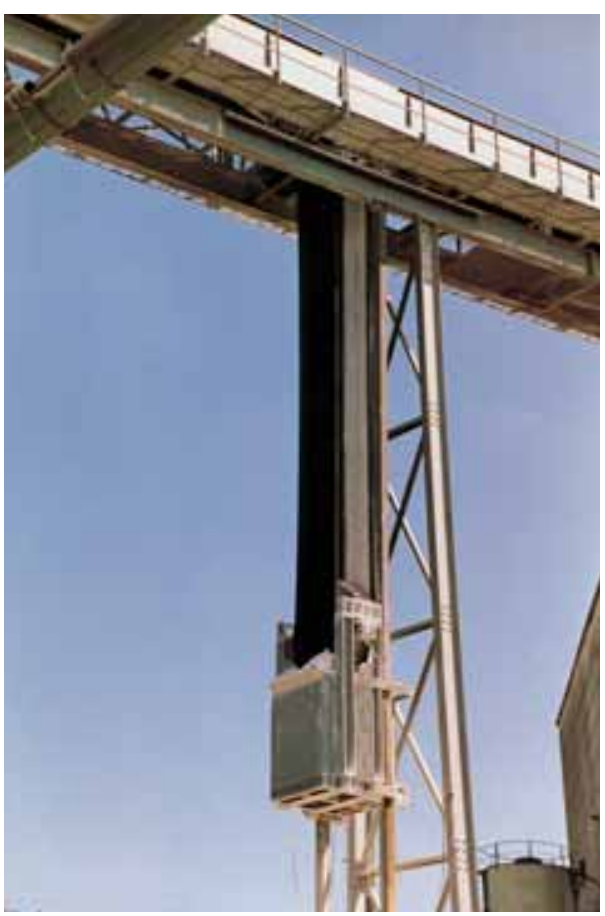




\subsection{Belt Tracking}

The sizing of a conveyor belt is normally based on the maximum values established in various operating and loading states in the area of the belt edges. According to the execution in Chapter 3.4, these can basically be determined from the following forms of belt tracking:

- Transition zones,

- Transition curves,

- Belt turnover device.

In these cases, the induced belt tension strains overlap the additional strains that are primarily determined by

- the geometry of the belt guidance,

- the elongation properties of the tensile member in the conveyor belt.

Therefore, the belt tracking facilities should be designed in such a way as to enable subsequent strains and elongations to be permanently carried by the tensile member. Taking into consideration Chapter 3.4, this initially means that under all operating and loading conditions of a belt conveyor system, belt stress in the midsection must be $k_{M} \geq 0$. Vice versa, the corresponding force $k_{K}$ in the area of the belt edge, in view of the maximum allowable tension on the conveyor belt from its type and rated breaking strength, must exceed the defined maximum determined value $\mathrm{k}_{\mathrm{Kzul}}$ :

$$
\mathrm{k}_{\mathrm{Kzul}}=\frac{\mathrm{k}_{\mathrm{N}} \cdot \mathrm{k}_{\text {trel }}}{\mathrm{c}_{\mathrm{K}} \cdot \mathrm{S}_{0} \cdot \mathrm{S}_{1}}
$$

Textile belt: $\quad \mathrm{c}_{\mathrm{K}}=1$

Steel cord belt: $c_{K}=1.25$ : transition trough

$$
=1.00: \text { other forms of belt tracking }
$$

On the other hand, the maximum value $\mathrm{k}_{\mathrm{Kzul}}$ determines the allowable value of the force difference $\Delta \mathrm{k}=\mathrm{k}_{\mathrm{K}}-\mathrm{k}_{\mathrm{M}}$ which according to Chapter 3.4 is directly connected to the geometry of the belt tracking devices.

To determine belt strain with the above mentioned forms of belt tracking and the dimensioning of the geometry, the following approximative procedures are usually used.

More exact calculations, which in addition to the geometrical relationships also take into consideration the specific elastomechanical key values, will be used by Phoenix as required.

\subsubsection{Transition Lengths}

Positive and negative additional elongations occur on flatto-trough and on trough-to-flat transitions which yield from belt elongations overriding the local belt tensions.

Guiding the belt from a pulley into the troughed shape (flat-to-trough transition) and the transition of the troughshaped belt to a pulley (trough-to-flat transition) must not lead to overstraining the belt (overstretching of edges). In addition, it shall be ensured that occurring negative additional elongations will not be so high as to lift the centre of the belt. Therefore the transition lengths shall be designed so that both criteria (elongation or lifting respectively) are duly taken into account.

By lifting the pulleys, the transition lengths can be shortened. The pulley lift may only be set at a level which ensures that the loaded belt is not lifted by the centre idler of the first (flat-to-trough-transition) or by the last idler station (trough-to-flat transition):

$$
\mathrm{h}_{\text {Trmax }}=3 \cdot \mathrm{h}_{\mathrm{KO}}
$$

(for sizes of $h_{T r}$ and $h_{K 0}$ see Figure 5 und Table 17).

Guide values for the minimum required trough-to-flat transition length IÜmin calculated as per the following rule of thumb:

$$
\mathrm{I}_{\text {Ümin }}=c_{I U ̈} \cdot h_{K 1}=c_{I U ̈} \cdot\left(h_{k 0}-h_{T r}\right)
$$

EP-belt: $\quad \mathrm{c}_{\mid \mathrm{U}}=8.5$

St-belt: $\quad \mathrm{c}_{\mid \mathrm{U}}=14$

Minimum values for the length $I_{\text {Ümin }}$ result when calculated with $\mathrm{k}_{\mathrm{M}}=0$ and $\Delta \mathrm{k}=\mathrm{k}_{\mathrm{Kzul}}$. In this case, the strength of the belt tensions in the transition zone must be thoroughly checked.

In the event of belt conveyor systems providing a lower belt tension in the flat-to-trough transition area (material feeding) in the steady operating state than in the flat-totrough transition area (material discharge), the transition length, in the event of carrying idlers of the same length, in the flat-to-trough transition area, can be generally made both for textile-carcass and steel cord belts with values of up to $20 \%$ lower.

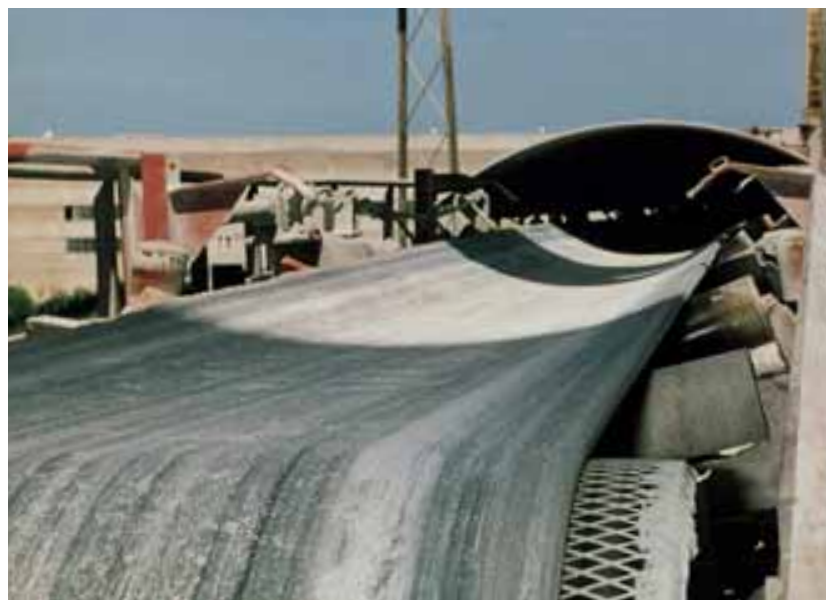




\subsubsection{Transition Curves}

Basically transition curves are differentiated as follows: - vertical curves,

- horizontal curves.

\section{nertical Curves - Convex Curves}

With convex belt tracking (see Figure 6) an additional elongation of the belt edge and a reduction of the belt center occurs (see Chapter 3.4.2). The curve radius $R_{e}$ has to be so selected that neither the positive additional elongation on the belt edge nor the negative additional elongation in the midsection of the belt reach inadmissably high values.

For the three part idler stations with idlers of equal length, values can be set with the aid of the following relationships for the minimum allowable radius $\mathrm{R}_{\mathrm{emin}}$ (for size of $\mathrm{h}_{\mathrm{K} 0}$ see Figure 5 and Table 17):

$$
\begin{array}{r}
R_{\text {emin }}=c_{R e} \cdot h_{K 0} \\
\text { EP-belts: } c_{R e}=125 \\
\text { St-belts: } \quad c_{R e}=360
\end{array}
$$

Minimum values for the radius $R_{\text {emin }}$ are yielded under the premise that $\mathrm{k}_{\mathrm{M}}=0$ is and $\Delta \mathrm{k}=\mathrm{k}_{\mathrm{Kzul}}$. In this case the size of the belt tension in the curve area must be thoroughly checked.

\section{- Vertical Curves - Concave Curves}

With concave belt tracking (see Figure 6) the radius of the curve is usually so measured that the conveyor belt in each operating and loading condition lies on the idlers, especially on the center idler:

$$
\mathrm{R}_{\mathrm{amin}}=\frac{\mathrm{F}_{\mathrm{Tmax}}}{\mathrm{g} \cdot \mathrm{m}_{\mathrm{G}}^{\prime} \cdot \cos \delta}
$$

$\mathrm{F}_{\text {Tmax }}$ maximal occurring belt forces in the curve $\delta \quad$ local incline (see Figure 6)

Smaller radii of the curves are possible if a lifting off the idlers is allowed with an unloaded conveyor belt under certain operating conditions. In this case, constructive measures, e.g. intercepting idlers, are required in the area of this conveyor section.

\section{norizontal Curves}

Where the conveyor belt is to be tracked in horizontal curves due to topographical features, it should be noted that this is possible only to a limited extent and comparatively complex calculations are involved.

In well implemented conveyor belt systems, the conveyor belt lies on the carrying idlers without forced guidance and and runs straight even with tension fluctuations. When the belt is guided through a horizontal curve, transverse forces act diagonally to the running direction, attempting to move the belt laterally. These forces consist mainly of:

- a force component due to local belt tension force, directed towards the inside/inner curve,

- a force component due to deadweight forces arising from the conveyor belt and the material being carried, directed towards the outer curve,

- a force component directed from the frictional force between conveyor belt and idlers when in a tilted position, directed towards the outer curve.

A perfect position of the conveyor belt in the idler trough is ensured only if the sum of the above mentioned force components results within set limits for the lateral drift of the belt towards the center of the idler trough. Due to the specific operating changes of belt tensions and the varying loading relationships, the resulting values are variable.

Taking into account all system data, occurring belt tensions and loading conditions of a curved belt conveyor system, the goal in calculating the design and the operation of a curved belt conveyor system is meant to ensure equilibrium between force components of lateral belt drift, within set limits, by raising the idler stations and by suitably tilting the positions of the idlers.
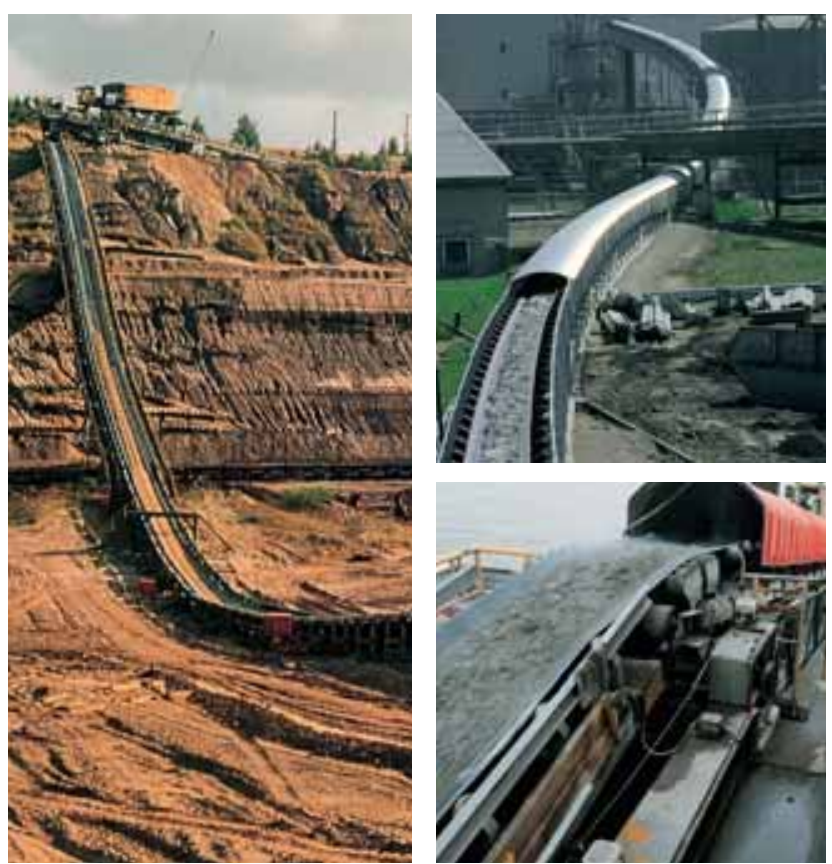


\subsubsection{Belt Turnover}

Belt cleaning and maintaining the cleanliness of belt conveyor systems along the conveying path are major operating aspects. Depending on the properties of the material handled, residues can still adhere to the top side of a conveyor belt despite the use of scraper systems. As time passes, these residues settle on the idlers in the return run, causing wear, and can affect the straight tracking of the belt and spoil the system. Under this aspect the possibility of turning over the conveyor belt in the return run, where conventional belt cleaning does not produce the effect as desired, is important.

Generally a differentiation is made between:

\section{- Unguided turnover:}

With this type of belt turnover, no support is given to the belt within the turnover length which is possible only with a maximum belt width of $1200 \mathrm{~mm}$ and relatively transversely rigid belts.

\section{- Guided turnover:}

The belt is turned over by using a vertical pulley guide (reversing lock) in the middle of the turnover length (for belt widths up to about $1600 \mathrm{~mm}$ ).

\section{- Supported turnover:}

In the event of wide conveyor belts (belt widths up to about $2400 \mathrm{~mm}$ ), the belt is turned over by means of support idlers in the turnover length.
Length and type of the selected belt turnover depends upon the following parameters of the conveyor belt:

- Sag,

- Width,

- Mass,

- Transverse rigidity,

- Elastic properties.

The turnover length of a conveyor belt should be several times the belt width so as to prevent non admissible stresses and strains with regard to positive and negative elongations in the belt. Information on the required belt turnover length for textile carcass and steel cord belts is given in Table 18.

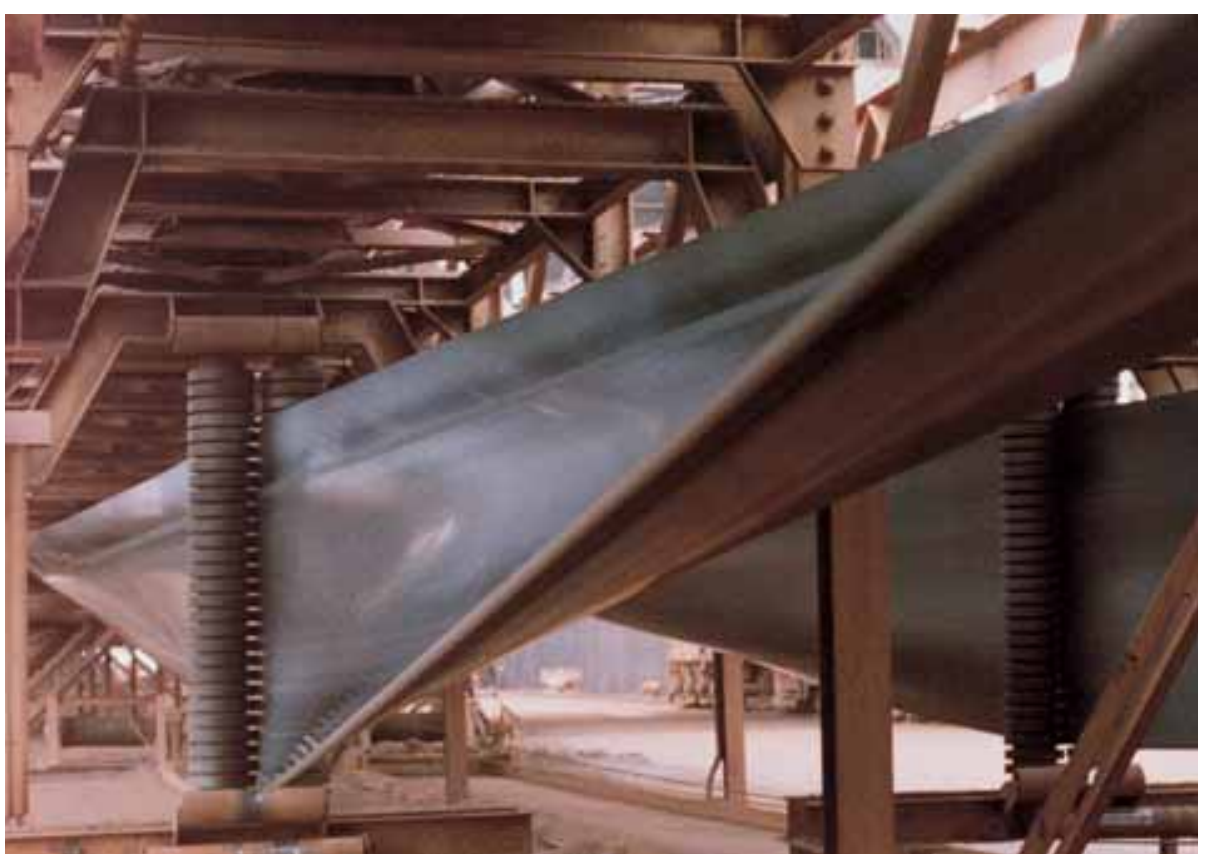




\section{Phoenix Questionnaire}

A questionnaire is available from Phoenix, on request, for determining the technical data required for the design of belt conveyor systems. This questionnaire should be fully completed by the customer and as precisely as possible.

Every possible detail helps to selects the conveyor belt in the optimum and, thus, most economical way.

A specification for the system to be designed is prepared with the assistance of the Phoenix questionnaire. This is drawn up in close cooperation with the user, in the project stage of new systems, with the system builder, the supplier for the start-up and braking equipments and with the idler manufacturer.
For calculation and layout, all factors such as further applicable standards (see Table 20) and shipment and delivery conditions (see Table 19) will be taken into consideration. 


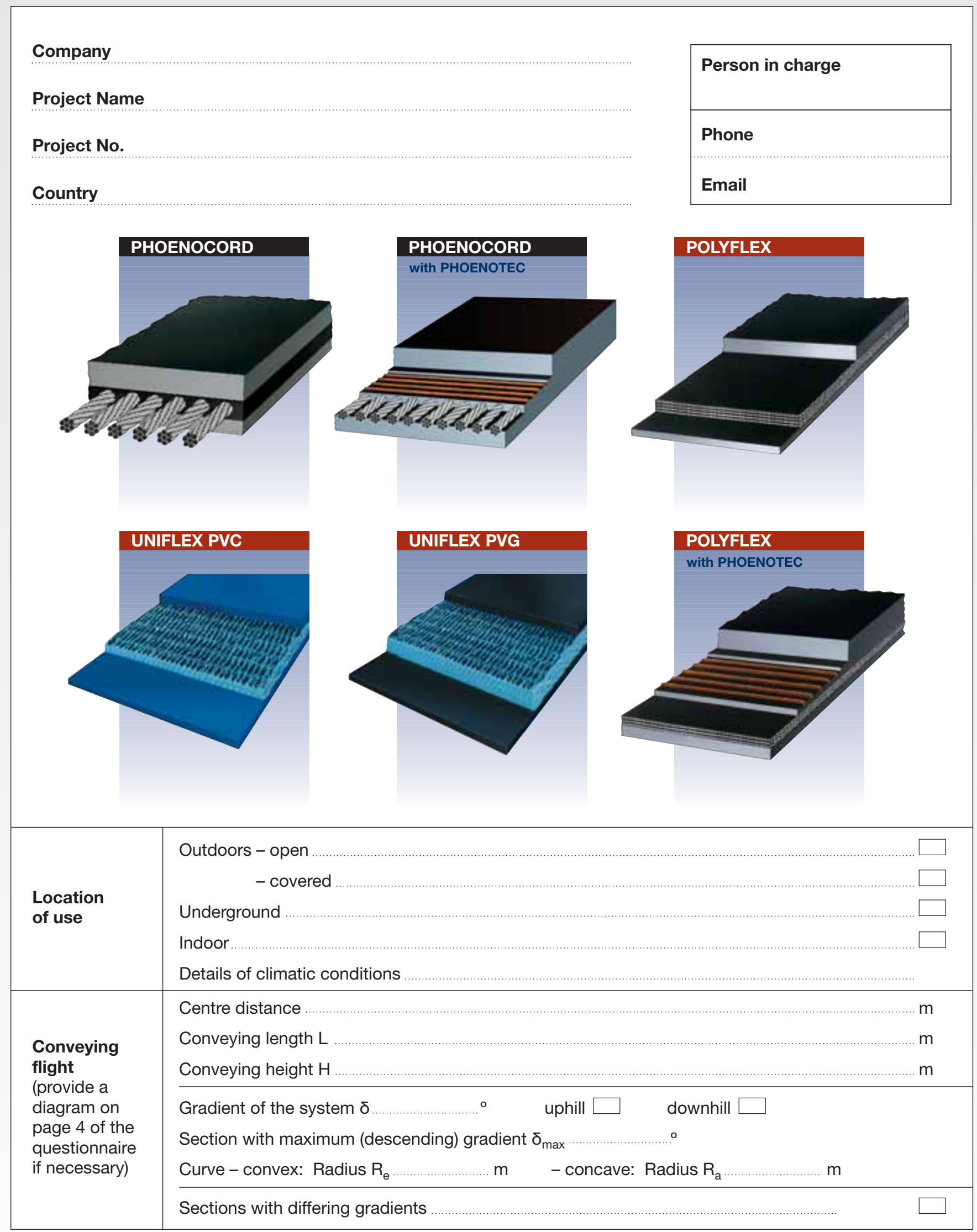




\section{Technical Data}

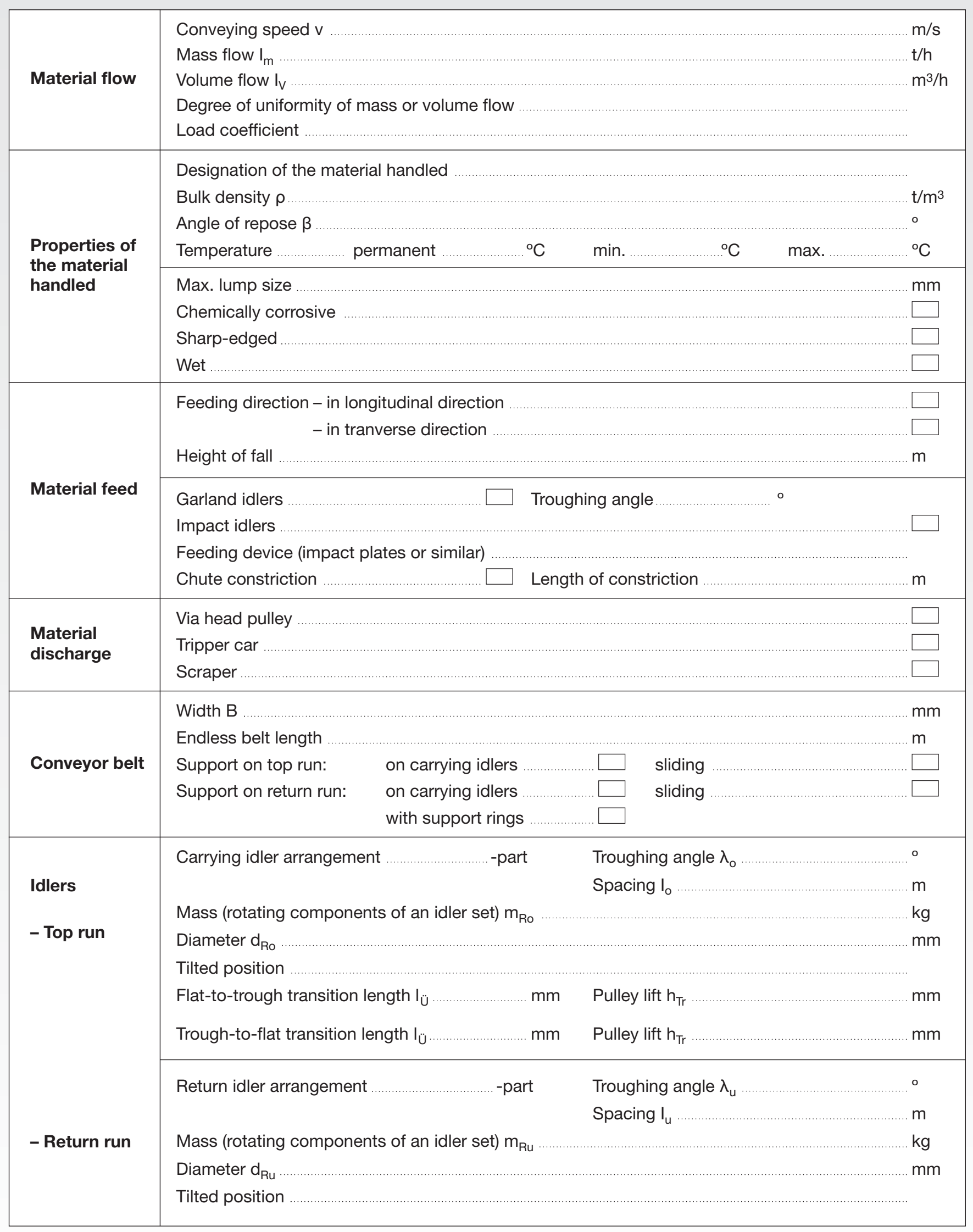




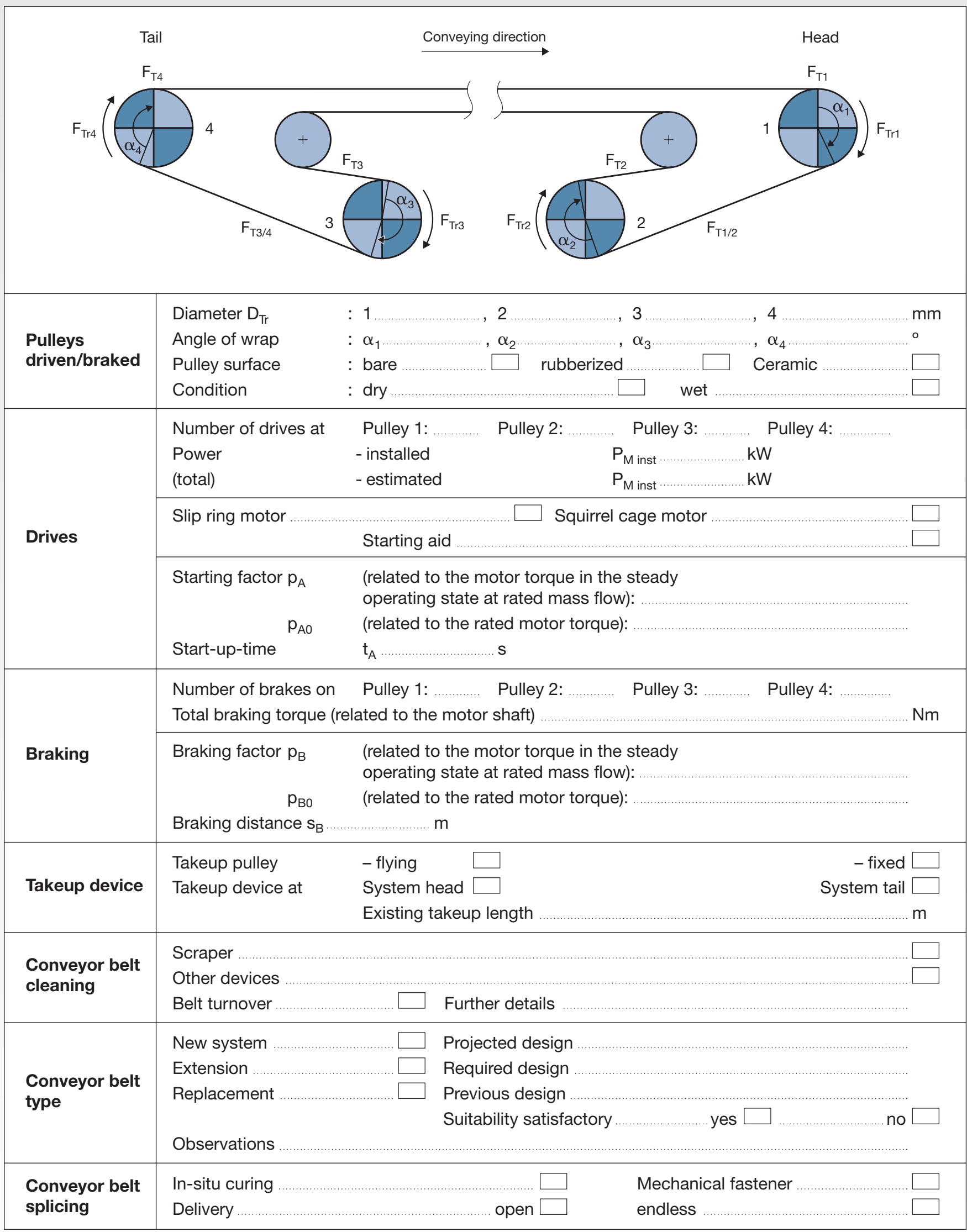


Space for sketches

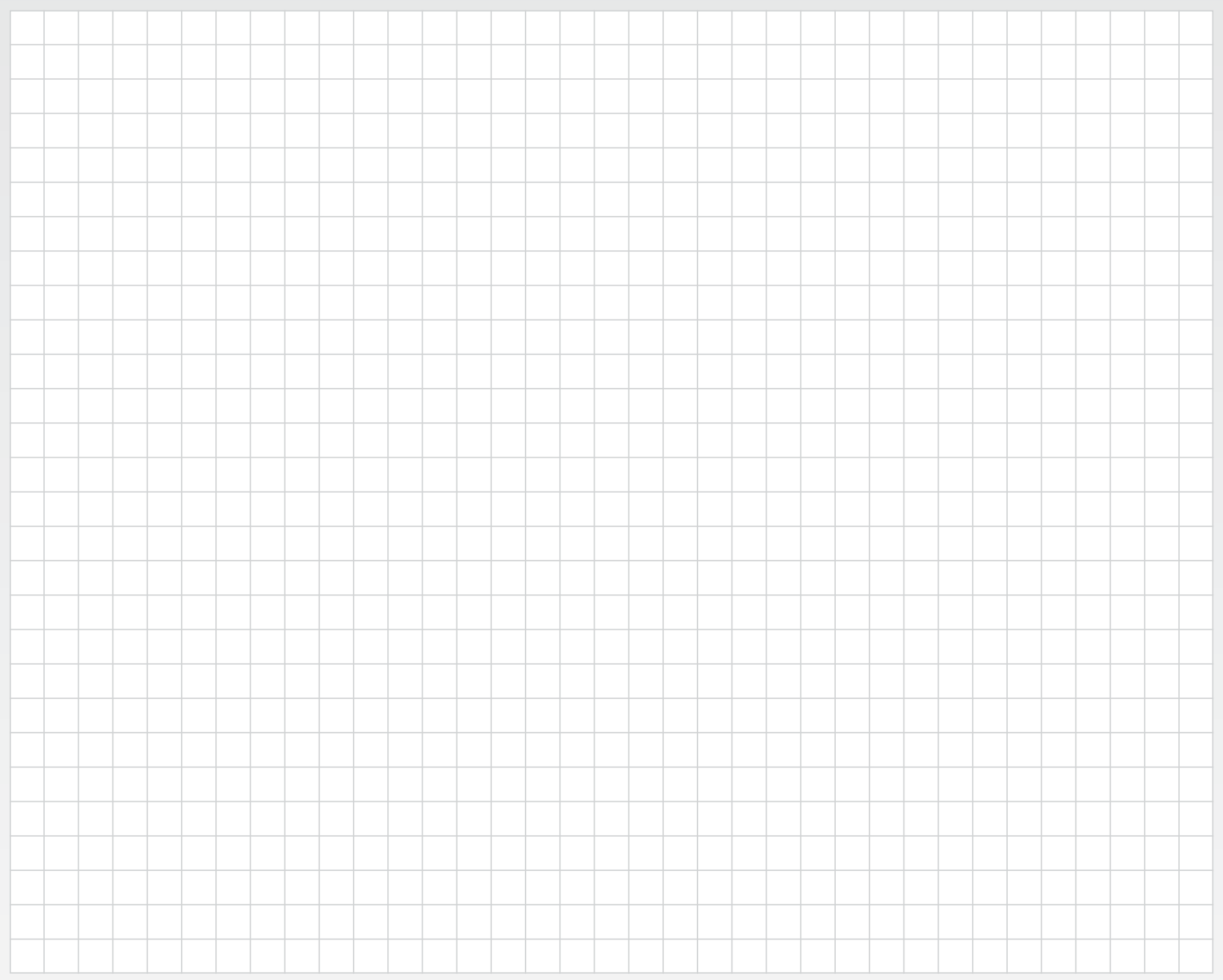

\section{PHOENIX CONVEYOR BELT}

\section{SYSTEMS GMBH}

Hannoversche Strasse 88

21079 Hamburg, Germany

Internet: www.phoenix-ag.com

Telefon +49-40-7667-1526, 1540

Fax +49-40-7667-2987

Email infopcbs@phoenix-ag.com 


\section{Tables for Belt Conveyor Systems Design and Calculation}

\begin{tabular}{|c|c|}
\hline Table 1 & Bulk density $\rho$ of conveyed material \\
\hline Table 2 & Theoretical volume flow $I_{V t h}$ \\
\hline Table 3 & $\begin{array}{l}\text { Coefficient } \varphi_{S t} \text { for determination } \\
\text { of volume flow of gradient belt } \\
\text { conveyor systems }\end{array}$ \\
\hline Table 4 & $\begin{array}{l}\text { Guide values for the mass of the } \\
\text { rotating idler components } m_{R}\end{array}$ \\
\hline Table 5 & $\begin{array}{l}\text { Guide values for the mass and thick- } \\
\text { ness of Phoenix conveyor belts }\end{array}$ \\
\hline Table 6 & $\begin{array}{l}\text { Guide values for the determination of } \\
\text { the main resistance of conveyors }\end{array}$ \\
\hline Table 7 & $\begin{array}{l}\text { Guide values for the determination } \\
\text { of the coefficient } C\end{array}$ \\
\hline Table 8 & $\begin{array}{l}\text { Recommended coefficients of } \\
\text { friction } \mu \text { between conveyor belts } \\
\text { and pulley surfaces }\end{array}$ \\
\hline Table 9 & Values for $\frac{1}{e^{\mu \alpha}-1}$ \\
\hline Table 10 & Value of the safety factor $S_{0}$ \\
\hline Table 11 & Value of the safety factor $S_{1}$ \\
\hline Table 12 & $\begin{array}{l}\text { Strength range of Phoenix } \\
\text { conveyor belts }\end{array}$ \\
\hline Table 13 & Survey on cover materials \\
\hline Table 14 & $\begin{array}{l}\text { Type categories of the covers according } \\
\text { to DIN } 22102 \text { or } 22131 \text { and to ISO } 10247\end{array}$ \\
\hline Table 15 & $\begin{array}{l}\text { Guide values for top and bottom } \\
\text { cover gauges }\end{array}$ \\
\hline Table 16 & Minimum pulley diameters \\
\hline Table 17 & $\begin{array}{l}\text { Distance between the belt edge } \\
\text { and the deepest level of the trough }\end{array}$ \\
\hline Table 18 & $\begin{array}{l}\text { Guide values for the belt turnover } \\
\text { length } I_{W} \text { minimum }\end{array}$ \\
\hline Table 19 & Reel diameters of conveyor belts \\
\hline Table 20 & DIN standards \\
\hline Table 21 & $\begin{array}{l}\text { Conversion factors for the most } \\
\text { important units of the fps- into } \\
\text { the SI-system }\end{array}$ \\
\hline
\end{tabular}

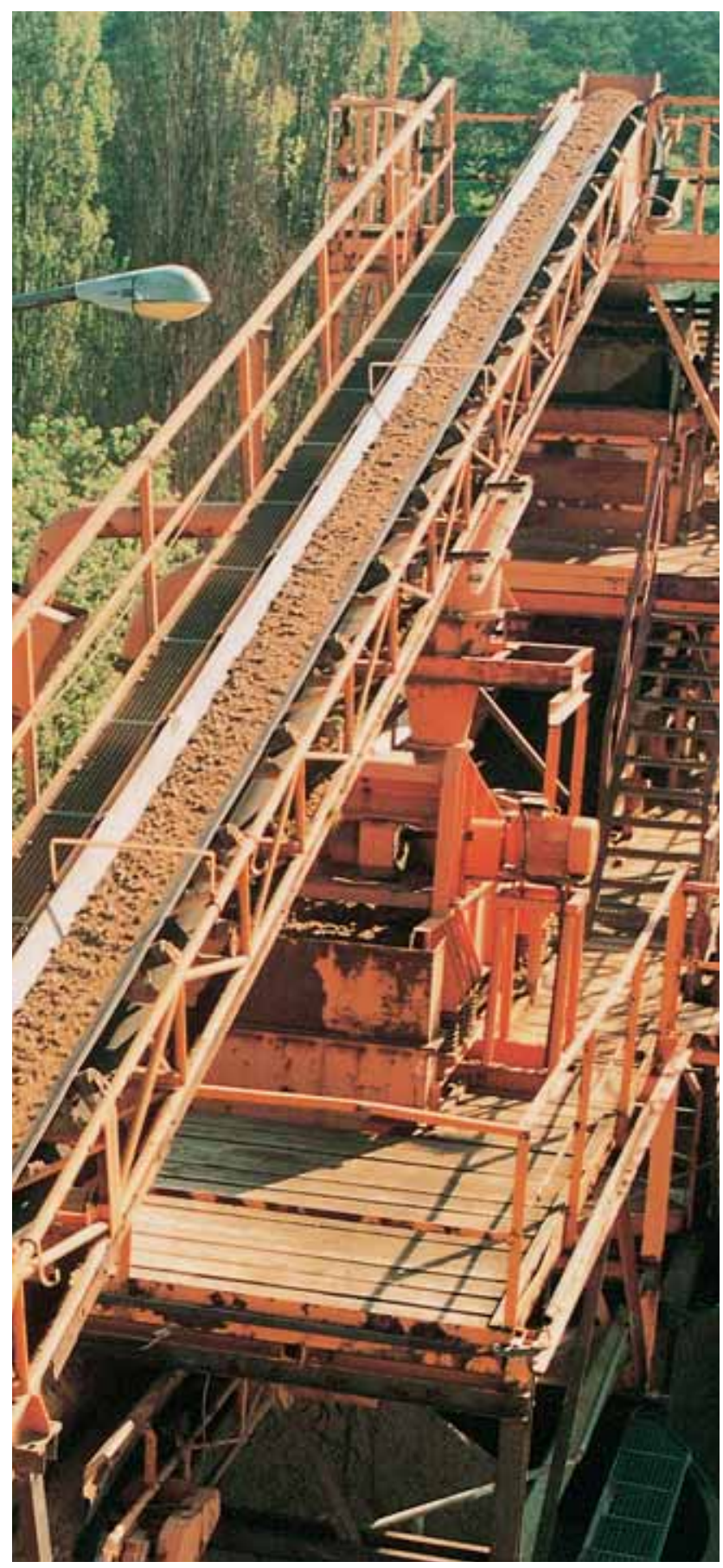


Table 1

\section{Bulk Density $\rho$ of Conveyed Material}

\begin{tabular}{|c|c|c|}
\hline & Material handled & $\begin{array}{l}\text { Bulk density } \rho \\
\text { in } t / m^{3}\end{array}$ \\
\hline A & $\begin{array}{l}\text { Ash, dry } \\
\text { Ash, wet } \\
\text { Asphalt, crushed }\end{array}$ & $\begin{array}{l}0.50 \text { to } 0.70 \\
0.90 \\
1.00 \text { to } 1.30\end{array}$ \\
\hline B & $\begin{array}{l}\text { Basalt, up to } 100 \mathrm{~mm} \\
\text { Bauxite, crushed } \\
\text { Blast furnace slag }\end{array}$ & $\begin{array}{l}1.60 \\
1.30 \\
2.50 \text { to } 3.00\end{array}$ \\
\hline C & $\begin{array}{l}\text { Cement } \\
\text { Chalk } \\
\text { Charcoal } \\
\text { Clay, dry } \\
\text { Coal, raw } \\
\text { Coal, fine } \\
\text { Coke } \\
\text { Concrete with limestone } \\
\text { Copper ore }\end{array}$ & $\begin{array}{l}1.35 \\
1.35 \text { to } 1.65 \\
0.20 \text { to } 0.30 \\
1.80 \\
1.10 \text { to } 1.40 \\
0.70 \text { to } 0.90 \\
0.35 \text { to } 0.55 \\
2.00 \\
2.15\end{array}$ \\
\hline $\mathbf{F}$ & Feldspar, crushed & 1.60 \\
\hline G & $\begin{array}{l}\text { Gobbing } \\
\text { Granit, crushed } \\
\text { Gravel } \\
\text { Gypsum, crushed } \\
\text { Gold ore }\end{array}$ & $\begin{array}{l}1.20 \text { to } 1.60 \\
1.45 \\
1.80 \text { to } 2.20 \\
1.35 \\
1.20\end{array}$ \\
\hline $\mathbf{L}$ & $\begin{array}{l}\text { Lignite, lumpy } \\
\text { Lime } \\
\text { Limestone }\end{array}$ & $\begin{array}{l}0.65 \text { to } 0.85 \\
1.70 \text { to } 1.80 \\
1.50 \text { to } 1.90\end{array}$ \\
\hline M & $\begin{array}{l}\text { Maize/Corn } \\
\text { Manganese / Iron ore } \\
\text { Mineral salt, ground } \\
\text { Mortar } \\
\text { Moulding sand, mixed }\end{array}$ & $\begin{array}{l}0.75 \\
2.10 \\
1.00 \\
1.70 \text { to } 1.80 \\
1.30\end{array}$ \\
\hline 0 & $\begin{array}{l}\text { Oats } \\
\text { Oil sand } \\
\text { Ore, fine } \\
\text { Overburden }\end{array}$ & $\begin{array}{l}0.45 \text { to } 0.60 \\
1.50 \\
1.70 \\
1.50 \text { to } 1.80\end{array}$ \\
\hline $\mathbf{P}$ & $\begin{array}{l}\text { Peat } \\
\text { Phosphate } \\
\text { Potash }\end{array}$ & $\begin{array}{l}0.50 \\
1.20 \text { to } 1.50 \\
1.35\end{array}$ \\
\hline $\mathbf{R}$ & Rock debries & 1.80 \\
\hline S & $\begin{array}{l}\text { Salt } \\
\text { Sand, dry } \\
\text { Sand, wet } \\
\text { Slate, crushed } \\
\text { Slag } \\
\text { Soil, dry } \\
\text { Soil, wet } \\
\text { Sugar, raw }\end{array}$ & $\begin{array}{l}1.20 \text { to } 1.50 \\
1.60 \\
2.00 \\
1.50 \\
0.60 \text { to } 1.30 \\
1.60 \\
2.00 \\
1.00\end{array}$ \\
\hline W & Wheat & 0.75 \\
\hline
\end{tabular}

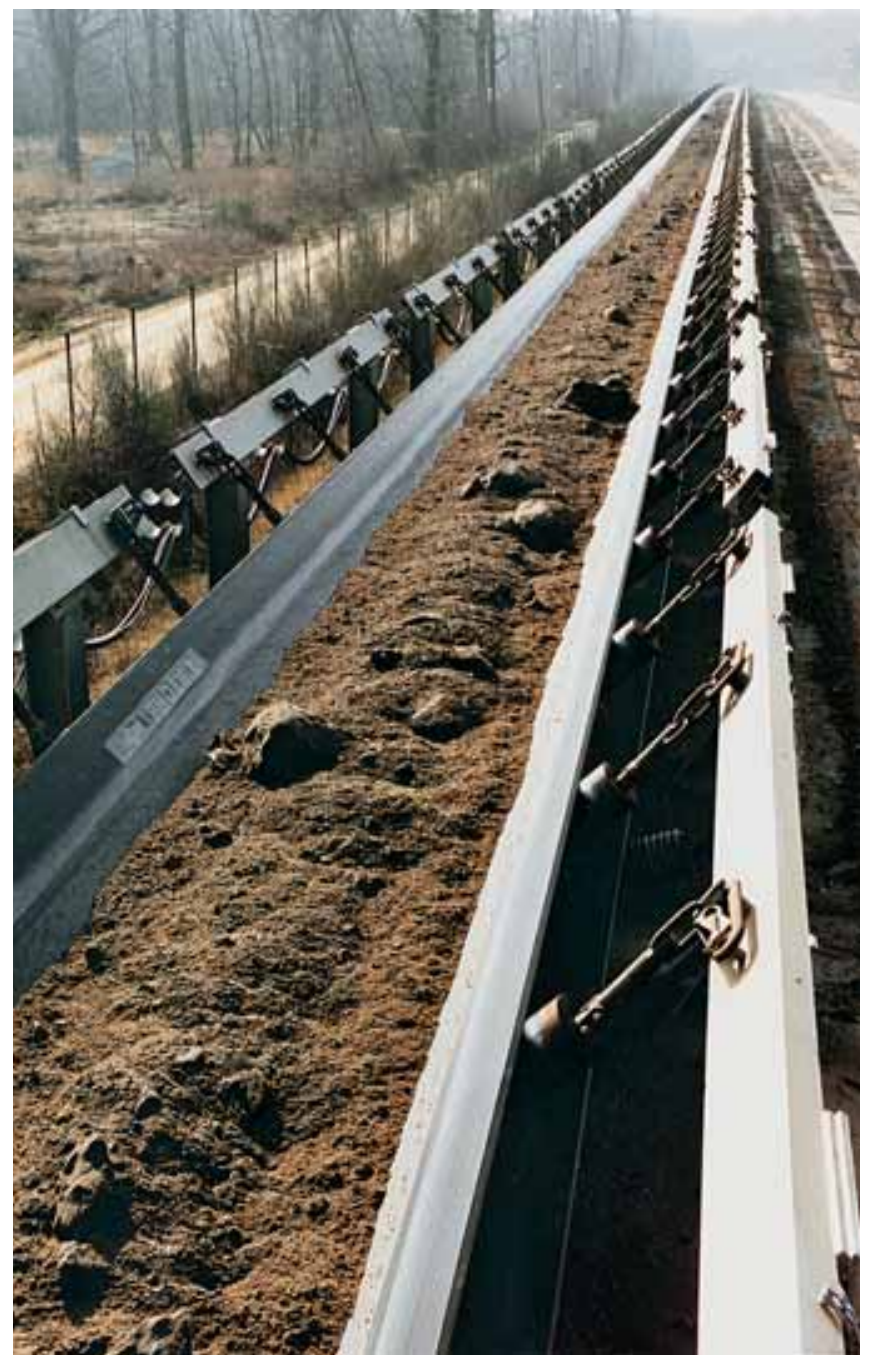


Table 2

Theoretical volume flow $\left(I_{v t h}\right)_{v=1 \mathrm{~m} / \mathrm{s}}$ (in $\mathrm{m}^{3} / \mathrm{h}$ ) with 3-part equal length carrying idler arrangement, conveying speed $v=1 \mathrm{~m} / \mathrm{s}$ and the "equivalent"* angle of repose $\beta=15^{\circ}$

\begin{tabular}{|c|c|c|c|c|c|c|c|c|}
\hline \multirow{2}{*}{$\begin{array}{c}\text { Belt width } \\
\text { B } \\
\text { in } \mathrm{mm}\end{array}$} & \multirow{2}{*}{$\begin{array}{c}\text { Carrying } \\
\text { idler tube } \\
\text { length } \mathrm{I}_{M} \\
\text { in } \mathrm{mm}\end{array}$} & \multicolumn{7}{|c|}{ Troughing angle $\lambda$ of the belt } \\
\hline & & $0^{\circ}$ & $20^{\circ}$ & $25^{\circ}$ & $30^{\circ}$ & $35^{\circ}$ & $40^{\circ}$ & $45^{\circ}$ \\
\hline 500 & 200 & 39 & 72 & 79 & 85 & 90 & 94 & 97 \\
\hline 650 & 250 & 69 & 132 & 145 & 155 & 164 & 171 & 176 \\
\hline 800 & 315 & 108 & 207 & 226 & 243 & 257 & 268 & 276 \\
\hline 1000 & 380 & 174 & 337 & 369 & 396 & 419 & 437 & 449 \\
\hline 1200 & 465 & 256 & 493 & 540 & 580 & 614 & 640 & 658 \\
\hline 1400 & 530 & 353 & 685 & 750 & 806 & 853 & 888 & 913 \\
\hline 1600 & 600 & 466 & 907 & 993 & 1067 & 1128 & 1175 & 1208 \\
\hline 1800 & 670 & 594 & 1160 & 1270 & 1365 & 1443 & 1502 & 1544 \\
\hline 2000 & 740 & 739 & 1443 & 1581 & 1699 & 1795 & 1869 & 1920 \\
\hline 2200 & 800 & 917 & 1802 & 1974 & 2121 & 2241 & 2332 & 2394 \\
\hline 2400 & 870 & 1115 & 2196 & 2406 & 2585 & 2730 & 2840 & 2915 \\
\hline 2600 & 940 & 1332 & 2628 & 2880 & 3094 & 3268 & 3399 & 3486 \\
\hline 2800 & 1000 & 1568 & 3104 & 3402 & 3654 & 3859 & 4012 & 4113 \\
\hline 3000 & 1070 & 1824 & 3615 & 3961 & 4255 & 4492 & 4670 & 4788 \\
\hline 3200 & 1140 & 2099 & 4164 & 4563 & 4902 & 5174 & 5379 & 5513 \\
\hline
\end{tabular}

* An explanation of the terms "equivalent" angle of repose is given in the notes of DIN 22101

The theoretical volume flow $I_{V t h}$ at a conveying speed $v$ is calculated as follows from the values $\left(\mathrm{l}_{\mathrm{Vth}}\right)_{\mathrm{v}=1 \mathrm{~m} / \mathrm{s}}$ according to the above table:

$$
I_{V t h}=v \cdot\left(I_{V t h}\right)_{V=1} \mathrm{~m} / \mathrm{s}
$$

The conversion of the volume flow $I_{V t h}$ (quoted in $\mathrm{m}^{3} / \mathrm{h}$ ) to a mass flow $I_{m}$ (quoted in $t / h$ ) is calculated with bulk density $\rho$ of the material handled (quoted in $\mathrm{t} / \mathrm{m}^{3}$ ) according to Table 1 and the effective filling coefficient $\varphi$ (DIN 22101):

$$
\mathrm{I}_{\mathrm{m}}=\mathrm{I}_{\mathrm{Vth}} \cdot \rho \cdot \varphi
$$

For the continuous loading of material and correct tracking of the belt the effective filling coefficient $\varphi$ equals the coefficient $\varphi_{S t}$.

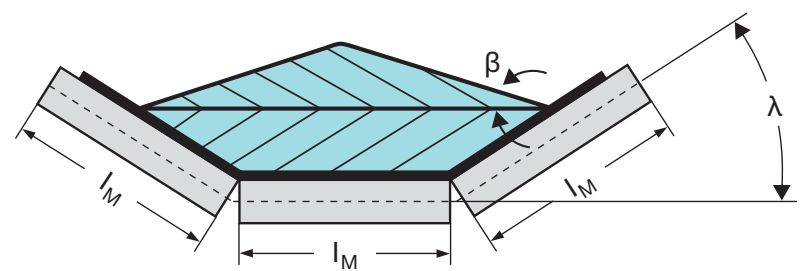

From the mass flow $\mathrm{I}_{\mathrm{m}}$ the length related mass of the material handled $m_{L}$ can be calculated as follows:

$$
\mathrm{m}_{\mathrm{L}}^{\prime}=\frac{\mathrm{I}_{\mathrm{m}}}{\mathrm{v}}=\frac{\mathrm{I}_{\mathrm{Vth}} \cdot \rho \cdot \varphi_{\mathrm{St}}}{\mathrm{v}}
$$

V conveying speed

$I_{V \text { th }} \quad$ theoretical volume flow

$\rho \quad$ bulk density of the material handled

$\varphi_{\text {St }}$ coefficient for determining the volume flow of gradient conveyors according to Table 3

Guide values for the parameters $\rho, \varphi_{S t}, m_{R}^{\prime}$ and $m_{G}$ are given in Tables 1, 3, 4 and 5.

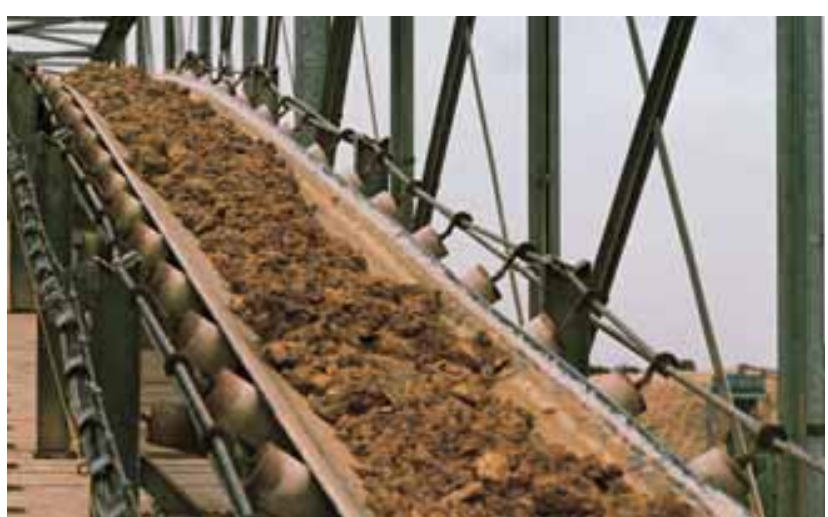




\section{Table 3}

\section{Coefficient $\varphi_{\text {St }}$ for the determination of volume flow of gradient belt conveyor systems}

For conveyor systems which are stoped completely or in sections only, the achievable volume flow is lower than the theoretical volume flow stated in Table 2.

This must be multiplied by the coefficient $\varphi_{\mathrm{St}}$ for which DIN 22101 provides the relationship of the dynamical angle of inclination, the bulk material, the shape of the belt trough and the gradient of the system.
For bulk materials with a relatively high inner friction, the guide values given in the following table can be used in case of 3-part equal length carrying idler arrangements and usual troughing angles:

\begin{tabular}{|l|c|c|c|c|c|c|c|c|c|c|}
\hline Angle of incline $\delta$ & $2^{\circ}$ & $4^{\circ}$ & $6^{\circ}$ & $8^{\circ}$ & $10^{\circ}$ & $12^{\circ}$ & $14^{\circ}$ & $16^{\circ}$ & $18^{\circ}$ & $20^{\circ}$ \\
\hline Coefficient $\varphi_{\text {St }}$ & 1.0 & 0.99 & 0.98 & 0.97 & 0.95 & 0.93 & 0.91 & 0.89 & 0.85 & 0.81 \\
\hline
\end{tabular}

\section{Example:}

\begin{tabular}{|c|c|}
\hline Belt width B & $1000 \mathrm{~mm}$ \\
\hline Conveying speed v & $2.5 \mathrm{~m} / \mathrm{s}$ \\
\hline Troughing angle of the belt $\lambda$ & $30^{\circ}$ \\
\hline $\begin{array}{l}\text { Theoretical volume flow }\left(\mathrm{I}_{\mathrm{Vth}}\right)_{\mathrm{v}=1 \mathrm{~m} / \mathrm{s}} \\
\text { according to Table } 2\end{array}$ & $396 \mathrm{~m}^{3} / \mathrm{h}$ \\
\hline Conveyor system gradient & $10^{\circ}$ \\
\hline $\begin{array}{l}\text { Associated coefficient } \varphi_{\mathrm{St}} \\
\text { according to Table } 3\end{array}$ & 0.95 \\
\hline $\begin{array}{l}\text { Achievable volume flow } \\
I_{V}=2.5 \cdot 396 \cdot 0.95=\end{array}$ & $941 \mathrm{~m}^{3} / \mathrm{h}$ \\
\hline
\end{tabular}

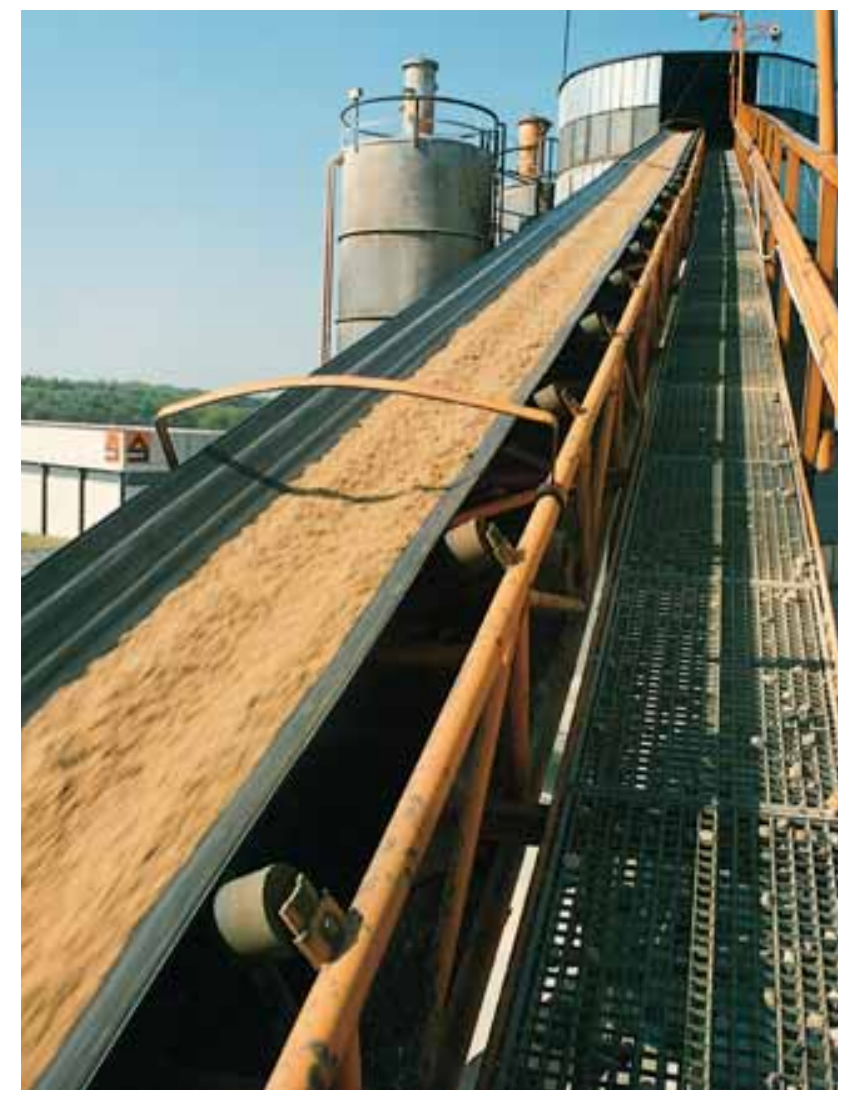


Table 4

Guide Values for the Mass of the Rotating idler Components $m_{R}$ of 3-/2- and 1-Part Idler Set (in kg)

\begin{tabular}{|c|c|c|c|c|c|c|}
\hline \multirow{2}{*}{$\begin{array}{c}\text { Belt } \\
\text { width B } \\
\text { in } \mathrm{mm}\end{array}$} & \multicolumn{6}{|c|}{ Outer idler diameter $d_{R}$ in $\mathbf{~ m m}$} \\
\hline & 63.5 & 89 & 108 & 133 & 159 & 194 \\
\hline 400 & $5.0 / 4.2 / 3.2$ & $7.5 / 6.4 / 5.2$ & & & & \\
\hline 500 & $5.6 / 4.6 / 3.6$ & $8.4 / 7.4 / 6.0$ & & & & \\
\hline 650 & $6.3 / 5.2 / 4.4$ & $9.6 / 8.5 / 7.2$ & $12.2 / 10.7 / 8.9$ & & & \\
\hline 800 & & $11.1 / 9.8 / 8.8$ & $14.1 / 12.3 / 10.9$ & & & \\
\hline 1000 & & $12.6 / 12.0 / 10.4$ & $16.0 / 15.0 / 12.8$ & $24.6 / 21.6 / 17.4$ & & \\
\hline 1200 & & & $18.6 / 16.9 / 15.3$ & 27.6 / $24.0 / 20.4$ & $34.5 / 30.0 / 25.1$ & \\
\hline 1400 & & & 20.4 / $18.8 / 17.2$ & 30.0 / 26.4 / 22.8 & $37.5 / 32.8 / 28.0$ & \\
\hline 1600 & & & & 32.4 / 28.8 / 25.3 & 40.5 / 38.6 / 30.9 & \\
\hline 1800 & & & & & 46.2 / 40.4 / 34.6 & $79.1 / 71.9$ / 62.4 \\
\hline 2000 & & & & & 49.5 / 43.2 / 37.5 & $86.7 / 78.8 / 67.4$ \\
\hline 2200 & & & & & 51.9 / $47.6 / 41.9$ & 92.4 / 84.0 / 74.9 \\
\hline 2400 & & & & & & 97.9 / 89.0 / 80.4 \\
\hline 2600 & & & & & & 103.4 / $94.1 / 85.9$ \\
\hline 2800 & & & & & & 108.9 / 98.9 / 91.4 \\
\hline 3000 & & & & & & 114.4 / 103.9 / 96.9 \\
\hline 3200 & & & & & & $120.0 / 109.1 / 102.4$ \\
\hline
\end{tabular}

To determine the length related mass of the rotating idler components $\mathrm{m}_{\mathrm{Ro}}^{\prime}, \mathrm{m}_{\mathrm{Ru}}^{\prime}, \mathrm{m}_{\mathrm{R}}^{\prime}$ according to Chapter 3.1.2 the above masses shall be converted into the specific values:

$m_{R o}^{\prime}=\frac{m_{R o}}{I_{R o}} \quad m_{R u}^{\prime}=\frac{m_{R u}}{I_{R u}} \quad m_{R}^{\prime}=m_{R o}^{\prime}+m_{R u}^{\prime}$

$\mathrm{I}_{\mathrm{Ro}, \mathrm{u}}$ : Spacing of the idler stations in the top run and return run

\section{Example:}

Belt width $B$

(Outer) idler diameter $d_{R}$

Spacing of idler stations in top run $I_{R o}$

Spacing of idler stations in return run $\mathrm{I}_{\mathrm{Ru}}$

Mass of the rotating components of an idler set in the top run (3-part idler set) $m_{\mathrm{Ro}}$

Mass of the rotating components of an idler set in the return run (1-part idler set) $m_{R u}$ $1200 \mathrm{~mm}$ $133 \mathrm{~mm}$ $1.25 \mathrm{~m}$ $2.5 \mathrm{~m}$

\section{$27.6 \mathrm{~kg}$}

$20.4 \mathrm{~kg}$

Length related mass of the rotating idler components in the top run $\mathrm{m}_{\text {Ro }}$ $22.1 \mathrm{~kg} / \mathrm{m}$ Length related mass of the rotating idler components in the return run $\mathrm{m}_{\mathrm{Ru}}$ $8.2 \mathrm{~kg} / \mathrm{m}$

Length related mass of the rotating idler components of the top run and return run together $m^{\prime}{ }_{R}$

$30.3 \mathrm{~kg} / \mathrm{m}$

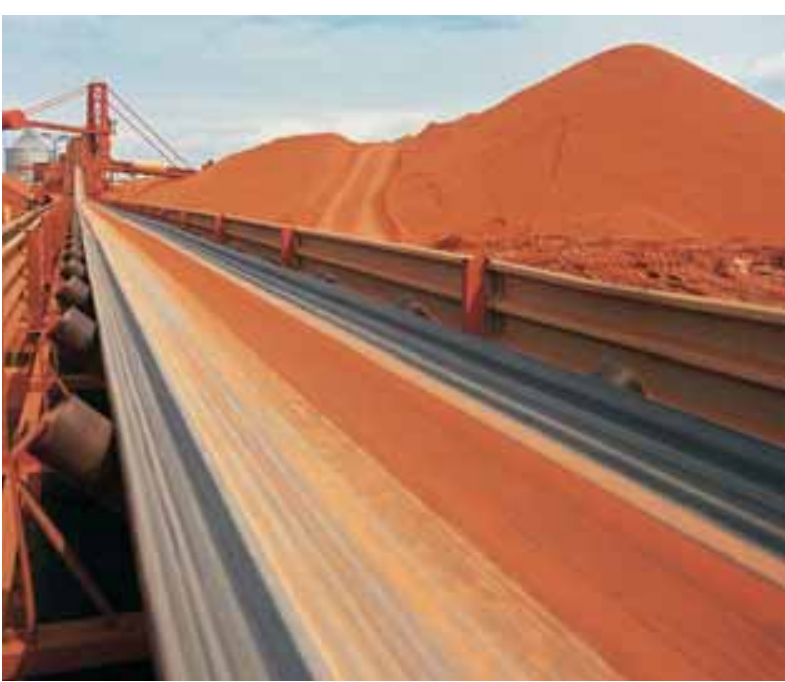




\section{Table 5}

Guide Values for the Mass and Thickness of Phoenix Conveyor Belts

1 Textile carcass belts

1.1 Phoenix 2- and multi-ply textile carcass belts for general material handling purposes with covers of type $X, Y$

\begin{tabular}{|c|c|c|c|c|c|}
\hline \multirow[t]{2}{*}{ Belt } & \multicolumn{2}{|c|}{$\begin{array}{l}\text { Cover gauge } d_{D p} \\
\text { in } \mathrm{mm}\end{array}$} & \multirow[t]{2}{*}{$\begin{array}{l}\text { Belt thickness } d_{G} \\
\text { in } \mathrm{mm}\end{array}$} & \multicolumn{2}{|c|}{$\begin{array}{l}\text { Area related belt mass with cover type } \mathrm{m}_{\mathrm{G}} \\
\text { in } \mathrm{kg} / \mathrm{m}^{2} \text { with cover type }\end{array}$} \\
\hline & Top side : & Bottom side & & $x$ & $\mathbf{Y}$ \\
\hline \multicolumn{6}{|l|}{ 2-ply belts } \\
\hline EP $400 / 2$ & 4 & $: 2$ & 9.5 & 11.0 & 11.5 \\
\hline EP $630 / 2$ & 4 & $: 2$ & 10.5 & 12.0 & 12.5 \\
\hline EP $800 / 2$ & 4 & $: 2$ & 11.0 & 12.5 & 13.0 \\
\hline \multicolumn{6}{|l|}{ 3-ply belts } \\
\hline EP $400 / 3$ & 4 & $: 2$ & 9.0 & 10.0 & 10.5 \\
\hline EP $500 / 3$ & 6 & $: 3$ & 12.0 & 13.5 & 14.0 \\
\hline EP $630 / 3$ & 5 & $: 2$ & 10.5 & 12.0 & 12.5 \\
\hline \multicolumn{6}{|l|}{ 4-ply belts } \\
\hline EP $500 / 4$ & 4 & $: 2$ & 10.0 & 11.5 & 12.0 \\
\hline EP $630 / 4$ & 6 & $: 3$ & 13.0 & 14.5 & 15.0 \\
\hline EP $800 / 4$ & 7 & $: 3$ & 14.5 & 16.5 & 17.0 \\
\hline EP 1000/4 & 7 & $: 3$ & 16.5 & 18.0 & 18.5 \\
\hline \multicolumn{6}{|l|}{ 5-ply belts } \\
\hline EP $800 / 5$ & 5 & $: 2$ & 12.0 & 14.0 & 14.5 \\
\hline EP $1000 / 5$ & 6 & $: 3$ & 14.5 & 17.0 & 17.5 \\
\hline EP 1250/5 & 8 & $: 3$ & 19.0 & 21.0 & 21.5 \\
\hline EP $1600 / 5$ & 10 & $: 3$ & 22.0 & 25.0 & 25.5 \\
\hline
\end{tabular}
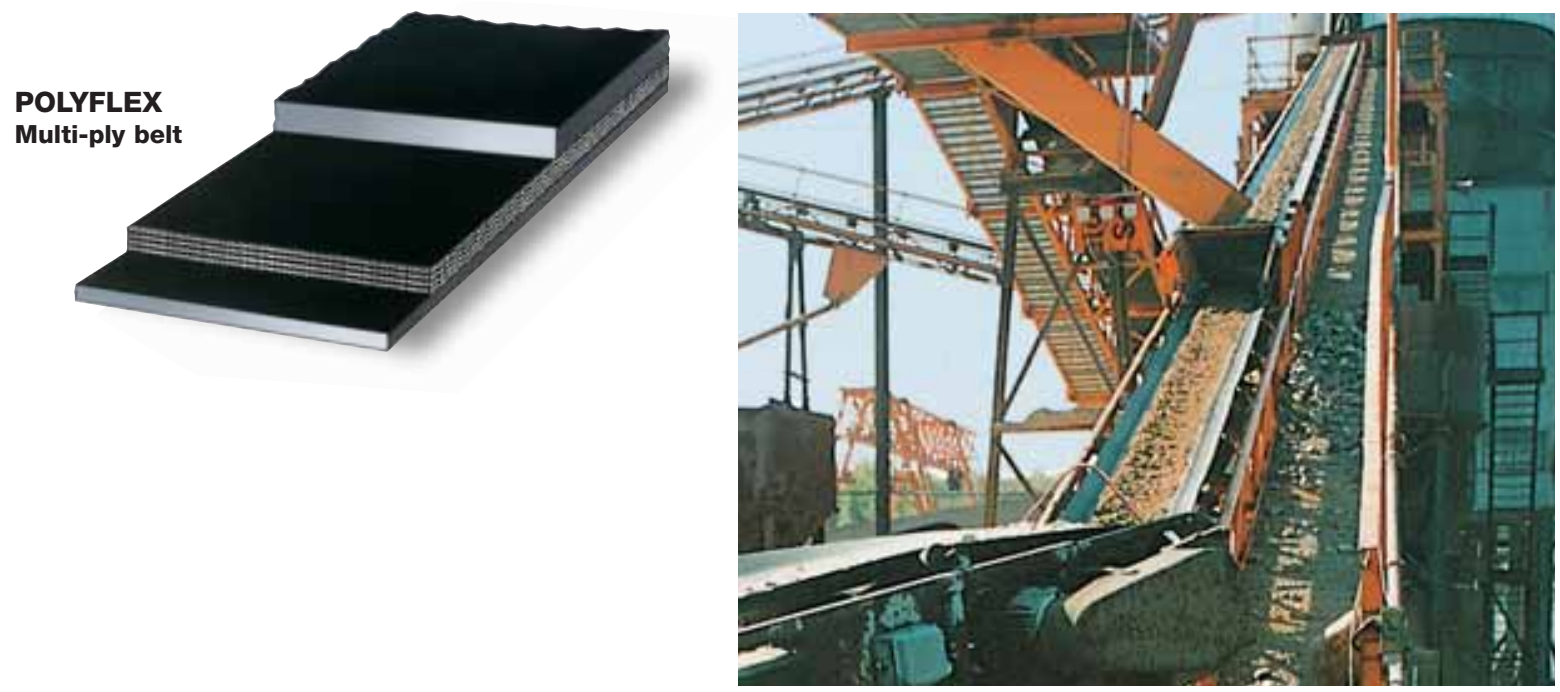
1.2 Phoenix 1- and 2-Ply Textile-Carcass Belts in Self-Extinguishing Version (V) for Underground Coal Mining

\begin{tabular}{|c|c|c|c|c|}
\hline \multirow[t]{2}{*}{ Belt } & \multicolumn{2}{|c|}{$\begin{array}{l}\text { Cover gauge } d_{D p} \\
\text { in } \mathrm{mm}\end{array}$} & \multirow[t]{2}{*}{$\begin{array}{l}\text { Belt thickness } d_{G} \\
\text { in } \mathrm{mm}\end{array}$} & \multirow{2}{*}{$\begin{array}{l}\text { Area related belt } \\
\text { mass } \mathrm{m}_{\mathrm{G}}^{\prime \prime} \\
\text { in } \mathrm{kg} / \mathrm{m}^{2}\end{array}$} \\
\hline & Top side : & Bottom side & & \\
\hline \multicolumn{5}{|l|}{ 1-ply UNIFLEX ${ }^{\circledast}$ belts } \\
\hline E/P-B-P/B $\quad 800 / 1$ & 2 & $: 2$ & 11.5 & 15.0 \\
\hline E/P-B-P/B $\quad 1000 / 1$ & 2.5 & $: 2.5$ & 13.0 & 18.0 \\
\hline E/P-B-P/B 1250/1 & 2.5 & : 2.5 & 14.0 & 20.0 \\
\hline E/P-B-P/B 1600/1 & 3 & $: 3$ & 16.0 & 24.0 \\
\hline E/P-B-P/B 2000/1 & 3.5 & $: \quad 3.5$ & 20.0 & 31.0 \\
\hline E/P-B-P/B 2500/1 & 4 & $: 4$ & 22.0 & 33.5 \\
\hline E/P-B-P/B $3150 / 1$ & 6 & $: 3$ & 26.5 & 36.0 \\
\hline \multicolumn{5}{|l|}{ 2-ply DUOFLEX ${ }^{\circledast}$ belts } \\
\hline E/PP $800 / 2$ & 1.5 & $: 1.5$ & 10.0 & 12.5 \\
\hline E/PP 1000/2 & 1.5 & $: 1.5$ & 11.0 & 13.5 \\
\hline E/PP 1250/2 & 4 & $: 2$ & 15.0 & 19.5 \\
\hline E/PP $1600 / 2$ & 4 & $: 2$ & 16.0 & 21.0 \\
\hline
\end{tabular}

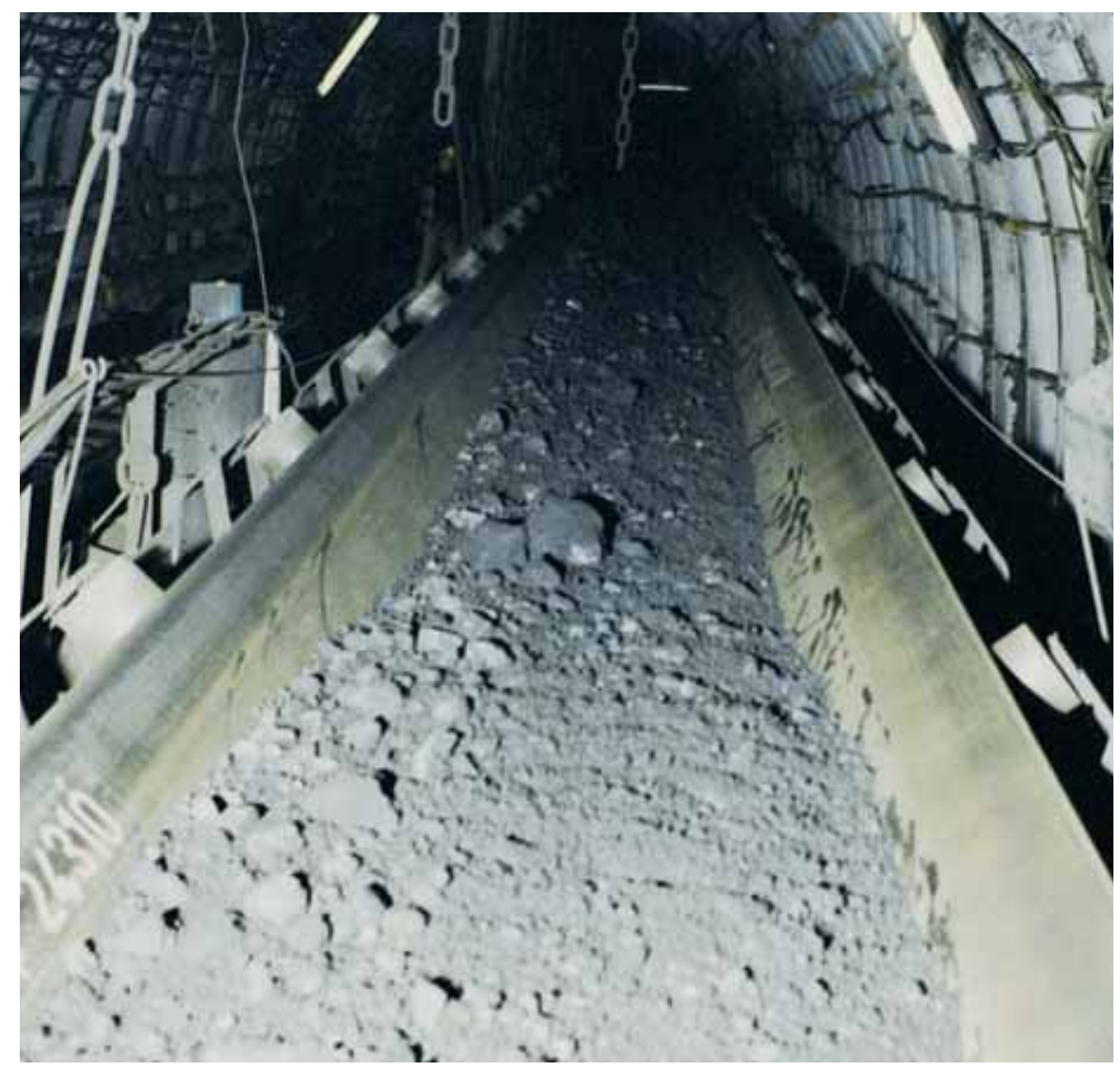

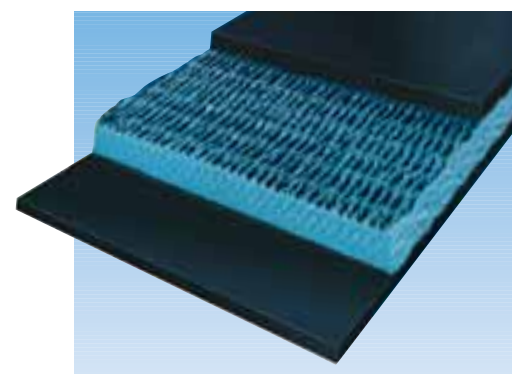

UNIFLEX PVG 
Tables for Belt Conveyor Systems

Design and Calculation

2 Steel Cord Conveyor Belts

2.1 Phoenix steel cord conveyor belts for general material handling purposes with covers of type $X$

\begin{tabular}{|c|c|c|c|c|}
\hline \multirow[t]{2}{*}{ Belt } & \multicolumn{2}{|c|}{$\begin{array}{l}\text { Cover gauge } d_{D p} \\
\text { in } \mathrm{mm}\end{array}$} & \multirow[t]{2}{*}{$\begin{array}{l}\text { Belt thickness } d_{G} \\
\text { in } \mathrm{mm}\end{array}$} & \multirow{2}{*}{$\begin{array}{c}\text { Area related belt mass } \mathrm{m}_{\mathrm{G}}{ }_{\mathrm{G}} \\
\text { in } \mathrm{kg} / \mathrm{m}^{2} \text { with cover type } \\
\mathrm{X}\end{array}$} \\
\hline & Top side : & Bottom side & & \\
\hline St 400 & 4 & 4 & 10.5 & 13.5 \\
\hline St 500 & 4 & $: 4$ & 10.5 & 14.0 \\
\hline St 630 & 6 & $: 4$ & 13.5 & 17.5 \\
\hline St 800 & 6 & : 4 & 13.5 & 18.0 \\
\hline St 1000 & 6 & $: 4$ & 14.0 & 19.5 \\
\hline St 1250 & 6 & 4 & 14.0 & 21.5 \\
\hline St 1600 & 8 & 6 & 19.5 & 28.0 \\
\hline St 1800 & 8 & 6 & 19.5 & 28.5 \\
\hline St 2000 & 8 & 6 & 19.5 & 29.0 \\
\hline St 2500 & 10 & $: 8$ & 25.0 & 38.5 \\
\hline St 3150 & 10 & $: 8$ & 26.0 & 41.0 \\
\hline St 3500 & 10 & $: 8$ & 26.5 & 42.5 \\
\hline St 4000 & 12 & $: 8$ & 29.0 & 48.0 \\
\hline St 4500 & 12 & $: 8$ & 29.5 & 50.5 \\
\hline St 5000 & 12 & : 10 & 32.0 & 55.0 \\
\hline St 5400 & 12 & $: 10$ & 32.5 & 56.0 \\
\hline St 6300 & 12 & $: 10$ & 34.0 & 66.0 \\
\hline St 7500 & 12 & : 10 & 36.5 & 69.0 \\
\hline St 8500 & 14 & $: 10$ & 37.5 & 73.0 \\
\hline
\end{tabular}

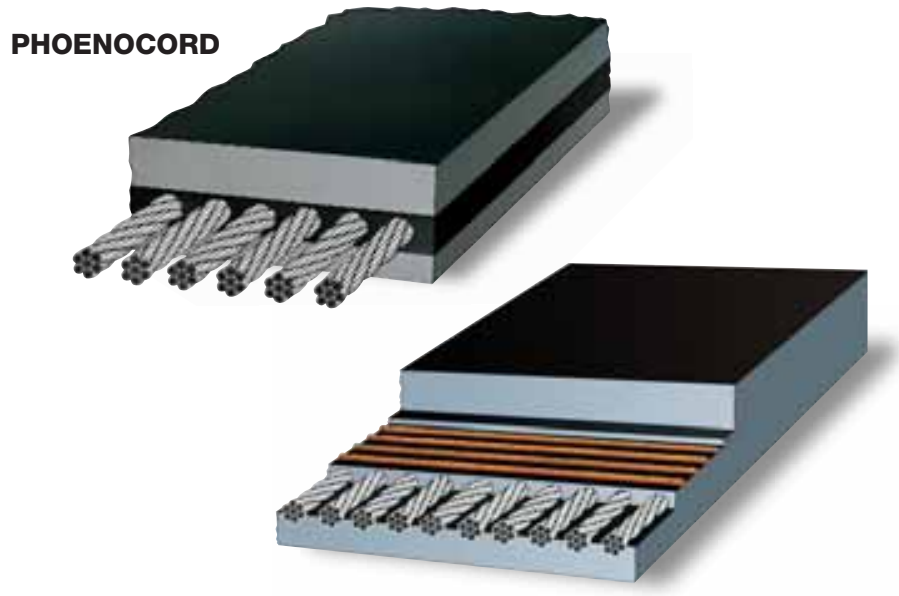

PHOENOCORD

with PHOENOTEC

transverse reinforcement

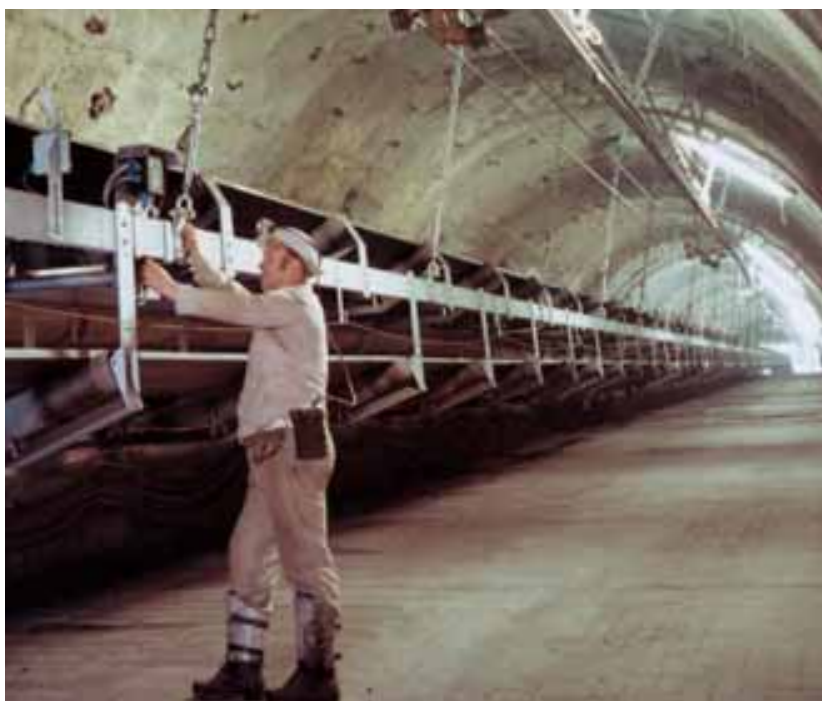


2.2 Phoenix Steel Cord Conveyor Belts with Textile Transverse Reinforcement (T) in Self-Extinguishing Version (V) for Underground Coal Mining

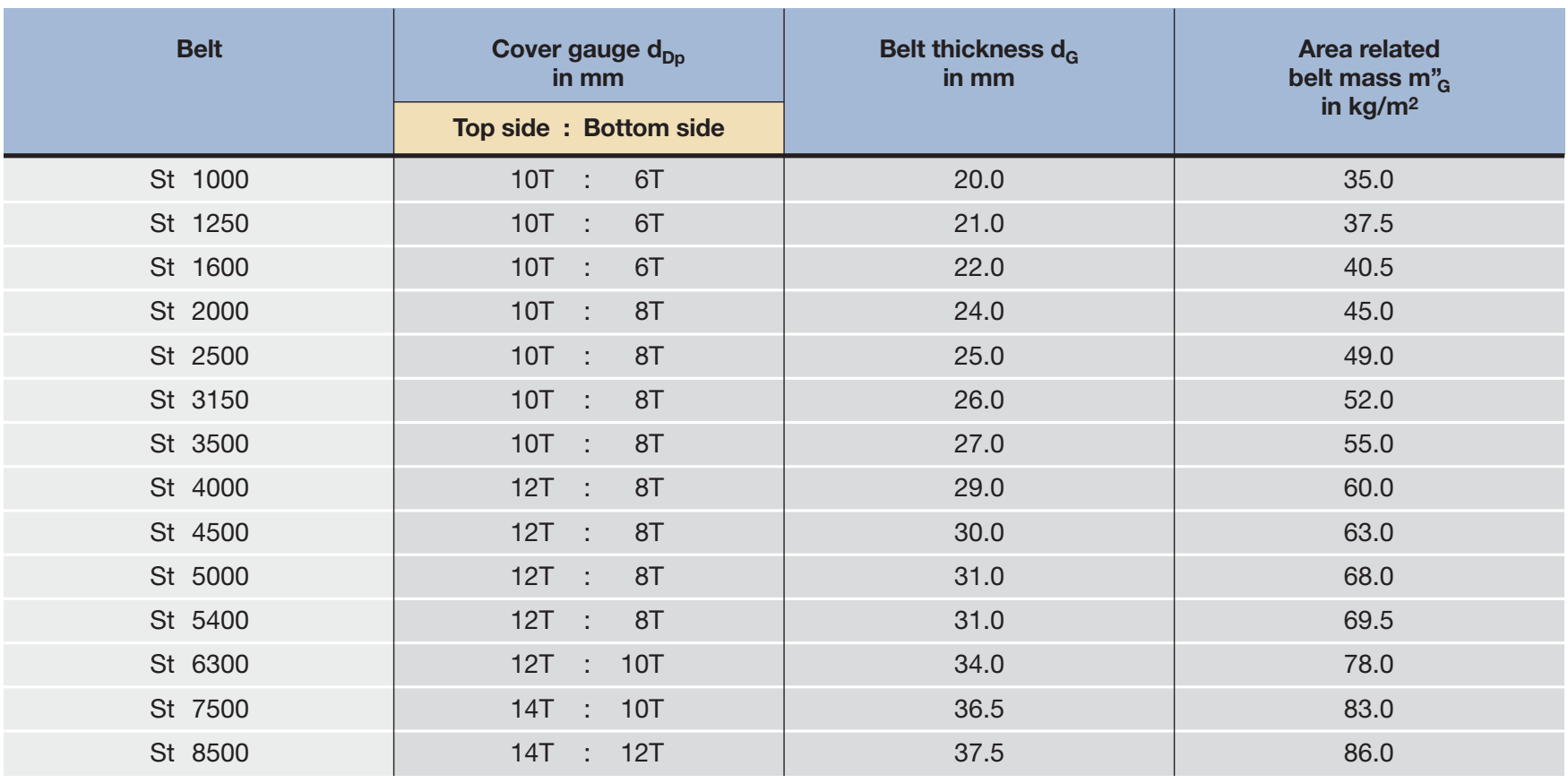

\section{Explanation for the tabular sections}

\section{- Area related belt mass $\mathrm{m}_{\mathrm{G}}$}

Data on the size parameter $\mathrm{m}_{\mathrm{G}}$ apply only for the cover gauges as listed providing the following range of tolerances:

\begin{tabular}{lc}
\hline Tabular section 1.1 & $+1.7 /-1.0 \mathrm{~kg} / \mathrm{m}^{2}$ \\
\hline Tabular section 1.2 & $+/-\quad 2.2 \mathrm{~kg} / \mathrm{m}^{2}$ \\
\hline Tabular section 2.1 & $+1.2 /-0.6 \mathrm{~kg} / \mathrm{m}^{2}$ \\
\hline Tabular section 2.2 & $+1.5 /-0.8 \mathrm{~kg} / \mathrm{m}^{2}$
\end{tabular}

With other cover gauges, the following deviations per $\mathrm{mm}$ cover result:

\begin{tabular}{lcc}
\hline Cover type $X$ & 1.10 & $\mathrm{~kg} / \mathrm{m}^{2}$ \\
\hline Cover type $Y$ & 1.15 & $\mathrm{~kg} / \mathrm{m}^{2}$ \\
\hline Cover type $V$ & 1.50 & $\mathrm{~kg} / \mathrm{m}^{2}$ \\
\hline
\end{tabular}

From the area related mass of the conveyor belt $m^{\prime \prime}$ the length related mass $m^{\prime}{ }_{G}$ can be calculated, taking into account belt width $B$ in $m$ according to the following equation:

$$
m_{G}^{\prime}=B \cdot m_{G}^{\prime \prime}
$$

\section{- Belt thickness $\mathrm{d}_{\mathrm{G}}$}

The data on belt thickness $d_{G}$ only apply for the cover gauges as listed above with a tolerance range of $+1.0 /-0.5 \mathrm{~mm}$ for all tabular sections.

The thickness of the belt carcass $d_{\mathrm{Gk}}$ can be calculated, taking the total cover gauge of top and bottom sides $d_{\text {Dpges }}$ according to the following equation:

$$
d_{G k}=d_{G}-d_{D p g e s}
$$




\section{Table 6}

Guide Values for the Determination of the Main Resistance of Conveyors for Filling Degrees of the Loaded Upper Run between 70 and $110 \%$ (according DIN 22101)

\section{Friction value $f$ for top and bottom run together}

\begin{tabular}{|c|c|c|c|}
\hline Characteristic & \multicolumn{3}{|c|}{ Classification of the characteristics } \\
\hline Inner friction of the material handled & medium & minor & high \\
\hline Alignment of the conveyor & medium & good & bad \\
\hline Belt tension & medium & high & low \\
\hline Operational conditions (dusty, sticky) & medium & good & bad \\
\hline Idler diameter & 108 to 159 & $>159$ & $<108$ \\
\hline Spacing of idler stations in top run in $\mathrm{m}$ & 1.0 to 1.5 & $<1.0$ & $>1.5$ \\
\hline Spacing of idler stations in bottom run in $\mathrm{m}$ & 2.5 to 3.5 & $<2.5$ & $>3.5$ \\
\hline Belt speed in $\mathrm{m} / \mathrm{s}$ & 4 to 6 & $<4$ & $>6$ \\
\hline Troughing angle in ${ }^{\circ}$ & 25 to 35 & $<25$ & $>35$ \\
\hline \multirow{2}{*}{ Ambient temperature in ${ }^{\circ} \mathrm{C}$} & 15 to 25 & $>25$ & $<15$ \\
\hline & \multirow{5}{*}{$\begin{array}{l}\text { guiding value } \\
\quad \approx 0.020\end{array}$} & \multicolumn{2}{|c|}{ result in } \\
\hline \multirow[t]{4}{*}{ Friction value $f$} & & a decrease & an increase \\
\hline & & \multicolumn{2}{|c|}{ of the friction value $f$} \\
\hline & & down to & up to \\
\hline & & $\geq 0.010$ & $\leq 0.040$ \\
\hline
\end{tabular}

\section{Note:}

Higher safety in the design of the drive units

is achieved

- with motor-operated drive units

by selecting a higher $f$ value,

- with generator-induced operation of the drive units by selecting a smaller $f$ value.

2. Coefficient $q_{o}$ for the determination of the main resistance of the loaded upper run

\begin{tabular}{|c|c|c|c|}
\hline Characteristic & \multicolumn{3}{|c|}{ Classification fo the characteristics } \\
\hline Relative belt sag $h_{\text {rel }}$ & medium & high, however $\leq 1 \%$ & low \\
\hline Inner friction of the material handled & medium & high & low \\
\hline Rolling resistance of the idlers & medium & low & high \\
\hline \multirow[t]{2}{*}{ Rolling indentation resistance } & medium & low & high \\
\hline & \multirow{5}{*}{$\begin{array}{l}\text { suggested value } \\
\quad \approx 0,7\end{array}$} & \multicolumn{2}{|c|}{ results in } \\
\hline \multirow{4}{*}{ Coefficient $q_{\circ}$} & & a decrease & an increase \\
\hline & & \multicolumn{2}{|c|}{ of the coefficient $q_{\circ}$} \\
\hline & & down to & up to \\
\hline & & $\geq 0.5$ & $\leq 0.85$ \\
\hline
\end{tabular}


Table 7

Guide Values for the Determination of the Coefficient C of Conveyors for Filling Degrees of the Loaded Upper Run between 70 and $110 \%$ (DIN 22101)

\begin{tabular}{|l|c|c|c|c|c|c|c|}
\hline Conveying length $\mathbf{L}$ in $\mathbf{m}$ & 80 & 100 & 150 & 200 & 300 & 400 & 500 \\
\hline Coefficient C & 1.92 & 1.78 & 1.58 & 1.45 & 1.31 & 1.25 & 1.20 \\
\hline Conveying length $\mathrm{L}$ in $\mathbf{m}$ & 600 & 700 & 800 & 900 & 1000 & 1500 & $\geq 2000$ \\
\hline Coefficient C & 1.17 & 1.14 & 1.12 & 1.10 & 1.09 & 1.06 & 1.05 \\
\hline
\end{tabular}

Note:

With a large proportion of secondary resistance in the total resistance, e.g. in case of horizontal belt conveyor systems providing conveying lengths $L<80 \mathrm{~m}$ or with several feeding points, the determination of the individual secondary resistances is required.

\section{Table 8}

Recommended coefficients of friction $\mu$ between conveyor belts with rubber covers* and pulley surfaces of differing finish (DIN 22101) in the steady operating state.

\begin{tabular}{c|c|c|c|c|}
\hline \multirow{2}{*}{$\begin{array}{c}\text { Operating } \\
\text { conditions }\end{array}$} & $\begin{array}{c}\text { Bare steel pulley } \\
\text { (smooth) }\end{array}$ & $\begin{array}{c}\text { Polyurethane } \\
\text { friction lagging } \\
\text { (herring-bone grooves) }\end{array}$ & $\begin{array}{c}\text { Pulley surface } \\
\text { Rubber } \\
\text { friction lagging } \\
\text { (herring-bone grooves) }\end{array}$ & $\begin{array}{c}\text { Ceramic lagging } \\
\text { (porous, } \\
\text { herring-bone grooves) }\end{array}$ \\
\hline dry & 0.35 to 0.4 & 0.35 to 0.4 & 0.4 to 0.45 & 0.4 to 0.45 \\
\hline $\begin{array}{c}\text { wet } \\
\text { (pure water) }\end{array}$ & 0.1 & 0.35 & 0.35 & 0.35 to 0.4 \\
\hline $\begin{array}{c}\text { wet (contaminated } \\
\text { with loam, clay) }\end{array}$ & 0.05 to 0.1 & 0.2 & 0.25 to 0.3 & 0.35 \\
\hline
\end{tabular}

* For belts with PVC cover plates, friction values should be assumed to be approximately $10 \%$ lower

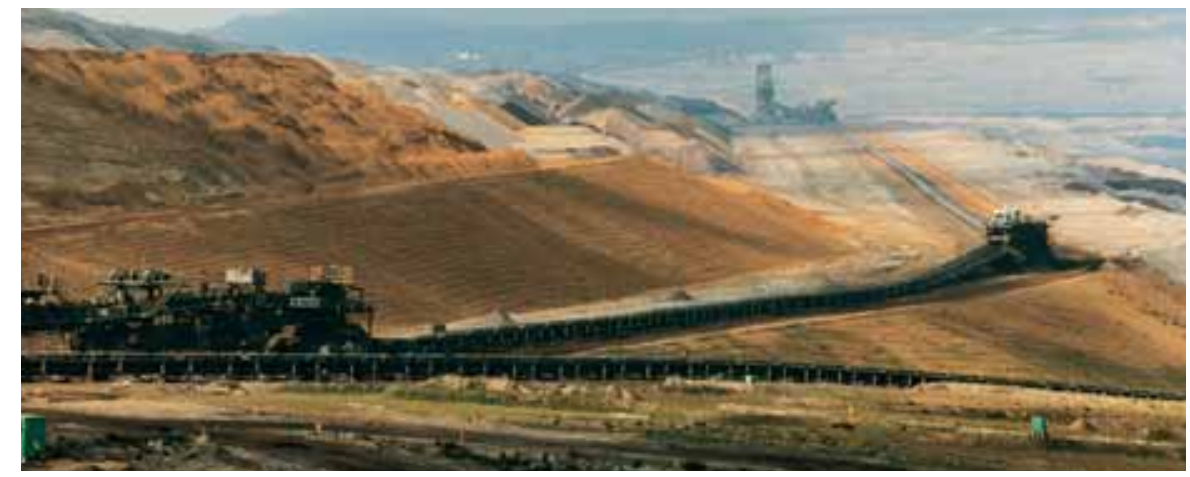


Table 9 Values for $\frac{1}{e^{\mu \alpha}-1}$ for the Determination of the Minimum Belt Forces to ensure

\begin{tabular}{|c|c|c|c|c|c|c|c|c|}
\hline \multirow{2}{*}{$\begin{array}{c}\text { Coefficient } \\
\text { of friction } \\
\mu\end{array}$} & \multicolumn{8}{|c|}{ Angle of wrap $\alpha$} \\
\hline & $170^{\circ}$ & $175^{\circ}$ & $180^{\circ}$ & $185^{\circ}$ & $190^{\circ}$ & $195^{\circ}$ & $200^{\circ}$ & $205^{\circ}$ \\
\hline 0.05 & 6.25 & 6.06 & 5.88 & 5.71 & 5.55 & 5.39 & 5.24 & 5.10 \\
\hline 0.10 & 2.90 & 2.80 & 2.71 & 2.62 & 2.54 & 2.47 & 2.39 & 2.32 \\
\hline 0.15 & 1.78 & 1.72 & 1.66 & 1.60 & 1.55 & 1.50 & 1.45 & 1.41 \\
\hline 0.20 & 1.23 & 1.19 & 1.14 & 1.10 & 1.06 & 1.03 & 0.99 & 0.96 \\
\hline 0.25 & 0.91 & 0.87 & 0.84 & 0.81 & 0.77 & 0.75 & 0.72 & 0.69 \\
\hline 0.30 & 0.70 & 0.67 & 0.64 & 0.61 & 0.59 & 0.56 & 0.54 & 0.52 \\
\hline 0.35 & 0.55 & 0.52 & 0.50 & 0.48 & 0.46 & 0.44 & 0.42 & 0.40 \\
\hline 0.40 & 0.44 & 0.42 & 0.40 & 0.38 & 0.36 & 0.34 & 0.33 & 0.31 \\
\hline 0.45 & 0.36 & 0.34 & 0.32 & 0.31 & 0.29 & 0.28 & 0.26 & 0.25 \\
\hline
\end{tabular}

\begin{tabular}{|c|c|c|c|c|c|c|c|c|}
\hline \multirow{2}{*}{$\begin{array}{c}\text { Coefficient } \\
\text { of friction } \\
\mu\end{array}$} & \multicolumn{8}{|c|}{ Angle of wrap $\alpha$} \\
\hline & $210^{\circ}$ & $215^{\circ}$ & $220^{\circ}$ & $225^{\circ}$ & $230^{\circ}$ & $235^{\circ}$ & $240^{\circ}$ & $245^{\circ}$ \\
\hline 0.05 & 4.97 & 4.85 & 4.72 & 4.61 & 4.50 & 4.39 & 4.29 & 4.20 \\
\hline 0.10 & 2.26 & 2.20 & 2.14 & 2.08 & 2.02 & 1.97 & 1.92 & 1.87 \\
\hline 0.15 & 1.36 & 1.32 & 1.28 & 1.25 & 1.21 & 1.18 & 1.14 & 1.11 \\
\hline 0.20 & 0.92 & 0.89 & 0.87 & 0.84 & 0.81 & 0.79 & 0.76 & 0.74 \\
\hline 0.25 & 0.67 & 0.64 & 0.62 & 0.60 & 0.58 & 0.56 & 0.54 & 0.52 \\
\hline 0.30 & 0.50 & 0.48 & 0.46 & 0.44 & 0.43 & 0.41 & 0.40 & 0.38 \\
\hline 0.35 & 0.38 & 0.37 & 0.35 & 0.34 & 0.33 & 0.31 & 0.30 & 0.29 \\
\hline 0.40 & 0.30 & 0.29 & 0.27 & 0.26 & 0.25 & 0.24 & 0.23 & 0.22 \\
\hline 0.45 & 0.24 & 0.23 & 0.22 & 0.21 & 0.20 & 0.19 & 0.18 & 0.17 \\
\hline
\end{tabular}

\section{Table 10}

Value of the Safety Factor $S_{0}$ in Dependence of the Manufacturing

Conditions of the Splice (according to DIN 22101)

\begin{tabular}{|l|c|c|c|}
\multicolumn{1}{|c|}{ Condition } & \multicolumn{2}{|c}{ Description of condition } \\
\hline Atmosphere & normal & dust free & dusty \\
\hline Protection from sunlight & normal & very good & poor \\
\hline Ambient temperature & normal & $\geq 18^{\circ} \mathrm{C}$ and $\leq 22^{\circ} \mathrm{C}$ & $<10^{\circ} \mathrm{C}$ or $>30^{\circ} \mathrm{C}$ \\
\hline Working conditions & normal & spacious & narrow \\
\hline Qualification of splicers & normal & very good & poor \\
\hline Quality of splicing material & normal & fresh & expiration date \\
\hline Quality of splicing press & normal & very good & poor \\
\hline Safety factor $\mathrm{S}_{0}$ & & \multicolumn{2}{|c|}{ causes } \\
& & decrease & increase \\
\hline
\end{tabular}


Table 11

Value of the Safety Factor $S_{1}$ in Dependence of the Operating Conditions of the Belt (according to DIN 22101).

\begin{tabular}{|c|c|c|c|}
\hline Condition & \multicolumn{3}{|c|}{ Description of condition } \\
\hline Life time & normal & low & high \\
\hline Consequences of failure & normal & small & severe \\
\hline Chemical/mechanical influence & normal & small & severe \\
\hline Startups and stops & $>3$ and $<30$ per day & $\leq 3$ per day & $\geq 30$ per day \\
\hline Revolution frequency & $\begin{array}{l}>2 \text { per hour and } \\
<1 \text { per minute }\end{array}$ & $\leq 2$ per hour & $\geq 1$ per minute \\
\hline \multirow{4}{*}{ Safety factor $\mathrm{S}_{1}$} & \multirow{4}{*}{1.7} & \multicolumn{2}{|c|}{ causes } \\
\hline & & decrease & increase \\
\hline & & \multicolumn{2}{|c|}{ of the safety factor to } \\
\hline & & $\geq 1.5$ & $\leq 1.9$ \\
\hline
\end{tabular}

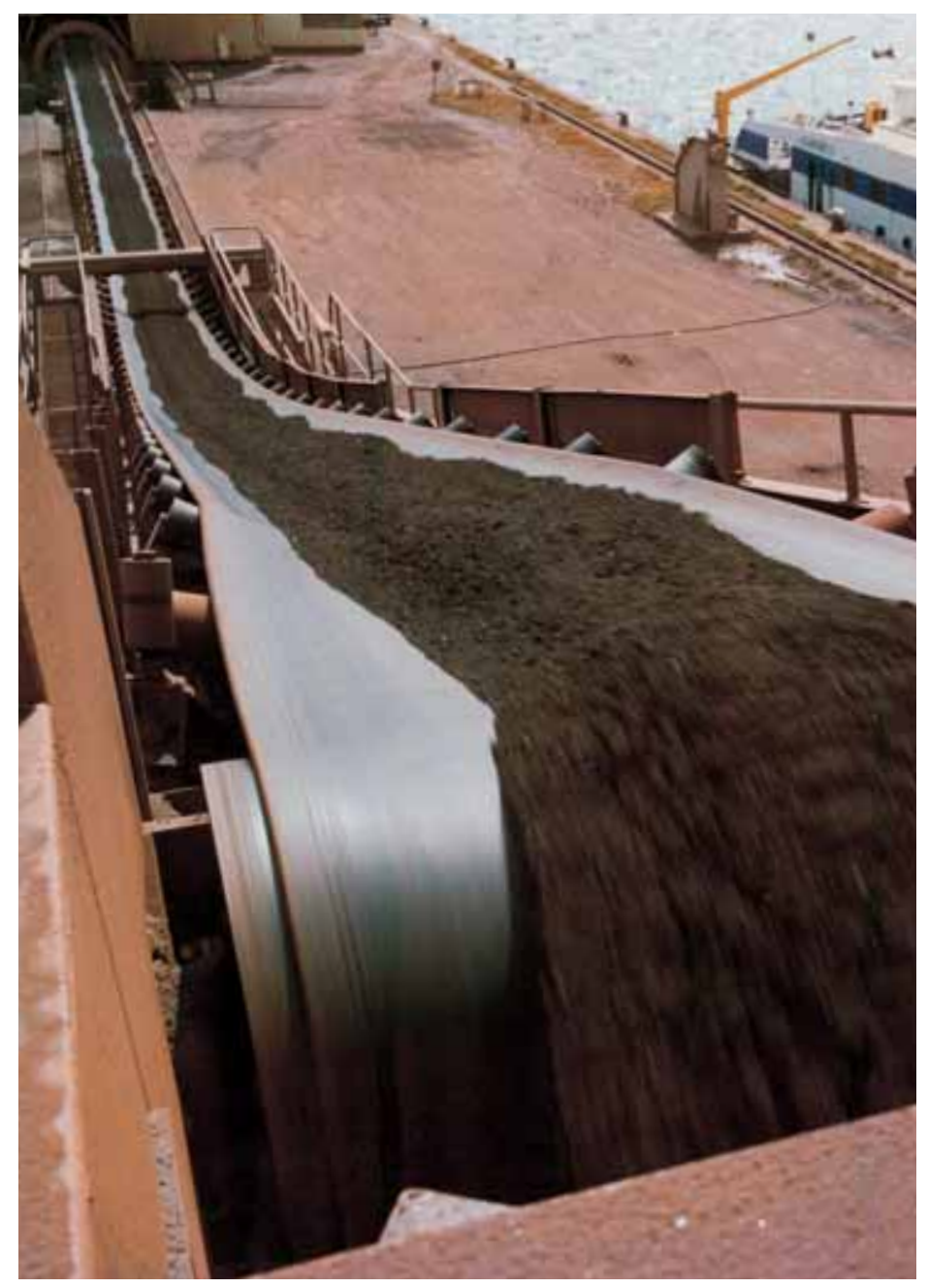




\section{Table 12}

\section{Strength Range of Phoenix Conveyor Belts for Use Above and} Underground (Belt Breaking Strength in $\mathrm{N} / \mathrm{mm}$ Belt Width)

\begin{tabular}{|c|c|c|c|c|c|c|c|c|c|}
\hline \multicolumn{10}{|c|}{ Phoenix textile carcass conveyor belt } \\
\hline \multicolumn{10}{|l|}{ 1-ply belts } \\
\hline Underground use & $800 / 1$ & $1000 / 1$ & $1250 / 1$ & $1600 / 1$ & $2000 / 1$ & $2500 / 1$ & $3150 / 1$ & & \\
\hline \multicolumn{10}{|l|}{ 2-ply belts } \\
\hline Surface use & $200 / 2$ & $250 / 2$ & $315 / 2$ & $400 / 2$ & $630 / 2$ & $800 / 2$ & $1000 / 2$ & $1250 / 2$ & $1600 / 2$ \\
\hline Underground use & $630 / 2$ & $800 / 2$ & $1000 / 2$ & $1250 / 2$ & $1600 / 2$ & & & & \\
\hline \multicolumn{10}{|l|}{ 3-ply belts } \\
\hline Surface use & $315 / 3$ & $400 / 3$ & $500 / 3$ & $630 / 3$ & $800 / 3$ & $1000 / 3$ & & & \\
\hline \multicolumn{10}{|l|}{ 4-ply belts } \\
\hline Surface use & $500 / 4$ & $630 / 4$ & $800 / 4$ & $1000 / 4$ & $1250 / 4$ & $1600 / 4$ & $2000 / 4$ & $2500 / 4$ & \\
\hline \multicolumn{10}{|l|}{ 5-ply belts } \\
\hline Surface use & $630 / 5$ & $800 / 5$ & $1000 / 5$ & $1250 / 5$ & $1600 / 5$ & $2000 / 5$ & $2500 / 5$ & $3150 / 5$ & \\
\hline
\end{tabular}

Phoenix steel cord conveyor belt
\begin{tabular}{l|l|l|l|l|l|l|c}
\hline $\begin{array}{l}\text { Above and under- } \\
\text { ground use }\end{array}$ & St 400 & St 500 & St 630 & St 800 & St 1000 & St 1250 & St 1600 \\
& St 1800 & St 2000 & St 2500 & St 3150 & St 3500 & St 4000 & St 4500 \\
& St 5000 & St 5400 & St 6300 & St 7000 & St 7500 & St 8000 & St 8500
\end{tabular}

Higher belt strengths on request

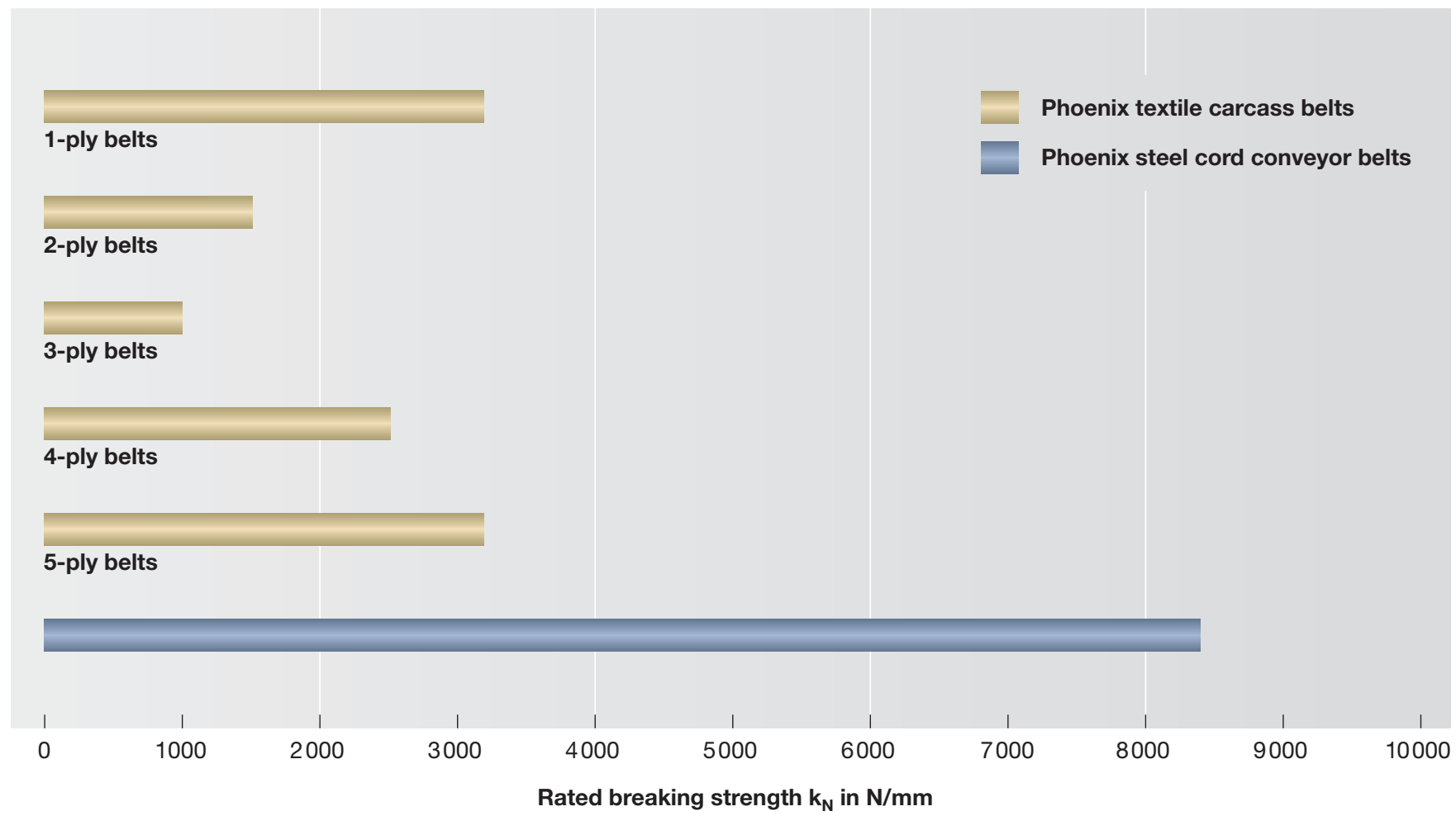




\section{Table 13}

\section{Cover Materials}

\section{Cover standard design}

With regard to

Strength,

Elongation,

Abrasion,

standard cover grades are being graded in accordance with DIN 22102 or DIN 22131 respectively into the type categories $\mathrm{X}, \mathrm{Y}$ und $\mathrm{Z}$ or $\mathrm{K}$. ISO 10247 differentiates between the categories $\mathrm{D}, \mathrm{H}$ and $\mathrm{L}$ with minor deviations.

Type categories of DIN and ISO and their mechanical characteristics are summarized in Table 14.

\section{Covers with special properties}

For special-purpose applications the cover material shall have special properties in connection with the tensile member as follows:

(See also DIN 22100, 22102, 22103, 22104, 22109, 22118, 22129, 22131)

\begin{tabular}{|l|c|}
\hline Special properties & $\begin{array}{c}\text { Code letter in } \\
\text { accordance } \\
\text { with DIN }\end{array}$ \\
\hline With antistatic covers & $\mathrm{E}$ \\
\hline $\begin{array}{l}\text { With antistatic covers and flame- } \\
\text { resistant with covers }\end{array}$ & $\mathrm{K}$ \\
\hline $\begin{array}{l}\text { Flame resistant with and without } \\
\text { covers and with antistatic covers }\end{array}$ & $\mathrm{S}$ \\
\hline Heat resistant & $\mathrm{T}$ \\
\hline Cold resistant & $\mathrm{R}$ \\
\hline \begin{tabular}{l} 
Oil and grease resistant \\
\hline For foodstuffs
\end{tabular} & $\mathrm{G}$ \\
\hline $\begin{array}{l}\text { For chemical products } \\
\text { Safety specifications with regard } \\
\text { to fire-engineering properties } \\
\text { for surface use }\end{array}$ & $\mathrm{C}$ \\
\hline $\begin{array}{l}\text { Safety specifications with regard } \\
\text { to fire engineering, hygienical and } \\
\text { electrical properties for underground } \\
\text { use in German coal mining }\end{array}$ & $\mathrm{vt}$ \\
\hline
\end{tabular}

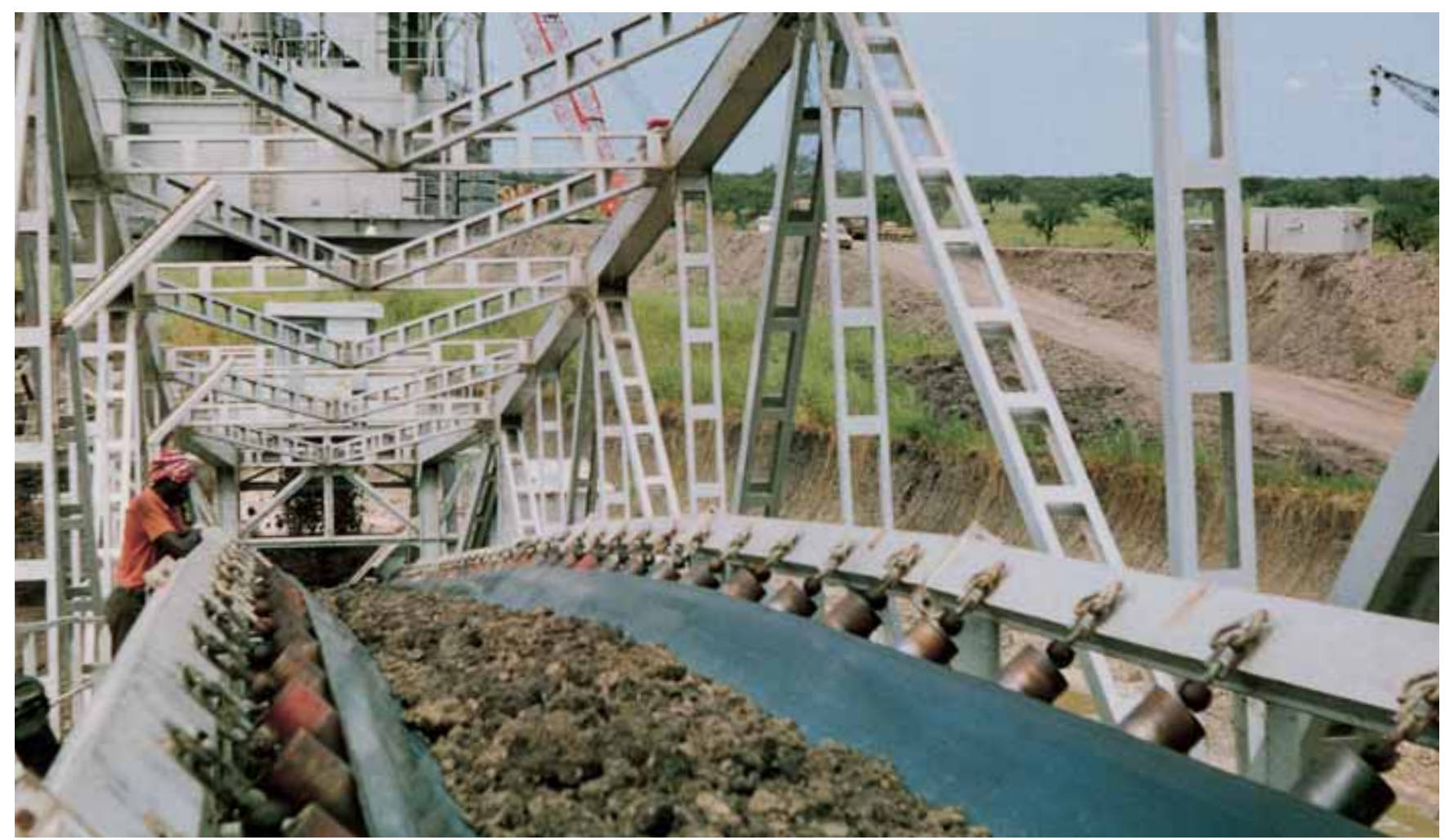




\section{Phoenix Special Cover Materials}

In addition to the cover types stated under 1. and 2. Phoenix offers other cover materials for surface use providing the following special properties:

\begin{tabular}{|l|c|}
\hline Special properties & $\begin{array}{c}\text { Phoenix } \\
\text { designation }\end{array}$ \\
\hline Highly wear resistant (high tear resistance) & WVF \\
\hline Extremely abrasion resistant and dirt repellant & MVF \\
\hline Heat resistant up to $180^{\circ}$ & MAGMA \\
\hline Heat resistant up to $180^{\circ}$ and self-extinguishing & MAGMA EXTRA \\
\hline Heat resistant up to $240^{\circ}$ and acid resistant & MAGMA SUPER \\
\hline Extremely abrasion resistant and acid protected & MVF-A \\
\hline Oil-grease and heat-resistant and flame-resistant & FR-MOR \\
\hline Flame retardant & FH \\
\hline Energy optimized & EOB \\
\hline
\end{tabular}

Please ask for our special leaflets.

\section{Table 14}

Type Categories of the Covers for Conveyor Belts according to DIN 22102 or to DIN 22131 or to ISO 10247

\begin{tabular}{|c|c|c|c|c|}
\hline \multicolumn{2}{|c|}{ Cover type as per } & \multirow{2}{*}{$\begin{array}{c}\text { Tensile strength } \\
\text { in } \mathrm{N} / \mathrm{mm}^{2} \\
\mathrm{~min} .\end{array}$} & \multirow{2}{*}{$\begin{array}{l}\text { Elongation at break } \\
\text { in } \% \\
\text { min. }\end{array}$} & \multirow{2}{*}{$\begin{array}{c}\text { Abrasion } \\
\text { in } \mathrm{mm}^{3} \\
\text { max. }^{2}\end{array}$} \\
\hline $\begin{array}{l}\text { DIN } 22102 \\
\text { DIN } 22131\end{array}$ & ISO 10247 & & & \\
\hline W & (D) & $18(18)$ & $400(400)$ & $90(100)$ \\
\hline$x$ & $(\mathrm{H})$ & $25(24)$ & $450(450)$ & $120(120)$ \\
\hline $\mathrm{Y}$ & & 20 & 400 & 150 \\
\hline Z & $(L)$ & $15(15)$ & $350(350)$ & $250(200)$ \\
\hline$\left.K^{*}\right)$ & & 20 & 400 & 200 \\
\hline
\end{tabular}

* For flame resistant conveyor belts according to DIN 22103 with antistatic covers according to DIN 22104 


\section{Table 15}

Guide Values for Top and Bottom Cover Gauges

for Textile Carcass and Steel Cord Conveyor

Belts for different Uses (in $\mathrm{mm}$ )

\begin{tabular}{|c|c|c|c|c|}
\hline Belt type & Use & Material handled & Top side & Bottom side \\
\hline \multirow{4}{*}{ 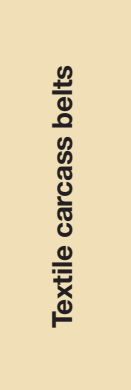 } & Mobile belt conveyors & $\begin{array}{l}\text { Fine bulk material, } \\
\text { light bulk material }\end{array}$ & 2 & 1 \\
\hline & $\begin{array}{l}\text { Loading and unloading plants } \\
\text { and coal handling plants }\end{array}$ & $\begin{array}{l}\text { Coal, potassium, } \\
\text { gravel, sand, fine ore }\end{array}$ & 2 to 4 & 2 \\
\hline & $\begin{array}{l}\text { Loading and unloading plants, } \\
\text { gravel pits, quarries }\end{array}$ & $\begin{array}{l}\text { Lump coal, rocks, } \\
\text { rough gravel, ore, overburden }\end{array}$ & 4 to 8 & 2 to 3 \\
\hline & $\begin{array}{l}\text { Excavators and spreaders, } \\
\text { crushers }\end{array}$ & $\begin{array}{l}\text { Coarse lumps of rock, } \\
\text { ore, overburden }\end{array}$ & 8 to 16 & 3 to 4 \\
\hline \multirow{3}{*}{$\begin{array}{l}\frac{0}{\Phi} \\
\frac{0}{0} \\
\frac{0}{0} \\
\frac{0}{\Phi} \\
\Phi\end{array}$} & $\begin{array}{l}\text { Loading and unloading plants } \\
\text { and coal handling plants }\end{array}$ & $\begin{array}{l}\text { Coal, potassium, } \\
\text { gravel, sand, fine ore }\end{array}$ & 4 to 8 & 4 to 6 \\
\hline & $\begin{array}{l}\text { Loading and unloading plants, } \\
\text { coal mines, quarries }\end{array}$ & $\begin{array}{l}\text { Lump coal, rocks } \\
\text { rough gravel, ore, overburden }\end{array}$ & 6 to 12 & 4 to 8 \\
\hline & $\begin{array}{l}\text { Excavators and spreaders, } \\
\text { crushers }\end{array}$ & $\begin{array}{l}\text { Rocks in lumps, } \\
\text { ore, coal, overburden }\end{array}$ & 10 to 20 & 6 to 10 \\
\hline
\end{tabular}

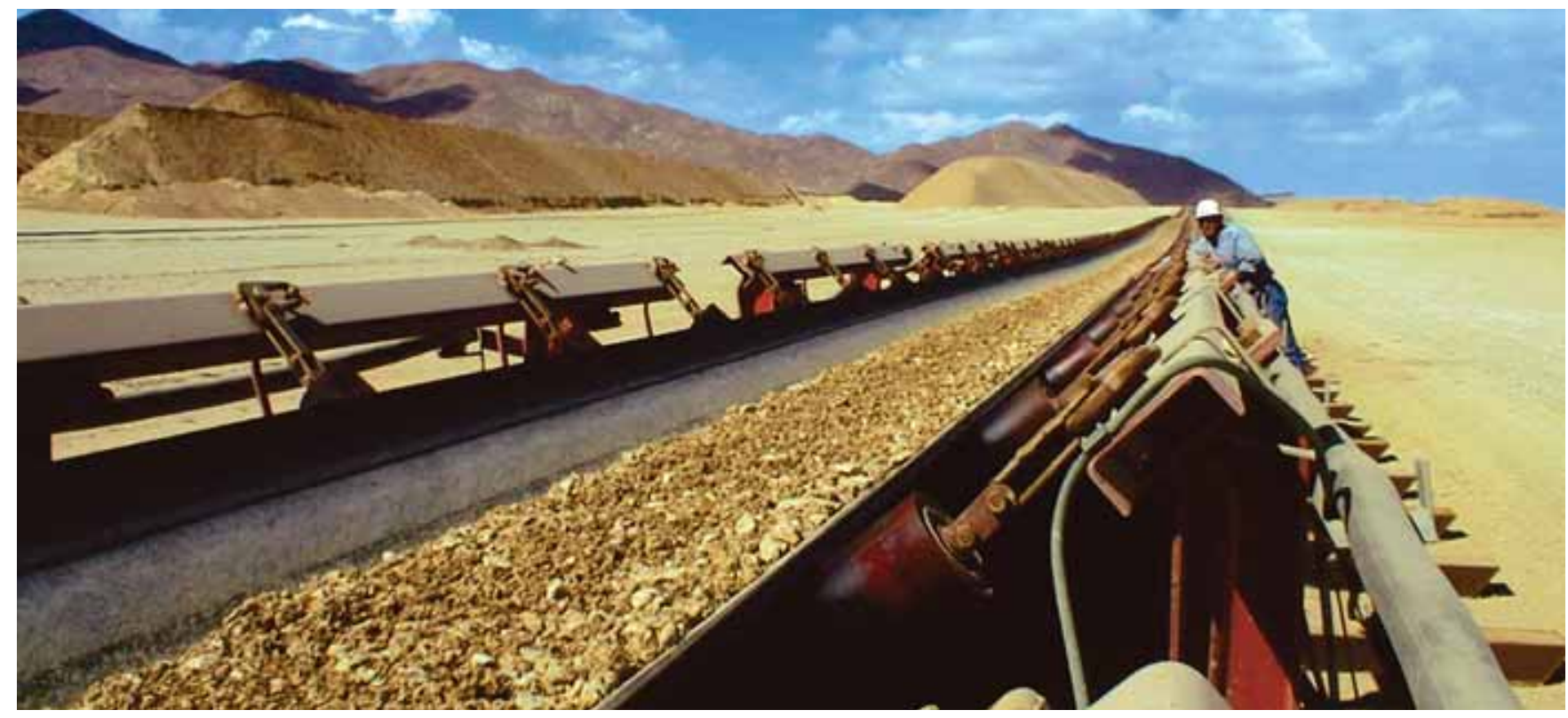




\section{Table 16}

\section{Minimum Pulley Diameters (according to DIN 22101)}

The pulley diameters in a belt conveyor system depend on the design, on strains and on the type of splice of the conveyor belt. For determining the minimum diameters, the following pulley groups will be distinguished:

- Group A: Drive pulleys and other pulleys in the range of high belt tensions

- Group B: Deflection pulleys in the range of low belt tensions

- Group C: Snub pulleys (change in belt moving direction $\leq 30^{\circ}$ )

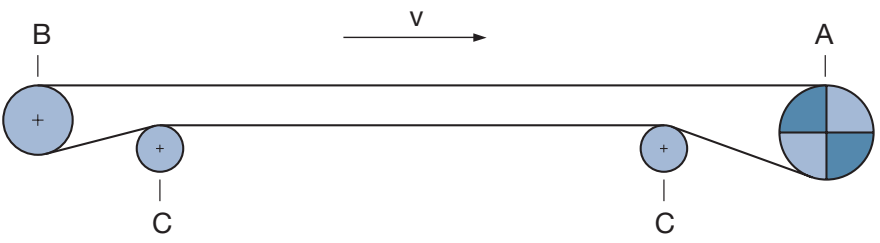

The minimum pulley diameters for pulleys of groups $A, B$ and $C$ can be determined for four different loading factors with the parameters thickness of the belt carcass $\mathrm{d}_{\mathrm{Gk}}$ and a coefficient $\mathrm{c}_{\mathrm{Tr}}$, which is determined by the material of the tensile member in the belt:

$$
\mathrm{D}_{\mathrm{Tr}}=\mathrm{c}_{\mathrm{Tr}} \cdot \mathrm{d}_{\mathrm{Gk}}
$$

\begin{tabular}{|c|c|}
\hline $\begin{array}{c}\text { Material of the } \\
\text { tensile member }\end{array}$ & $\begin{array}{c}\text { Coefficient } \\
\mathbf{c}_{\text {Tr }}\end{array}$ \\
\hline B (cotton) & 80 \\
\hline E (polyester) & 108 \\
\hline P (polyamide) & 90 \\
\hline St (steel cords) & 145 \\
\hline
\end{tabular}

A pulley diameter so obtained shall be rounded up to the next higher value of the table below.

\begin{tabular}{|c|c|c|c|c|c|c|c|c|c|c|c|c|}
\hline \multirow{4}{*}{$\begin{array}{c}\mathrm{D}_{\mathrm{Tr}}= \\
\mathrm{c}_{\mathrm{Tr}} \cdot \mathrm{d}_{\mathrm{Gk}}\end{array}$} & \multicolumn{12}{|c|}{ Minimum pulley diameter in $\mathrm{mm}$ (without lagging) } \\
\hline & \multicolumn{6}{|c|}{ Pulley load factor } & $\frac{\mathbf{k}_{\max }}{\mathbf{k}_{\mathrm{N}}}$ & 100 in $\%$ & & & & \\
\hline & \multicolumn{3}{|c|}{$\begin{array}{l}\geq 100 \% \\
\text { pulley group }\end{array}$} & \multicolumn{3}{|c|}{$\begin{array}{c}60 \% \text { to } 100 \% \\
\text { pulley group }\end{array}$} & \multicolumn{3}{|c|}{$\begin{array}{c}30 \% \text { to } 60 \% \\
\text { pulley group }\end{array}$} & \multicolumn{3}{|c|}{$\begin{array}{c}\leq \mathbf{3 0} \% \\
\text { pulley group }\end{array}$} \\
\hline & A & B & C & A & B & C & A & B & C & A & B & C \\
\hline 100 & 125 & 100 & & 100 & & & & & & & & \\
\hline 125 & 160 & 125 & 100 & 125 & 100 & & 100 & & & & & \\
\hline 160 & 200 & 160 & 125 & 160 & 125 & 100 & 125 & 100 & & 100 & 100 & \\
\hline 200 & 250 & 200 & 160 & 200 & 160 & 125 & 160 & 125 & 100 & 125 & 125 & 100 \\
\hline 250 & 315 & 250 & 200 & 250 & 200 & 160 & 200 & 160 & 125 & 160 & 160 & 125 \\
\hline 315 & 400 & 315 & 250 & 315 & 250 & 200 & 250 & 200 & 160 & 200 & 200 & 160 \\
\hline 400 & 500 & 400 & 315 & 400 & 315 & 250 & 315 & 250 & 200 & 250 & 250 & 200 \\
\hline 500 & 630 & 500 & 400 & 500 & 400 & 315 & 400 & 315 & 250 & 315 & 315 & 250 \\
\hline 630 & 800 & 630 & 500 & 630 & 500 & 400 & 500 & 400 & 315 & 400 & 400 & 315 \\
\hline 800 & 1000 & 800 & 630 & 800 & 630 & 500 & 630 & 500 & 400 & 500 & 500 & 400 \\
\hline 1000 & 1250 & 1000 & 800 & 1000 & 800 & 630 & 800 & 630 & 500 & 630 & 630 & 500 \\
\hline 1250 & 1400 & 1250 & 1000 & 1250 & 1000 & 800 & 1000 & 800 & 630 & 800 & 800 & 630 \\
\hline 1400 & 1600 & 1400 & 1000 & 1400 & 1250 & 1000 & 1250 & 1000 & 800 & 1000 & 1000 & 800 \\
\hline 1600 & 1800 & 1600 & 1250 & 1600 & 1250 & 1000 & 1250 & 1000 & 800 & 1000 & 1000 & 800 \\
\hline 1800 & 2000 & 1800 & 1250 & 1800 & 1400 & 1250 & 1600 & 1250 & 1000 & 1250 & 1250 & 1000 \\
\hline 2000 & 2200 & 2000 & 1400 & 2000 & 1600 & 1250 & 1600 & 1250 & 1000 & 1250 & 1250 & 1000 \\
\hline
\end{tabular}

$\mathrm{k}_{\max }$ maximum width related belt tension force in the area of the pulley during stationary operation
$k_{N}$ width related nominal breaking force of the belt 
Table 17

Distance between the Belt Edge and the deepest Level of the Trough $h_{k 0}$ for Idler Stations with 3 equal Length Idlers

\begin{tabular}{|c|c|c|c|c|c|c|c|c|}
\hline \multirow{2}{*}{$\begin{array}{c}\text { Belt width } \\
\text { B } \\
\text { in } \mathrm{mm}\end{array}$} & \multirow{2}{*}{$\begin{array}{l}\text { Roll face } \\
\text { length of } \\
\text { idlers } I_{M} \\
\text { in } \mathrm{mm}\end{array}$} & \multirow{2}{*}{$\begin{array}{l}\text { Belt width } \\
\mathbf{b}_{\mathrm{s}} \text { in } \mathbf{m m} \\
\text { acc. to } \\
\text { Figure } 5\end{array}$} & \multicolumn{6}{|c|}{ Troughing angle $\lambda$ of the belt } \\
\hline & & & $25^{\circ}$ & $30^{\circ}$ & $35^{\circ}$ & $37,5^{\circ}$ & $40^{\circ}$ & $45^{\circ}$ \\
\hline 500 & 200 & 150 & 63 & 75 & 86 & 91 & 96 & 106 \\
\hline 650 & 250 & 200 & 85 & 100 & 115 & 122 & 129 & 141 \\
\hline 800 & 315 & 242.5 & 102 & 121 & 139 & 148 & 156 & 171 \\
\hline 1000 & 380 & 310 & 131 & 155 & 178 & 189 & 199 & 219 \\
\hline 1200 & 465 & 367.5 & 155 & 184 & 211 & 224 & 236 & 260 \\
\hline 1400 & 530 & 435 & 184 & 218 & 250 & 265 & 280 & 308 \\
\hline 1600 & 600 & 500 & 211 & 250 & 287 & 304 & 321 & 354 \\
\hline 1800 & 670 & 565 & 239 & 283 & 324 & 344 & 363 & 400 \\
\hline 2000 & 740 & 630 & 266 & 315 & 361 & 384 & 405 & 445 \\
\hline 2200 & 800 & 700 & 296 & 350 & 402 & 426 & 450 & 495 \\
\hline 2400 & 870 & 765 & 323 & 383 & 439 & 466 & 492 & 541 \\
\hline 2600 & 940 & 830 & 351 & 415 & 476 & 505 & 534 & 587 \\
\hline 2800 & 1000 & 900 & 380 & 450 & 516 & 548 & 579 & 636 \\
\hline 3000 & 1070 & 965 & 408 & 483 & 554 & 587 & 620 & 682 \\
\hline 3200 & 1140 & 1030 & 435 & 515 & 591 & 627 & 662 & 728 \\
\hline
\end{tabular}
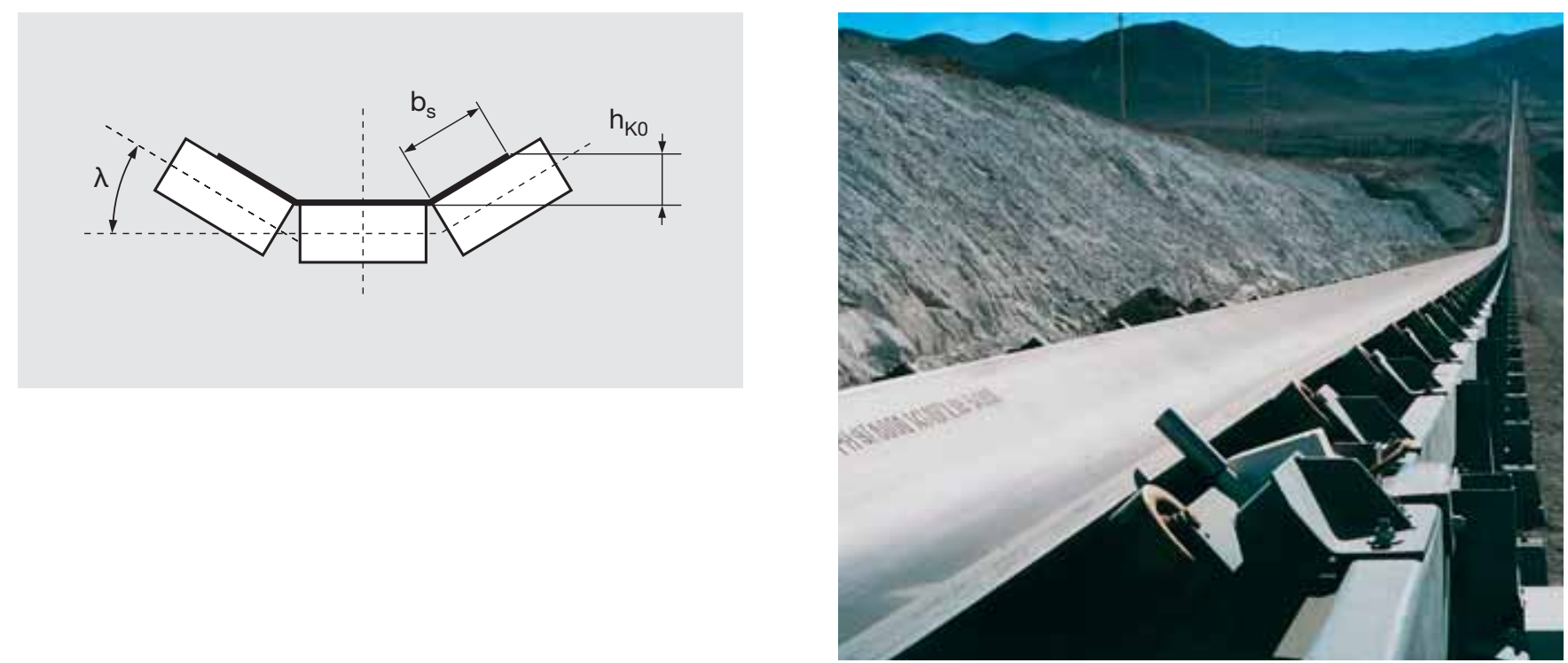


\section{Table 18}

Guide Values for the Minimum Belt Turnover-Length $\mathrm{I}_{\mathrm{w}}$ as required for Textile Carcass and Steel Cord Conveyor Belts (according to DIN 22101)

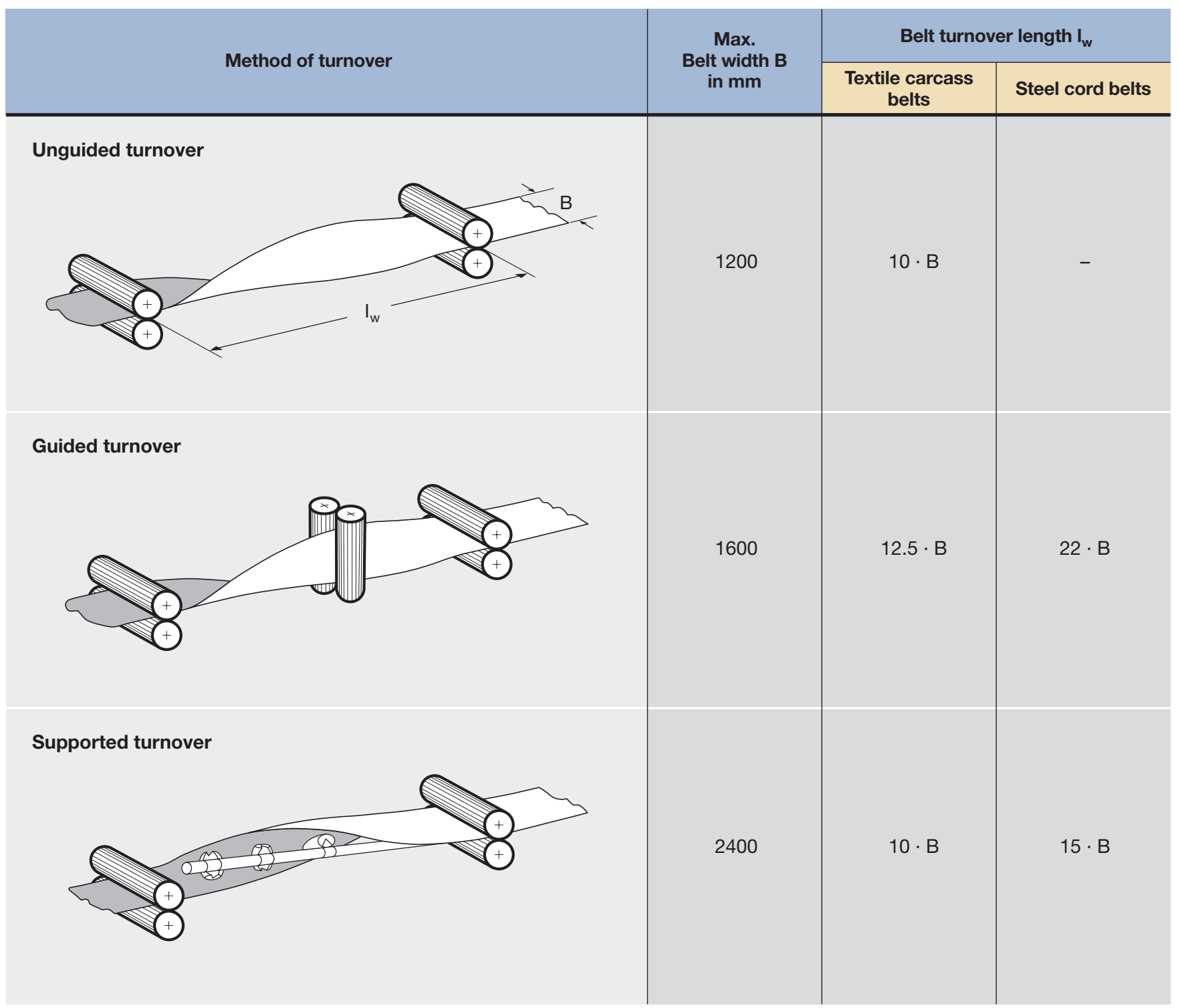

\section{Note:}

The guide values given above are sufficient when the bottom run lies in the area of low belt tension. Otherwise a more exact calculation must be performed.

\section{Note (in addition to DIN 22101):}

Analogously to the belt sag between regular idlers, a minimum belt tension must be maintained in the belt turnover in order to avoid excessive belt sag, which may lead to clinching.

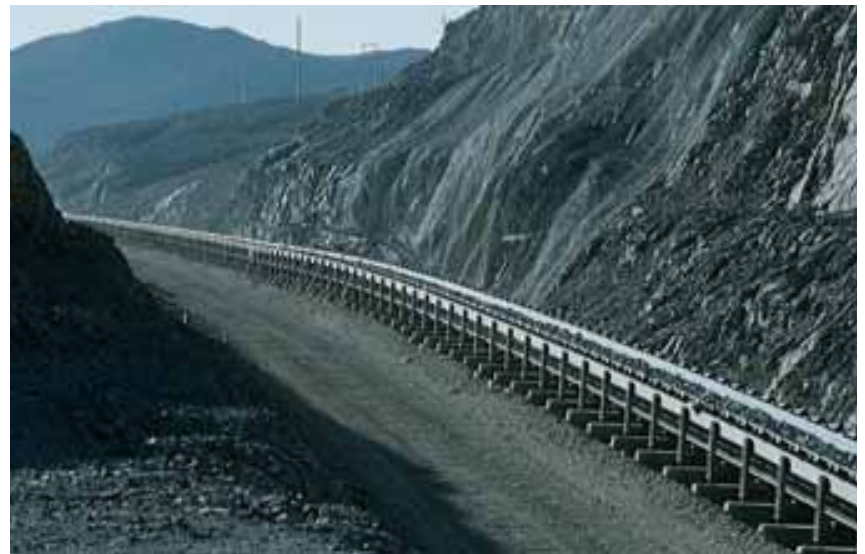




\section{Table 19}

\section{Reel Diameters of Conveyor Belts}

$\mathrm{D}_{\mathrm{W}}$ : Reel diameter

$\mathrm{d}_{\mathrm{G}}$ : Belt thickness

$\mathrm{L}$ : Belt length

k : Reel core diameter

Values of reel diameter $D_{W}$ (quoted in $\mathrm{m}$ ) depending on belt thickness $d_{G}$ and on reel core diameter $\mathbf{k}$

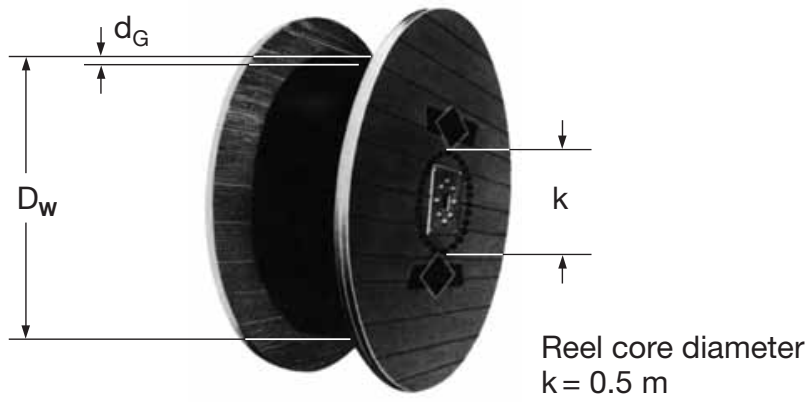

\begin{tabular}{|c|c|c|c|c|c|c|c|c|c|c|c|c|c|c|c|c|}
\hline \multirow{2}{*}{$\begin{array}{c}\text { Belt } \\
\text { length } L \\
\text { in } \mathbf{m}\end{array}$} & \multicolumn{16}{|c|}{ Belt thickness $d_{G}$ in $\mathrm{mm}$} \\
\hline & 10 & 12 & 14 & 16 & 18 & 20 & 22 & 24 & 26 & 28 & 30 & 32 & 34 & 36 & 38 & 40 \\
\hline 10 & 0.61 & 0.63 & 0.65 & 0.67 & 0.69 & 0.71 & 0.73 & 0.75 & 0.76 & 0.78 & 0.79 & 0.81 & 0.83 & 0.84 & 0.86 & 0.87 \\
\hline 20 & 0.71 & 0.75 & 0.78 & 0.81 & 0.84 & 0.87 & 0.90 & 0.92 & 0.96 & 0.98 & 1.01 & 1.03 & 1.06 & 1.08 & 1.10 & 1.13 \\
\hline 40 & 0.87 & 0.93 & 0.98 & 1.03 & 1.08 & 1.13 & 1.17 & 1.21 & 1.25 & 1.29 & 1.33 & 1.37 & 1.41 & 1.44 & 1.48 & 1.51 \\
\hline 60 & 1.00 & 1.08 & 1.15 & 1.21 & 1.27 & 1.33 & 1.39 & 1.44 & 1.50 & 1.55 & 1.59 & 1.64 & 1.69 & 1.73 & 1.76 & 1.82 \\
\hline 80 & 1.13 & 1.21 & 1.29 & 1.37 & 1.44 & 1.51 & 1.58 & 1.64 & 1.70 & 1.76 & 1.82 & 1.87 & 1.93 & 1.98 & 2.03 & 2.08 \\
\hline 100 & 1.23 & 1.33 & 1.43 & 1.51 & 1.59 & 1.67 & 1.75 & 1.82 & 1.87 & 1.95 & 2.02 & 2.08 & 2.14 & 2.20 & 2.26 & 2.31 \\
\hline 120 & 1.33 & 1.44 & 1.54 & 1.64 & 1.73 & 1.82 & 1.90 & 1.98 & 2.05 & 2.13 & 2.20 & 2.27 & 2.33 & 2.40 & 2.46 & 2.52 \\
\hline 140 & 1.43 & 1.55 & 1.66 & 1.78 & 1.86 & 1.95 & 2.04 & 2.13 & 2.21 & 2.29 & 2.37 & 2.44 & 2.51 & 2.58 & 2.65 & 2.72 \\
\hline 160 & 1.51 & 1.64 & 1.76 & 1.87 & 1.98 & 2.08 & 2.17 & 2.27 & 2.36 & 2.44 & 2.52 & 2.60 & 2.68 & 2.75 & 2.83 & 2.90 \\
\hline 180 & 1.59 & 1.73 & 1.86 & 1.98 & 2.09 & 2.20 & 2.30 & 2.40 & 2.49 & 2.58 & 2.66 & 2.75 & 2.84 & 2.92 & 2.99 & 3.07 \\
\hline 200 & 1.67 & 1.82 & 1.95 & 2.08 & 2.20 & 2.31 & 2.42 & 2.52 & 2.62 & 2.72 & 2.81 & 2.90 & 2.98 & 3.07 & 3.15 & 3.23 \\
\hline 220 & 1.75 & 1.90 & 2.04 & 2.17 & 2.30 & 2.42 & 2.53 & 2.64 & 2.74 & 2.84 & 2.94 & 3.04 & 3.13 & 3.21 & 3.30 & 3.38 \\
\hline 240 & 1.82 & 1.98 & 2.13 & 2.26 & 2.40 & 2.52 & 2.64 & 2.75 & 2.86 & 2.97 & 3.07 & 3.17 & 3.26 & 3.35 & 3.44 & 3.53 \\
\hline 260 & 1.89 & 2.05 & 2.21 & 2.36 & 2.49 & 2.62 & 2.74 & 2.86 & 2.98 & 3.09 & 3.18 & 3.29 & 3.39 & 3.49 & 3.58 & 3.67 \\
\hline 280 & 1.95 & 2.13 & 2.29 & 2.44 & 2.58 & 2.72 & 2.84 & 2.97 & 3.08 & 3.20 & 3.31 & 3.41 & 3.51 & 3.62 & 3.71 & 3.80 \\
\hline 300 & 2.02 & 2.20 & 2.37 & 2.52 & 2.67 & 2.80 & 2.94 & 3.07 & 3.19 & 3.31 & 3.42 & 3.53 & 3.64 & 3.74 & 3.84 & 3.94 \\
\hline 320 & 2.08 & 2.27 & 2.44 & 2.60 & 2.75 & 2.90 & 3.04 & 3.17 & 3.29 & 3.41 & 3.53 & 3.65 & 3.76 & 3.86 & 3.97 & 4.07 \\
\hline 340 & 2.14 & 2.33 & 2.51 & 2.68 & 2.84 & 2.98 & 3.13 & 3.26 & 3.39 & 3.52 & 3.64 & 3.76 & 3.87 & 3.98 & 4.09 & \\
\hline 360 & 2.20 & 2.40 & 2.58 & 2.75 & 2.92 & 3.06 & 3.21 & 3.35 & 3.49 & 3.62 & 3.74 & 3.86 & 3.98 & 4.09 & & \\
\hline 380 & 2.25 & 2.46 & 2.65 & 2.82 & 2.99 & 3.15 & 3.30 & 3.44 & 3.58 & 3.71 & 3.84 & 3.97 & 4.09 & & & \\
\hline 400 & 2.31 & 2.52 & 2.72 & 2.90 & 3.07 & 3.23 & 3.38 & 3.53 & 3.67 & 3.81 & 3.94 & 4.07 & & & & \\
\hline 420 & 2.37 & 2.58 & 2.78 & 2.96 & 3.14 & 3.30 & 3.46 & 3.62 & 3.76 & 3.90 & 4.04 & & & & & \\
\hline 440 & 2.42 & 2.64 & 2.84 & 3.03 & 3.21 & 3.38 & 3.55 & 3.70 & 3.85 & 3.99 & & & & & & \\
\hline 460 & 2.47 & 2.70 & 2.91 & 3.10 & 3.29 & 3.46 & 3.62 & 3.78 & 3.93 & 4.08 & & & & & & \\
\hline 480 & 2.52 & 2.75 & 2.98 & 3.17 & 3.35 & 3.53 & 3.70 & 3.86 & 4.02 & & & & & & & \\
\hline
\end{tabular}

Twin reel

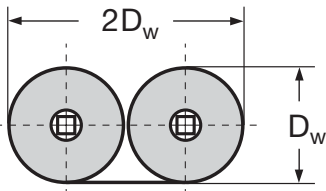

Flat reel

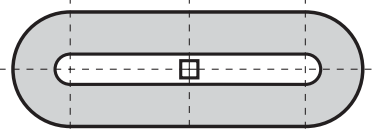

Note:

For the transportation of conveyor belts the twin reel or the flat reel can be of advantage in limited spaces. A suitable unwinding device shall, however, be available at the assembly site.

Other special types of reel on request. 


\section{Table 20}

DIN Standards

DIN 7 716* Rubber products; requirements for storage, cleaning and maintenance

DIN 15207 Continuous mechanical handling equipment; idlers for belt conveyors

DIN 15220 * Continuous mechanical handling equipment; belt conveyors: examples for protection of nip points by guards

DIN 15223 Continuous mechanical handling equipment; examples of solutions for the protection of narrows on idlers

DIN 22100 Synthetic operating material and fuels for use in underground hard coal mines

DIN $22101^{*}$ Continuous mechanical handling equipment; belt conveyors for bulk materials; base for calculation and design

DIN 22102 * Conveyor belts with textile plies

DIN 22103 Flame-resistant conveyor belts; specifications and test methods

DIN $22104^{*}$ Antistatic conveyor belts; requirements, testing

DIN $22107^{*}$ Continuous mechanical handling equipment; idler sets: idler sets for loose bulk materials; principle dimensions

DIN 22109 * Conveyor belts with textile plies for coal mining

DIN 22110 Testing of conveyor belt splices

DIN $22117^{*}$ Conveyor belts for coal mining; determination of the oxygen index

DIN 22118 * Conveyor belts with textile plies for use in coal mining; fire-testing

DIN 22120 Scraper and side-tracking rubber for belt conveyor systems for use in coal mining

DIN 22121 * Conveyor belts with textile plies for underground coal mining; permanent splices of conveyor belts

DIN 22129 * Steel cord conveyor belts for underground coal mining

DIN 22131 * Steel cord conveyor belts for hoisting and conveying

\section{Testing of rubber}

DIN 53504 * Testing of rubber; determination of tensile strength at break, tensile stress at yield, elongation at break and stress values in a tensile test

DIN 53505 * Testing of rubber, elastomers and plastics; Shore-hardness testing $A$ and $D$

DIN 53507 * Testing rubber and elastomers; determination of the tear strength of elastomers; trouser test piece

DIN 53516 * Testing of rubber and elastomers; determination of abrasion resistance

\section{Note:}

DIN-standards are available from Beuth-Vertrieb $\mathrm{GmbH}$, Berlin, the latest issue being mandatory.

* English-language translations available mostly in manuscript form by DIN Deutsches Institut für Normung e.V. (DIN German Institute for Standardization: Inc., Soc.

Berlin) from Beuth Verlag, Berlin (Publishers). 
Table 21

Conversion Factors of the Most Important Units of $f \mathrm{ps}^{*}$ - to the SI-system

\begin{tabular}{|c|c|c|c|c|}
\hline & \multicolumn{2}{|r|}{ fps } & \multicolumn{2}{|r|}{ SI $\left(M_{K} S^{\star \star}\right)$} \\
\hline Length & $1 \mathrm{ft}$ & $=1 / 3 \mathrm{yd}=12 \mathrm{in}$ & $1 \mathrm{ft}$ & $=0.3048 \mathrm{~m} ; 1$ mile $=1609.34 \mathrm{~m}$ \\
\hline Area & $1 \mathrm{ft}^{2}$ & $=144 \mathrm{in}^{2}$ & $1 \mathrm{ft}^{2}$ & $=0.0929 \mathrm{~m}^{2}$ \\
\hline Volume & $\begin{array}{l}1 \mathrm{ft}^{3} \\
1 \mathrm{gal}(\mathrm{US})\end{array}$ & $\begin{array}{l}=1728 \mathrm{in}^{3}=6.22882 \mathrm{gal}(\mathrm{UK}) \\
=0.83268 \mathrm{gal}(\mathrm{UK})\end{array}$ & $\begin{array}{l}1 \mathrm{ft}^{3} \\
1 \mathrm{bu}(\mathrm{US})\end{array}$ & $\begin{array}{l}=0.0283 \mathrm{~m}^{3} \\
=35.2393 \mathrm{I} ; 1 \mathrm{bbl}(\mathrm{US})=115.627 \mathrm{I}\end{array}$ \\
\hline Speed & $\begin{array}{l}1 \mathrm{ft} / \mathrm{s} \\
1 \mathrm{knot}\end{array}$ & $=1.150785 \mathrm{mile} / \mathrm{h}=1.6877 \mathrm{ft} / \mathrm{s}$ & $1 \mathrm{ft} / \mathrm{s}$ & $=0.3048 \mathrm{~m} / \mathrm{s}$ \\
\hline Acceleration & $1 \mathrm{ft} / \mathrm{s}^{2}$ & & $1 \mathrm{ft} / \mathrm{s}^{2}$ & $=0.3048 \mathrm{~m} / \mathrm{s}^{2}$ \\
\hline Mass & $\begin{array}{l}1 \mathrm{lb} \\
1 \mathrm{slug}\end{array}$ & $\begin{array}{l}=\mathrm{cwt} / 112 ; 1 \mathrm{sh} \text { tn }=2000 \mathrm{lb} \\
=32.174 \mathrm{lb} ; 1 \mathrm{ln} \mathrm{tn}=2240 \mathrm{lb}\end{array}$ & $\begin{array}{l}1 \mathrm{lb} \\
1 \mathrm{slug}\end{array}$ & $\begin{array}{l}=0.453592 \mathrm{~kg} \\
=14.5939 \mathrm{~kg}\end{array}$ \\
\hline Force & $\begin{array}{l}1 \mathrm{lbf} \\
1 \mathrm{pdl}\end{array}$ & $=0.031081 \mathrm{lbf}$ & $\begin{array}{l}1 \mathrm{lbf} \\
1 \mathrm{pdl}\end{array}$ & $\begin{array}{l}=4.44822 \mathrm{~N} \\
=0.138255 \mathrm{~N}\end{array}$ \\
\hline Work & $\begin{array}{l}1 \mathrm{ft} \mathrm{lb} \\
1 \mathrm{btu}\end{array}$ & $\begin{array}{l}=0.323832 \mathrm{cal}_{\mathrm{IT}} \\
=252 \mathrm{cal}_{\mathrm{IT}}=778.21 \mathrm{ft} \mathrm{lb}\end{array}$ & $\begin{array}{l}1 \mathrm{ft} \mathrm{lb} \\
1 \mathrm{btu}\end{array}$ & $\begin{array}{l}=1.35582 \mathrm{~J} \\
=1.05506 \mathrm{~kJ}\end{array}$ \\
\hline Pressure & $\begin{array}{l}1 \mathrm{lb} / \mathrm{ft}^{2} \\
1 \mathrm{psi} \\
1 \mathrm{~atm}\end{array}$ & $\begin{array}{l}=6.9444 \cdot 10^{-3} \mathrm{lb} / \mathrm{in}^{2} \\
=0.068046 \mathrm{~atm} \\
=29.92 \mathrm{in} \mathrm{Hg}=33.90 \mathrm{ft} \text { water }\end{array}$ & $\begin{array}{l}1 \mathrm{lb} / \mathrm{ft}^{2} \\
1 \mathrm{psi} \\
1 \mathrm{~atm}\end{array}$ & $\begin{array}{l}=47.88 \mathrm{~N} / \mathrm{m}^{2} \\
=6894.76 \mathrm{~N} / \mathrm{m}^{2} \\
=1.01325 \mathrm{bar}\end{array}$ \\
\hline Density & $\begin{array}{l}1 \mathrm{lb} / \mathrm{ft}^{3} \\
1 \mathrm{lb} / \mathrm{gal}\end{array}$ & $\begin{array}{l}=5.78704 \cdot 10^{-4} \mathrm{lb} / \mathrm{in}^{3} \\
=6.22882 \mathrm{lb} / \mathrm{ft}^{3}\end{array}$ & $\begin{array}{l}1 \mathrm{lb} / \mathrm{ft}^{3} \\
1 \mathrm{lb} / \mathrm{gal}\end{array}$ & $\begin{array}{l}=16.0185 \mathrm{~kg} / \mathrm{m}^{3} \\
=99.7633 \mathrm{~kg} / \mathrm{m}^{3}\end{array}$ \\
\hline Temperature & $32 \operatorname{deg} F$ & $=0^{\circ} \mathrm{C}, 212 \operatorname{deg} \mathrm{F}=100^{\circ} \mathrm{C}$ & $1 \operatorname{deg} F$ & $=0.5556^{\circ} \mathrm{C}$ \\
\hline Power & $1 \mathrm{ft} \mathrm{lb} / \mathrm{s}$ & $\begin{array}{l}=1.8182 \cdot 10^{-3} \mathrm{hp} \\
=1.28505 \cdot 10^{-3} \mathrm{btu} / \mathrm{s}\end{array}$ & $1 \mathrm{ft} \mathrm{lb} / \mathrm{s}$ & $=1.35582 \mathrm{~W}$ \\
\hline
\end{tabular}

* MKS:

\begin{tabular}{lll} 
Abbreviations & atm & atmosphere \\
and names of & bbl & barrel \\
English units & btu & British thermal unit \\
& bu & bushel \\
cwt & hundredweight \\
cal & calorie \\
deg F & degree Fahrenheit \\
& ft & foot \\
gal & gallon \\
hp & horsepower \\
in & inch \\
Ib & pound \\
Ibf & pound force \\
In tn & long ton \\
pdl & poundel \\
psi & pound per square inch \\
sh tn & short ton \\
yd & yard \\
UK & United Kingdom \\
US & United States of America \\
\hline in/s & inch per second \\
in 2 & square inch \\
in 3 & cubic inch \\
&
\end{tabular}

Published by kind permission of Springer-Verlag Heidelberg from: Dubbel, Taschenbuch für den Maschinenbau (Mechanical Engineering Paperbook), 17th edition (1990)

\section{Note:}

The belt tensile strength related to the belt width is converted as follows:

1 piw $=0.175 \mathrm{~N} / \mathrm{mm}$ 


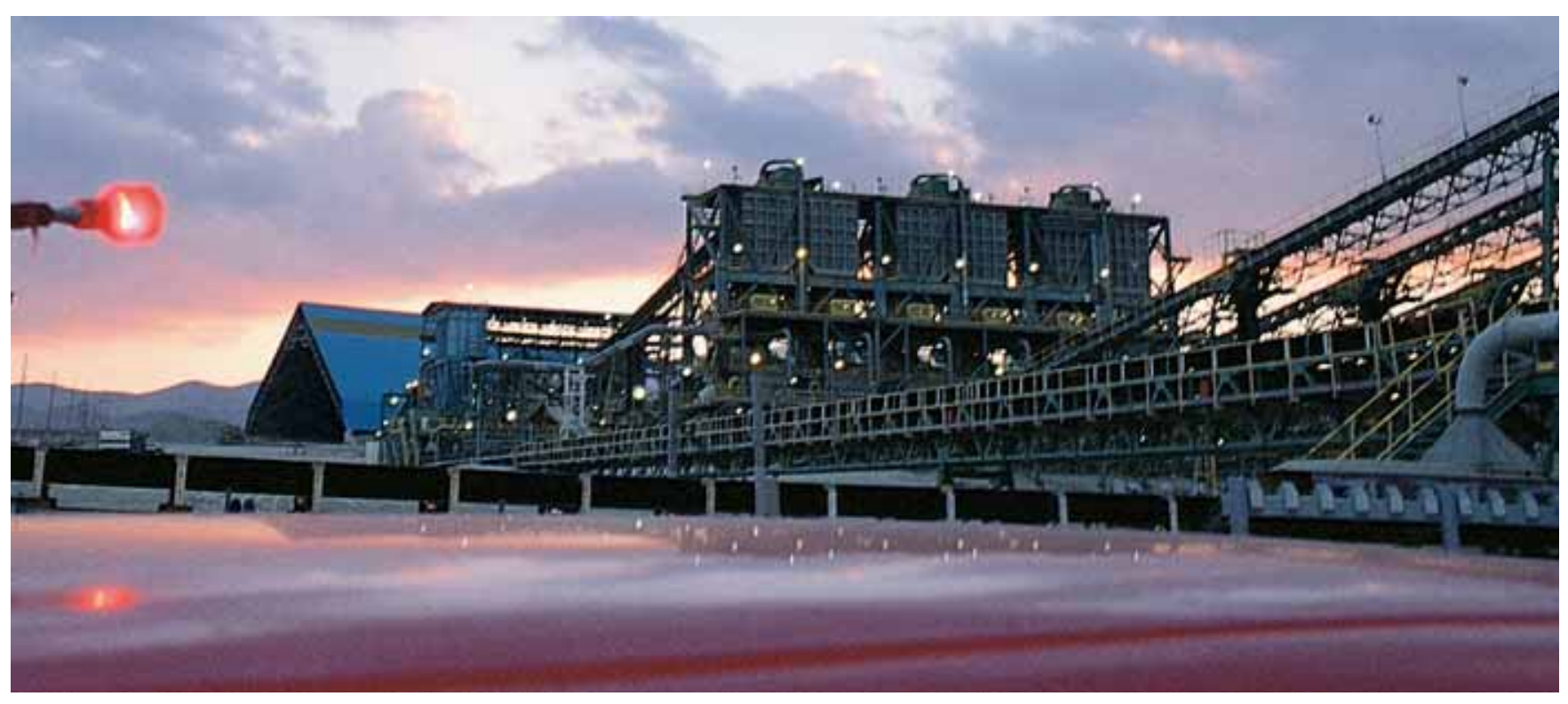


The content of this brochure has been compiled to the best of our knowledge. All details are not binding, even with regard to possible third party industrial rights. We reserve ourselves the right to make technical modifications due to further developments, at any time. No liability is accepted for the recommendations and details given in this brochure. 

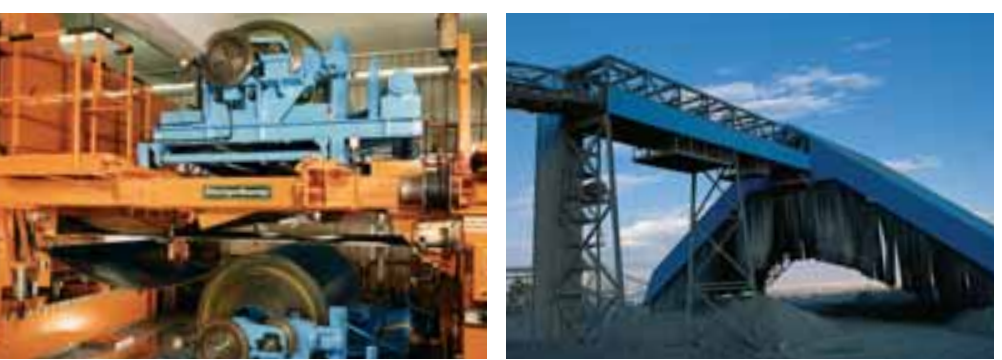

PHOENIX CONVEYOR BELT

SYSTEMS GMBH

Hannoversche Strasse 88

D-21079 Hamburg, Germany

Telefon +49-40-7667-1526, 1540

Fax +49-40-7667-2987

Email infopcbs@phoenix-ag.com

Internet: www.phoenix-ag.com 